\title{
Modified Electrospun Polymeric Nanofibers and Their Nanocomposites as Nanoadsorbents for Toxic Dye Removal from Contaminated Waters: A Review
}

\author{
Badr M. Thamer (D), Ali Aldalbahi *(D), Meera Moydeen A (D), Mostafizur Rahaman and Mohamed H. El-Newehy \\ Department of Chemistry, College of Science, King Saud University, Riyadh 11451, Saudi Arabia; \\ bthamer@ksu.edu.sa (B.M.T.); malhameed@ksu.edu.sa (M.M.A.); mrahaman@ksu.edu.sa (M.R.); \\ melnewehy@ksu.edu.sa (M.H.E.-N.) \\ * Correspondence: aaldalbahi@ksu.edu.sa
}

Citation: Thamer, B.M.; Aldalbahi, A.; Moydeen A, M.; Rahaman, M.; El-Newehy, M.H. Modified Electrospun Polymeric Nanofibers and Their Nanocomposites as Nanoadsorbents for Toxic Dye Removal from Contaminated Waters: A Review.

Polymers 2021, 13, 20. https:/ /dx.doi.org/ $10.3390 /$ polym 13010020

Received: 3 November 2020 Accepted: 18 December 2020 Published: 23 December 2020

Publisher's Note: MDPI stays neutral with regard to jurisdictional claims in published maps and institutional affiliations.

Copyright: () 2020 by the authors. Licensee MDPI, Basel, Switzerland. This article is an open access article distributed under the terms and conditions of the Creative Commons Attribution (CC BY) license (https: / / creativecommons.org/ licenses/by/4.0/).

\begin{abstract}
Electrospun polymer nanofibers (EPNFs) as one-dimensional nanostructures are characterized by a high surface area-to-volume ratio, high porosity, large number of adsorption sites and high adsorption capacity. These properties nominate them to be used as an effective adsorbent for the removal of water pollutants such as heavy metals, dyes and other pollutants. Organic dyes are considered one of the most hazardous water pollutants due to their toxic effects even at very low concentrations. To overcome this problem, the adsorption technique has proven its high effectiveness towards the removal of such pollutants from aqueous systems. The use of the adsorption technique depends mainly on the properties, efficacy, cost and reusability of the adsorbent. So, the use of EPNFs as adsorbents for dye removal has received increasing attention due to their unique properties, adsorption efficiency and reusability. Moreover, the adsorption efficiency and stability of EPNFs in aqueous media can be improved via their surface modification. This review provides a relevant literature survey over the last two decades on the fabrication and surface modification of EPNFs by an electrospinning technique and their use of adsorbents for the removal of various toxic dyes from contaminated water. Factors affecting the adsorption capacity of EPNFs, the best adsorption conditions and adsorption mechanism of dyes onto the surface of various types of modified EPNFs are also discussed. Finally, the adsorption capacity, isotherm and kinetic models for describing the adsorption of dyes using modified and composite EPNFs are discussed.
\end{abstract}

Keywords: nanofibers; polymers; functionalization; nanocomposites; adsorption; dyes; wastewater

\section{Introduction}

Water pollution is one of the most serious problems that has resulted from industrial development and rapid population growth. This problem has exacerbated over time and has become a global problem due to the increasing the amount of wastewater and its discharge into water systems. Dyeing wastewater is one of the riskiest wastewaters that causes water pollution because of its ability to change the color and the properties of water even in the presence of very low concentrations. Dyeing wastewater usually result from many industries such as textile, cosmetic, tannery, photographs, food and plastic industries. Annually, the estimated production of dyes is around 1.6 million tons and $10-15 \%$ of dyes are discharged as wastewater to the environment [1]. The main source of colored wastewater is from the textile industry, as it depends on water for most of its operations and the amount is estimated at 200 million liters annually [2]. The releasing of colored wastewater to aquatic systems causes many problems for living organisms due to the dye molecules, heavy metals and aromatic compounds contained in the water, as well as their stability and their ability to reduce sunlight transmission. To avoid these problems, dyeing wastewater must be treated before being released to the environment. In recent years, researchers have made great efforts in testing and developing various 
techniques to remove dyes from wastewater such as coagulation [3], chemical oxidation [4], biodegradation [5], ultrasonic degradation [6], photodegradation [7], membrane separation [8] and adsorption [9-11]. As a result of the high stability of dyes and the possibility of degradation into more toxic molecules, physical treatments such as adsorption are preferred. Since the adsorption process depends mainly on the properties and cost of the adsorbent, most efforts have been focused on producing highly efficient and low-cost adsorbents. With the advent of nanotechnology, various nanomaterials have been used as promising and effective adsorbents and as an alternative for conventional adsorbents. Among these nanomaterials, electrospun polymer nanofibers (EPNFs) have received much attention from researchers in the last two decades, whether in the field of water treatment or other fields [12]. More than 100 natural and synthetic polymers can be converted into nanofibers by dissolving them in a suitable solvent followed by spinning using electrospinning technique to produce EPNFs [13]. EPNFs as one-dimensional nanostructures have unique properties such as a large surface area, high surface-to-volume ratio, high porosity, large number of adsorption sites and high adsorption capacity. These properties allow the use of EPNFs as effective adsorbents for various pollutants such as heavy metals, dyes and others pollutants. To date, there are few reviews on EPNFs and their applications in water treatment. Most of them focus on discussing fabrication and applications of EPNFs in the field of water treatment in general, whether their applications as adsorbents and filtration for various pollutants, as sensors to detect pollutants or as nanocomposites for the degradation of pollutants [14-19]. Recently, Pereao et al. published in the Journal of Polymers and the Environment and discussed the applications of EPNFs in water treatment and the discussion was limited only to removing heavy metals [20]. Due to the unique properties of EPNFs, a systematic survey and analysis of modifying methods of EPNFs and the role of this in improving their ability to remove various toxic dyes from aqueous systems are useful for researchers to identify suitable methods of improving surface properties of EPNFs and their adsorption capacity and the main problems facing their application as adsorbents for various toxic dyes. Therefore, in this review, we highlight the progress in the preparation and surface functionalization of EPNFs as well as their applications in the removal of toxic dyes from wastewater. This review article will focus mainly on the fabrication of EPNFs, factors affecting on their adsorption capacity, their surface modification, crosslinking, as well as their nanocomposites with carbon nanomaterials, clay, silica, metal oxides, metal-organic frameworks (MOFs) and bacteria into EPNFs mats and their applications as adsorbents for dyes and as an adsorption mechanism.

\section{Fabrication of EPNFs}

Electrospinning is one of the most popular techniques used in the production of polymer nanofibers within the last two decades. This is because of its diversity and simplicity, and its ability to produce nanofibers in various forms with diameters varying from less than one nanometer to several micrometers [21,22]. The setup of this technique is simple and it consists of four main parts: high-voltage power supply, syringe pump, spinneret and collector (Figure 1). For the fabrication of EPNFs, polymer is dissolved in a suitable solvent to obtain a polymer solution with a specific viscosity, then it is spun by applying high voltage with either alternating current (AC) or direct current (DC). Initially, the viscous solution of polymer is pushed and controlled by the syringe pump and ejected from the spinneret as droplets that take a spherical shape due to surface tension. By applying high voltage, the spherical drops on the spinneret are charged with similar charges, which creates electrostatic repulsive forces between them that work to overcome the forces of surface tension and thus turn into a Taylor cone [23]. After formation of the Taylor cone, the jet initially stretches in a straight line and then undergoes strong whisking movements during transferring towards the collector due to the instability of the curvature. When the jet turns to thin fibers as it moves towards the collector, rapid evaporation of the solvent occurs and therefore the nanofibers are deposited onto the collector surface. The morphology and diameters of the formed nanofibers depend on the processing conditions of electrospinning 
(e.g., applied voltage (V), distance between the spinneret and the collector (TCD), flow rate (F.R), geometry of collector and diameter and geometry of spinneret) polymer solution (e.g., concentration, molecular weight, conductivity, viscosity and surface tension) and ambient conditions (e.g., temperature, humidity and air speed). For example, applied voltage is one of the factors that increase the spinnability of polymer solution and it must be sufficient, whereas if the lower voltage is applied it may not be enough to overcome the surface tension of the polymeric solution droplet. The insufficient or high voltage causes the droplets from the tip of the needle, which produces the beaded nanofibers. Flow rate of the solution definitely affects the fiber formation. The higher flow rates lead to the formation of beaded fibers due to the incomplete dryness of the fiber jet from the needle to the collector [24]. So, the required flow rate can be fixed as much as minimum value to produce a beadles and uniform nanofiber [25]. Theron et al. studied the relationship between the flow rate and applied voltage using different polymeric systems like polyvinyl alcohol (PVA), polycaprolactone (PCL), polyethylene oxide (PEO) and polyurethane (PU). The increase in the flow rate and voltage may decrease the charge density, which causes the merging of nanofibers before depositing on the collector [26]. The conductivity of the solution plays an important role in the fiber formation. The low conductive or the polymeric solutions with no conductivity, will result in the surface of droplet having no charges to form a Taylor cone [27]. The conductivity of polymeric solution needs to increase to a certain level, which may increase the charge density on the surface of the droplet leading to the formation of a Taylor cone. Increasing conductivity beyond the limit may also affect the fiber morphology. The bead-free nanofiber morphology can also be affected by the concentration of the polymeric solution and, at very low concentrations, the applied electric field and surface tension breaks the polymeric chains into small fragments before reaching the collector which may cause the formation of a beaded nanofiber [28]. The distance between the needle and collector is an important parameter that affects the quality of formed nanofibers. A minimum distance between the needle and collector may help to complete the evaporation of solvent before reaching the collector that cause the formation of bead free nanofiber. These distances can be adjusted according to the applied voltage [29]. In addition to that, the atmospheric condition like temperature and humidity may also affect the morphology of nanofiber mats [30]. By optimizing these parameters, the morphology and diameters of the nanofibers can be obtained according to the desired application of the prepared nanofibers [31-33]. Table 1 summarizes the best electrospinning conditions of some common polymers. The morphology of the formed nanofibers can also be varied according to the type of technique used, such as needleless electrospinning [34], multi-jet electrospinning [35], bubble electrospinning [36], electro blowing [37], co-axial electrospinning [38], emulsion electrospinning [39] as shown in Figure 1. A single layered nanofiber mat is typically fabricated by the simple electrospinning method [39]. Core shell structured nanofibers are prepared by typical coaxial electrospinning method or simple emulsion electrospinning method [40]. In the coaxial method, two needles are coaxially placed together for two different polymeric solutions. The core material, which was pumped through the inner needle, whereas the shell material was pumped from the outer needle of the coaxial spinneret [41]. The main parameter for this method is that the shell material is likely to be in the electrospinnable polymer solution, whereas the core material is likely to be a drug solution or other non-spinnable material. Multi-layered nanofibers can be prepared by triaxial electrospinning set up, which consisted of three needles connected to the spinneret device core, intermediate and sheath solutions. In this method, core and intermediate solutions should be immiscible, whereas outer sheath and intermediate solutions can be miscible to each other [42]. Core-shell and multilayered nanofibers are mainly used for biomedical application due to the high loading capacity and easiness of poor soluble drug loading into the polymeric shell [43]. 


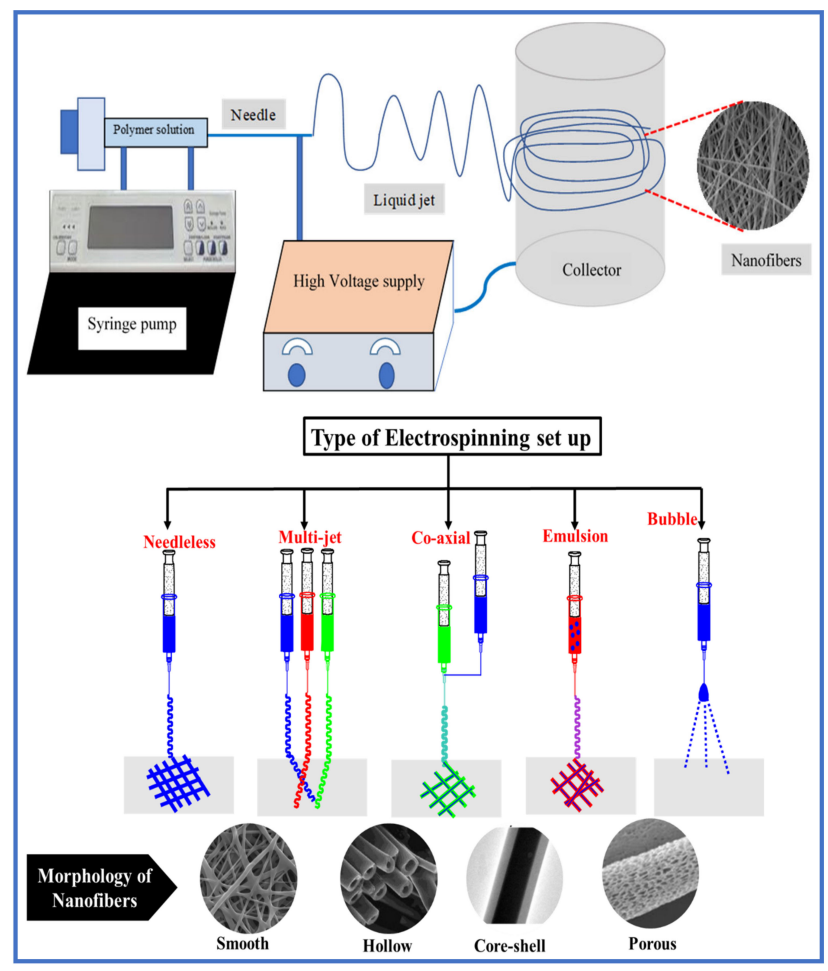

Figure 1. Schematic of types of electrospinning setup and morphology of nanofibers.

Table 1. Optimization of electrospinning conditions for fabricating common polymer nanofibers.

\begin{tabular}{|c|c|c|c|c|c|c|}
\hline Polymer & $\begin{array}{l}\text { Avg. Mw } \\
\text { (g/mol) }\end{array}$ & Concn $(w / w \%)$ & Solvent & $\begin{array}{l}\text { Optimum Conditions } \\
\text { for Fabricating } \\
\text { Bead-Free Nanofibers }\end{array}$ & $\begin{array}{l}\text { Avg. Diameter } \\
(\mathrm{nm})\end{array}$ & Ref \\
\hline PVA & 130k & 7 & $\mathrm{H}_{2} \mathrm{O}$ & $\begin{array}{c}\mathrm{V}=25 \mathrm{kv}, \mathrm{TCD}=5 \mathrm{~cm}, \mathrm{~F} \\
\mathrm{R}=0.1 \mathrm{~mL} / \mathrm{h}\end{array}$ & 510 & [44] \\
\hline PAN & $100 \mathrm{k}$ & 10 & DMF & $\begin{array}{c}\mathrm{V}=25 \mathrm{kv}, \mathrm{TCD}=20 \mathrm{~cm} \\
\text { F. } \mathrm{R}=1 \mathrm{~mL} / \mathrm{h}\end{array}$ & 88 & [45] \\
\hline PVAc & $140 \mathrm{k}$ & 15 & $\mathrm{EtOH}$ & $\begin{array}{l}\mathrm{V}=15 \mathrm{kv}, \mathrm{TCD}=10 \mathrm{~cm} \\
\text { F. } \mathrm{R}=0.06 \mathrm{~mL} / \mathrm{h}\end{array}$ & 700 & [46] \\
\hline PVP & $360 \mathrm{k}$ & 13 & DMF & $\begin{array}{l}\mathrm{V}=15 \mathrm{kv}, \mathrm{TCD}=20 \mathrm{~cm} \\
\text { F. } \mathrm{R}=0.25 \mathrm{~mL} / \mathrm{h}\end{array}$ & 172 & [47] \\
\hline PCL & $80 \mathrm{k}$ & 10 & $\begin{array}{c}\text { DCM/DMF } \\
3: 1\end{array}$ & $\begin{array}{c}\mathrm{V}=12 \mathrm{kv}, \mathrm{TCD}=10 \mathrm{~cm} \\
\text { F. } \mathrm{R}=1 \mathrm{~mL} / \mathrm{h}\end{array}$ & 455 & [48] \\
\hline Chitosan & $294 k$ & 7 & $\mathrm{AcOH}$ & $\begin{array}{c}\mathrm{V}=17 \mathrm{kv}, \mathrm{TCD}=16 \mathrm{~cm} \\
\text { F. } \mathrm{R}=1.6 \mathrm{~mL} / \mathrm{h}\end{array}$ & 250 & [49] \\
\hline Nylon 6 & - & 20 & Formic acid & $\begin{array}{c}\mathrm{V}=15 \mathrm{kv}, \mathrm{TCD}=8 \mathrm{~cm}, \mathrm{~F} \\
\mathrm{R}=0.2 \mathrm{~mL} / \mathrm{h}\end{array}$ & 800 & {$[50]$} \\
\hline $\begin{array}{c}\text { Poly } \\
(\text { St-co-AN) }\end{array}$ & $2460 \mathrm{k}$ & 25 & n-Butanone & $\begin{array}{c}\mathrm{V}=12 \mathrm{kv}, \mathrm{TCD}=23 \mathrm{~cm} \\
\text { F. } \mathrm{R}=0.2 \mathrm{~mL} / \mathrm{h}\end{array}$ & 880 & [51] \\
\hline PMMA & $120 \mathrm{k}$ & 15 & DMF & $\begin{array}{c}\mathrm{V}=12 \mathrm{kv}, \mathrm{TCD}=11.4 \mathrm{~cm} \\
\text { F. } \mathrm{R}=2.36 \mathrm{~mL} / \mathrm{h}\end{array}$ & 177 & [52] \\
\hline $\mathrm{CA} / \mathrm{PVA}$ & $120 \mathrm{k}$ & $50 / 50$ & $\mathrm{AcOH}$ & $\begin{aligned} \mathrm{V}= & 22.5 \mathrm{kv}, \mathrm{TCD}=15 \mathrm{~cm} \\
& \text { F. } \mathrm{R}=1.99 \mathrm{~mL} / \mathrm{h}\end{aligned}$ & 11 & [53] \\
\hline PA6 & $17 k$ & 20 & Formic acid & $\begin{array}{c}\mathrm{V}=19 \mathrm{kv}, \mathrm{TCD}=10 \mathrm{~cm} \\
\text { F. } \mathrm{R}=0.9 \mathrm{~mL} / \mathrm{h}\end{array}$ & 141 & [54] \\
\hline
\end{tabular}




\section{Modification of Polymer Nanofibers}

Although the advantages of polymer nanofibers include their high surface area-tovolume ratios and high porosity, some pristine polymers still have limitations in the adsorption process [18]. Some have a lack of sufficient adsorption capacity for the removal of pollutants (e.g., polyacrylonitrile (PAN) and nylon), some of them are unstable in aqueous solutions (e.g., PVA, polyacrylic acid (PAA) and polyvinyl pyrrolidone (PVP)) and some of them have low mechanical properties such as chitosan. To overcome these problems, researchers have made great efforts to improve the properties of nanofibers via surface modification. The surface modification aims to enhance the stability of nanofibers in aqueous solutions, improve their hydrophilicity and wettability properties, increase their adsorption sites on the surface, and improving their mechanical properties $[55,56]$. The surface modification of nanofibers can be carried out by two methods; one-step treatments that can be carried out during electrospinning (nanocomposites and blends) and post-treatments that can be carried out after electrospinning (e.g., plasma, wet-chemistry, grafting and coating) as shown in Figure 2.

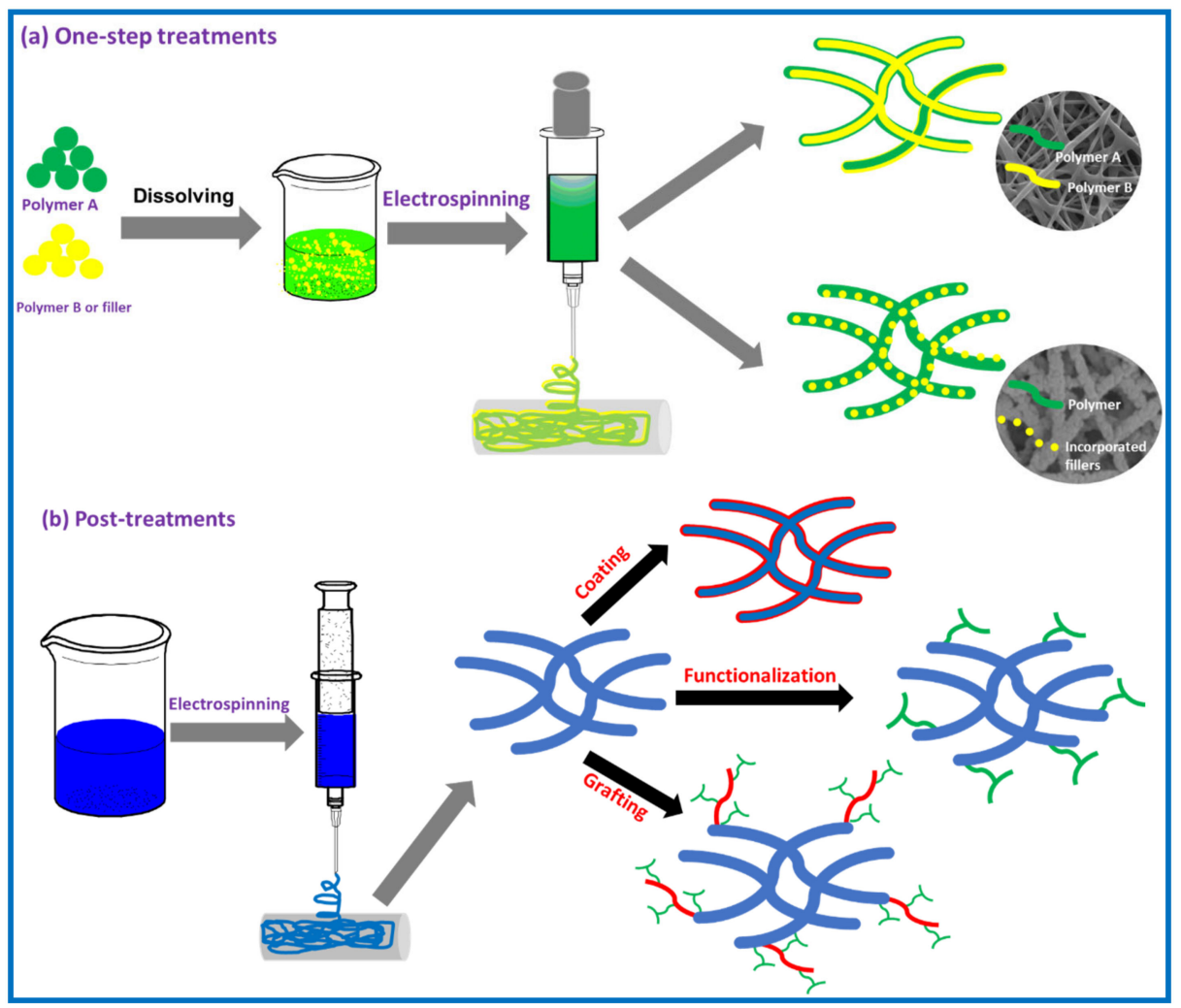

Figure 2. Surface modification of electrospun polymer nanofibers.

\subsection{One-Step Modification}

\subsubsection{Blending with Other Polymers}

The properties of pristine polymer nanofibers can be enhanced via blending of polymer with another polymer in certain ratios [57]. These properties depend on the ratio, surface energy and molecular weight of the added polymer as well as solvent [56]. The blending method was used to improve the surface properties of several hydrophobic polymers such PVDF [58] polystyrene [59], PET [60], PCL [61], PES [62]. Hydrophobic nanofibers that were used for the removal of ionic pollutants from aqueous solutions are often modified by adding hydrophilic homopolymer or amphiphilic copolymers before the electrospinning process. For example, Ghani et al. modified the surface of polyamide- 6 nanofibers by blending with different ratios of chitosan [63]. They found that the hydrophilicity of polyamide- 6 nanofibers increased by increasing the ratio of chitosan, and subsequently 
their adsorption capacity towards the removal of anionic dyes increased. In another study, $\mathrm{Xu}$ et al. fabricated blend of PES/P(MMA-co-AA) nanofibers by one-step electrospinning process [62]. They found that the hydrophilicity increased with increasing the ratio of $\mathrm{P}(\mathrm{MMA}-\mathrm{CO}-\mathrm{AA})$ as well as their adsorption capacity towards the removal of cationic (MB) dye.

\subsubsection{Incorporating Nanomaterials}

The incorporation of nanomaterials into the polymer nanofibers by dispersing them into the polymer solution and then electrospun is one of the appropriate methods for modifying the surface properties and mechanical properties of polymer nanofibers as well as improving their adsorption capacity. Incorporated nanomaterials must have a good dispersion property in the polymer solution and have the ability to segregate to the surface of nanofibers so that the modification process is effective. Carbon nanomaterials (e.g., MWCNTs-COOH and GO), metal oxide NPs, nano-clay, MOFs and bacteria are the most incorporated materials that used for modifying the surface of polymer nanofibers and applied for the removal of various pollutants.

\subsection{Post-Treatment Methods}

\subsubsection{Wet Chemistry}

A wet modification is an effective method for the functionalization of the surface of EPNFs, which can be through a chemical reaction between the surface of the nanofibers and functionalized agent in the solution. The surface properties of the modified electrospun polymer nanofibers depend on the nature of the functional agents. This method depends on the presence of functional groups on the surface of EPNFs that are susceptible to reacting with various agents. Polar functional groups on EPNFs can be created through the hydrolysis and aminolysis processes. For example, hydrolysis of polyester, PCL, PLGA and PBGL by alkali solution are the most wet-chemistry reaction for changing the surface properties of nanofibers [64-66]. Another example of wet chemistry modification, the hydrophilicity of PAN nanofibers was enhanced by converting the nitrile groups of PAN into more polar groups such as carboxylic, amino and amidoxime groups $[67,68]$.

\subsubsection{Surface Grafting}

Grafting method is an effective way to improve the surface properties of EPNFs such as hydrophilicity and their ability to adsorb ionic pollutants by introducing multiple functional groups [69]. The grafting process is carried out through two approaches via grafting-onto or grafting-from. The grafting-from requires the creation of initiators onto the surface of the nanofibers, which can be created by plasma, wet-chemistry and UV radiation treatment or by incorporating initiator int onto the surface of nanofibers during electrospinning [56]. For example with grafting-from, the PVDF nanofibers were modified with PMAA by plasma-induced graft copolymerization results in increasing its hydrophilicity as well as water flux performance [70]. It was found that the hydrophilicity increased after grafting process as well as water flux performance. Electrospun PVC nanofibers were modified with different hydrophilic polymers (e.g., PVP, PAA, PAM and PDMAEMA) by graft polymerization via pre-treatment with AIBN in acetone to produce free radicals on the surface followed by immersion of PVC nanofibers into monomer solution with heating under nitrogen [71]. Contact angle results revealed that the free radical grafting by hydrophilic monomer converted acquired the surface of PVC nanofibers hydrophilic character. In contrast, grafting-onto method requires pre-polymer preparation and then subsequently reacts with the surface of electrospun nanofibers. For example, polydopamine was grafted onto the surface of electrospun PAN nanofibers [72]. Initially, the surface of PAN nanofibers functionalized by DETA followed by grafting with polydopamine in the presence of glutaraldehyde. 


\subsubsection{Surface Coating}

Surface coating is carried out by depositing functional material onto the surface of nanofibers with a layer thickness ranging from a few nanometers to several micrometers. The bonding type between them is physical such as electrostatic interaction, $\pi-\pi$ interaction and hydrogen bonding interaction. The surface properties such as hydrophilicity and adsorption capacity will depend on the polarity, layer thickness and the homogeneity of the coating material. The coating technique can be completed by various processes such as immersion nanofiber mats into the material solution, self-assembly, layer-bylayer, electrospraying and polymerization onto the surface of nanofibers. For example, PAN nanofibers were fabricated by electrospinning followed by coating with chitosan through the immersion process and was used for dye removal [73]. The results confirmed that the coating PAN nanofibers with chitosan layer changed their hydrophobic surface to hydrophilic surface, which enhance the adsorption capacity by 28 times. In another study, polylactic acid (PLLA) nanofibers were coated via polymerization of aniline onto their surface. In a similar study, nylon-6 nanofibers were coated with polyaniline by insitu polymerization onto their surface with average thickness of $65 \mathrm{~nm}$ [74]. As another example, the surface of PCL/PEO blend nanofibers was coated by in-situ oxidation process by self-polymerization of polydopamine [75]. The surfaces of polymer nanofibers can be modified by coating them with non-polymeric materials such as metal oxides. The surface of cellulose nanofibers was coated with a few layers of manganese oxide nanosheets by the in-situ method, which revealed high adsorption capacity for the removal of MB [76].

\subsubsection{Plasma}

Plasma is one of the post-treatment methods used to increase the adsorption sites onto the surface of nanofibers [77]. The plasma treatment depends on using the ionized gases to create polar functional groups (e.g., $-\mathrm{OH},-\mathrm{COOH},-\mathrm{OOH},-\mathrm{NH}_{2}$ ) onto the surface of polymer nanofibers. The introduction of polar functional groups leads to improvement for the hydrophilicity of EPNFs as well as their ability towards the adsorption of ionic materials onto their surface. A number of hydrophobic polymer nanofibers can be treated by plasma such as PCL [78], PLLA [79], PLGA [79] and PVDF [80]. Bai et al. modified the surface of PLLA nanofibres by plasma etching treatment, which lead to changing in the surface of EPNFs from smooth to rough with porous structure and high surface area within 5 min of treatment as shown in Figure 3 [79].

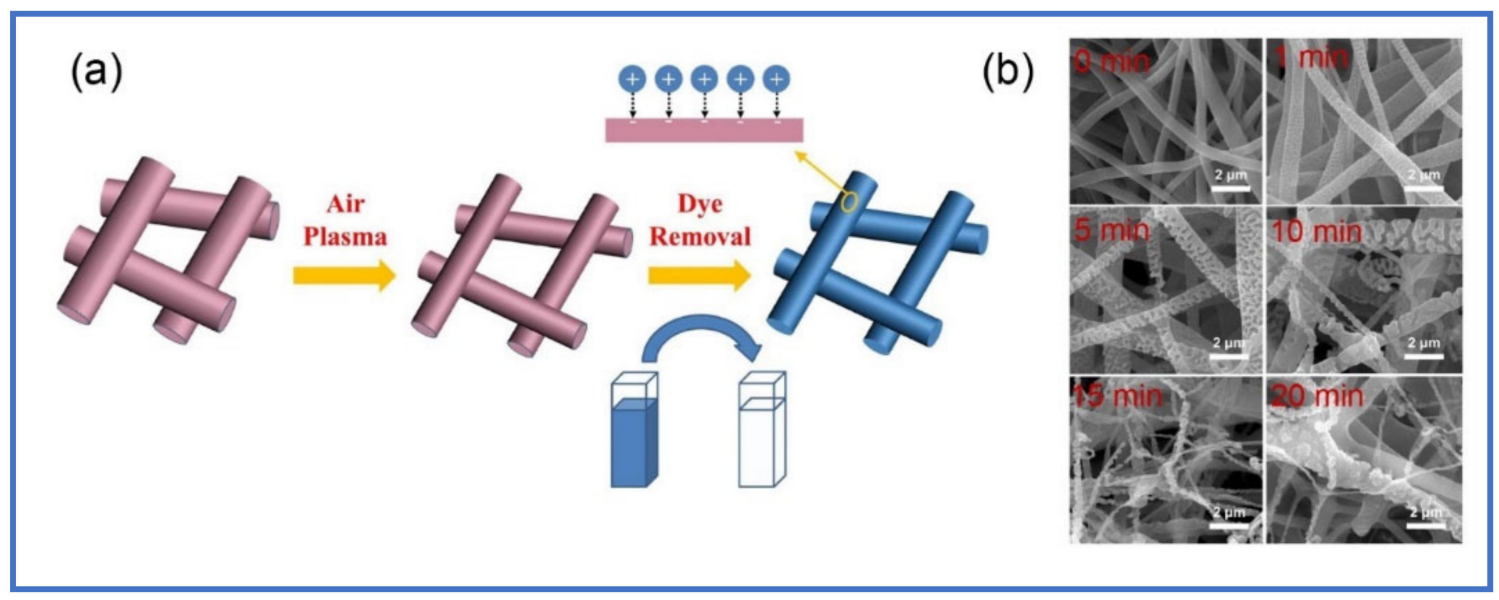

Figure 3. (a) plasma-treated polylactic acid (PLLA) electrospun membrane (b) effect of duration plasma treatment on morphology of PLLA nanofibers [79]. Copyright @ (2020) Elsevier. 


\section{Factors Affecting the Efficiency of Nanofibers for the Adsorption of Dyes}

The adsorption process is a complex process and depends on many factors including the properties of nanofibers, the structure of dyes and the medium of adsorption process.

\subsection{Effect of Physio-Chemical Properties of Nanofibers}

The adsorption capacity of dyes onto the surface of electrospun polymer nanofibers depends on the functional groups, their surface area, their porosity and hydrophilicity/hydrophobicity nature.

\subsubsection{Functional Groups}

The properties of polymers differ from each other according to the nature of the functional groups. The adsorption efficiency of polymeric nanofibers varies according to the nature of the functional groups onto their surface. The functional groups can be either in the main structure of polymer nanofibers, or created via surface modification methods.

A number of studies have proved that the oxygen-containing functional groups and nitrogen-containing functional groups play a pivotal role in interaction between nanofibers and dyes. For example, the adsorption capacity of PAN nanofibers towards removal of $\mathrm{MB}$ and RB was lower than of EDA-PAN nanofibers [81]. This difference in the adsorption capacity is due to the high hydrophilicity and nucleophilicity properties of amino groups compared to the nitrile groups. In a similar study, it was found that converting a nitrile group of PAN nanofibers to an oxime group increased the adsorption capacity from 42.662 , 72.46 and $99.30 \mathrm{mg} / \mathrm{g}$ to $102.1,118.3$ and $221.2 \mathrm{mg} / \mathrm{g}$ for the adsorption of MB, ST, RB, respectively [82]. Chunyan et al. functionalized PES nanofibers by PMETAC and observed the adsorption capacity of modified PES nanofibers for removal of CR dye was higher than of unmodified PES nanofibers [83]. Cheng et al. fabricated and modified cellulose acetate nanofibers and they found that the adsorption capacity of polydopamine-modified nanofibers for the removal of MB was 8.6 times higher than unmodified cellulose acetate nanofibers. This is due to the amine and catechol groups of polydopamine that increase the active adsorption sites onto the surface of cellulose acetate nanofibers.

\subsubsection{Surface Area and Porosity}

The surface area and porosity of many adsorbents plays a pivotal role in the adsorption process. High surface area and porosity of polymer nanofibers enhances the adsorption performance due to the creation of active adsorption sites. Chen et al. [84] fabricated negatively charged polyethersulfone nanofibers by in-situ cross-linking co-polymerization followed by electrospinning and used as adsorbent for the removal of MB. They found that the adsorption capacity of fabricated nanofibers towards the removal of MB was directly proportional to their surface area and porosity. Shourijeh et al. prepared porous PVDF/PAN nanofibers by electrospinning process through incorporation of different salts [85]. They found that the adsorption capacity of all type of porous PVDF/PAN nanofibers for removal of BB-41 dye was higher than nonporous fibers. Wang et al. [39] fabricated PCL/PEO by electrospinning and modified with polydopamine. They observed that the surface area and porosity of the prepared nanofibers increased by modification leading to enhancement of their adsorption capacity [75]. Guo et al. [50] observed that the surface area and porosity of PCL nanofibers can be increased after surface modification by beta-cyclodextrin leading to increase in their adsorption capacity towards the removal of MB dye [86]. Additionally, one of the factors that has a direct relationship to the surface area of EPNFs and may play a role in their efficiency is the diameter. Li et al. studied diameter's effect on adsorption capacity of chitosan nanofibers towards the removal of AB-113 dye [87]. They found that the relationship between diameters and adsorption capacity of EPNFs is an inverse relationship, as the adsorption capacity increased from 867 to $1338 \mathrm{mg} / \mathrm{g}$, with a decrease in diameter from $164 \pm 28$ to $86 \pm 18 \mathrm{~nm}$. 


\subsubsection{Hydrophilicity/Hydrophobicity of Nanofibers}

Hydrophilic EPNFs with their polar functional groups have higher adsorption capacity towards the removal of dyes compared to hydrophobic one. Polar functional groups play an important role in wettability of nanofibers surface as well as in reducing the repulsive forces between the surface and the dyes molecules in an aqueous solution. For example, Liu et al. observed that the adsorption capacity of copolyester nanofibers increased from 49.90 to $543.48 \mathrm{mg} / \mathrm{g}$ while the contact angle decreased from $135^{\circ}$ to $46^{\circ}$ upon surface functionalization with carboxymethyl- $\beta$-cyclodextrin [88]. In another study, they was found that the functionalized cellulose acetate nanofibers by polydopamine enhanced their hydrophilicity and improve their adsorption capacity for the removal of MB dye [89].

\subsection{Effect of Dye Nature}

Adsorption of dyes onto the surface of polymer nanofibers and their nanocomposites depends on their molecular structure, molecular size and functional groups. Table S1 displays the chemical structure and physical properties of some dyes that were used as models to test the efficiency adsorption of the nanofibers in literature. For instance, Min et al. investigated the adsorption of three types of anionic dyes (e.g., Sunset Yellow FCF, Fast Green FCF, Amaranth) onto the surface of PES/PEI nanofibers [90]. They found that the adsorption capacity of PES/PEI nanofibers was $1000,454.55$ and $344.83 \mathrm{mg} / \mathrm{g}$ for the SY FCF (M.W: 452.38g/mol) AM (M.W: $604.47 \mathrm{~g} / \mathrm{mol}$ ) and FG FCF (M.W: $808.85 \mathrm{~g} / \mathrm{mol}$ ), respectively. These results indicated the molecular weight of the dye has a contributory influence on the adsorption capacity. Dogan et al. fabricated P(HP $\beta C D) / P(B A-a)$ nanofibers and studied their adsorption for $\mathrm{MB}$ and $\mathrm{MO}$ [91]. They found that the adsorption affinity of $\mathrm{MB}$ onto the prepared nanofibers was higher than of $\mathrm{MO}$. This was attributed to the positively charged MB that enhances the electrostatic interaction with $\mathrm{P}(\mathrm{HP} \beta C \mathrm{C} 15 / \mathrm{P}(\mathrm{BA}-\mathrm{a})$ nanofibers. Zhan et al. observed that the adsorption of cationic dye onto the surface of ZIF8/PAN nanofibers depends on the molecular structure of dye [92]. They concluded that the adsorption capacity of MG $(1666.67 \mathrm{mg} / \mathrm{g})$ was much higher than of MB $(120.48 \mathrm{mg} / \mathrm{g})$ due to the interaction between aromatic ring of MG and double bonds and a pair of electrons in imidazole moieties. Table S1 summarizes the chemical structure and maximum absorption wavelength $\left(\lambda_{\max },(\mathrm{nm})\right.$ of the dyes addressed in this review.

\subsection{Effect of Operating Conditions of Adsorption}

The removal of dyes from aqueous solution by adsorption process is highly dependent on operating conditions like $\mathrm{pH}$, adsorbent dosage, initial concentration of dye, contact time and temperature.

\subsection{1. $\mathrm{pH}$ Effect}

The $\mathrm{pH}$ is one of the most important factors that affect the adsorption process, due to its effect on the ionization degree of functional groups for both polymer nanofibers and dye. In general, increasing the $\mathrm{pH}$ of the adsorption medium enhances the adsorption of cationic dyes due to increasing the electrostatic attraction between the dye and polar groups on the surface of nanofibers and vice versa with anionic dyes. Several studies have examined the effect of $\mathrm{pH}$ on the adsorption capacity of polymer nanofibers and their nanocomposites towards dyes removal from an aqueous system. Fan et al. performed the adsorption of cationic dye (MB) and anionic dye (MO) at various pH onto PANF-g-HPEI nanofibers [93]. They found that the maximum adsorption capacity and adsorption rate were happen at $\mathrm{pH}$ 3 and $\mathrm{pH} 10$ for $\mathrm{MO}$ and $\mathrm{MB}$, respectively. The adsorption dependence on $\mathrm{pH}$ confirmed that the electrostatic interaction between the dye molecules and the nanofibers surface is dominant. Mousavi et al. studied the adsorption-desorption of MB onto porous nanofiber aerogels that fabricated by electrospinning of pullulan/PVA/PAA followed by thermal crosslinking [94]. They found that the basic medium ( $\mathrm{pH}$ 11) was suitable for the adsorption of $\mathrm{MB}$ onto fabricated nanofiber aerogel, while the desorption process was achieved in acidic medium ( $\mathrm{pH}$ 2.6). This was due to the deprotonation of carboxylic and hydroxyl 
groups in basic medium, which enhances the electrostatic interaction between negatively charged surface of nanofibers and cationic ions of MB.

\subsubsection{Nanofibers Dosage}

Optimization of adsorbent doses required for complete removal of dye from aqueous solutions is very important to determine the cost-effectiveness of adsorbent. In general, the dye removal percentage increases with increasing the adsorbent dose until certain dose due to the increase of adsorption sites on the adsorbent surface with increasing the amount of adsorbent. In contrast, the adsorption capacity decreases with increasing adsorbent dose due to the mathematical inverse proportional to the adsorbent dosage. Mahmoodi et al. studied the effect of ZIF-8@chitosan/PVA nanofibers dose on the removal of MG dye and they found that the removal percentage increase with increasing the adsorbent dose and the optimum dosage was $0.03 \mathrm{~g} / \mathrm{L}$ [95]. Almasian et al. also investigated the effect of PAN/Tectomer nanofiber dosage on removal percentage of DR-80 and DR-23 and they observed that the removal percentage was increased with increasing the adsorbent dosage [96].

\subsubsection{Contact Time}

The contact time factor helps in determining the optimum time required to saturate the active adsorption sites on the surface of the nanofibers and complete removal of dye. The adsorption efficiency and adsorption capacity usually increase by increasing the contact time to reach the equilibrium state, then remains steady state thereafter. Most of the studies that used polymer nanofibers as an adsorbent to remove various types of dyes studied the effect of contact time and determined the time required to reach equilibrium. For example, Soltan et al. studied the effect of contact time on the removal of anionic dyes using nylon-6/poly(propylene imine) dendrimer nanofibers [97]. They found that within the first 2 minutes, more than $90 \%$ of the dye was removed. Lu et al. studied the effect of contact time on the adsorption capacity of PAN $/ \mathrm{MoS}_{2}$ nanofibers at different concentration of $\mathrm{RhB}$ dye [98]. They found that the adsorption capacity increased rapidly in the first few minutes and reached equilibrium after $50 \mathrm{~min}$ for an initial concentration less than $100 \mathrm{mg} / \mathrm{L}$ and $180 \mathrm{~min}$ for an initial concentration higher than $250 \mathrm{mg} / \mathrm{L}$. San et al. investigated the required contact time to reach equilibrium state for removal of $\mathrm{MB}$ using cellulose acetate/bacteria nanofibers [99]. They found that the highest percentage removal of MB dye was obtained after $48 \mathrm{~h}$. Therefore, the optimum contact time needed to reach the equilibrium state for the adsorption of dyes depends on the physical and chemical properties of the nanofibers as well as the nature of the incorporated materials inside nanofiber mats.

\subsubsection{Initial Dye Concentration}

The adsorption capacity of the nanofibers largely depends on the initial concentration of the dye in the aqueous solution. In general, the adsorption capacity increases with increasing dye concentration due to the increase in the number of dye molecules in the contact area between the surface of the nanofibers and aqueous solution. The increasing in the contact area enhances the driving force of the transferred mass as well as the number of collisions between dye ions and nanofibers surface. In contrast, the percentage of dye removal decreases with an increase in the initial concentration of the dye due to saturation of the active adsorption sites on the surface of the nanofibers, which leads to an increase in the remaining concentration of the dye in the aqueous solution. Wang et al. studied the adsorption of $\mathrm{MB}$ onto sodium alginate nanofibers that was crosslinked by $\mathrm{CaCl}_{2}$ and they found that the adsorption capacity increased from 500 to $2357.87 \mathrm{mg} / \mathrm{g}$ with increasing the initial concentration of MB from 200 to $1500 \mathrm{mg} / \mathrm{L}$ [100]. Almasiana et al. studied the removal of DR-80 and Dr-23 dye by PAMAM-grafted-PAN-DETA nanofibers at different initial concentration of dye [72]. They found that the dye removal percentage decreased with increasing the initial concentration of dyes. 


\subsubsection{Temperature}

The effect of the temperature on the adsorption of dyes onto EPNFs plays a vital role in interpreting the mechanism of adsorption. In general, increasing the adsorption capacity with increasing the temperature indicates that the adsorption process is endothermic and is exothermic with decreasing the temperature. The increase in the adsorption capacity with increasing the temperature is attributed to higher mobility of the dye molecules and strong interaction between the dye ions and the active adsorption sites on the surface of the nanofibers. For example, the adsorption of MB dye by P(NIPAM-co- $\beta C D) / P(N I A P M-$ co-MAA) [101] and DCA/PDA [89] nanofibers was an endothermic process while it was exothermic by sodium alginate [100], Keratin [102] and gelatin/ $\beta-C D$ [103] nanofibers. Table 2 summarizes the results of some studies that investigated the effect of temperature on the adsorption of different dyes on the surface of functionalized polymer nanofibers.

Table 2. Effect on adsorption of different dyes on the surface of electrospun polymer nanofibers (EPNFs).

\begin{tabular}{|c|c|c|c|c|c|}
\hline Adsorbent & Dye Class & Dye Name & $\begin{array}{c}\text { Temperature } \\
\text { Range (K) }\end{array}$ & Process Type & Ref. \\
\hline P(NIPAM-co- $\beta C D) / P($ NIAPM-co-MAA) & Cationic & MB & $298-328$ & Endothermic & [101] \\
\hline P(NIPAM-co-MAA) / $\beta$-CD & Cationic & $\mathrm{CV}$ & $298-333$ & Endothermic & [104] \\
\hline DCA/PDA & Cationic & MB & $288-323$ & Endothermic & [89] \\
\hline PMETAC/PES & Anionic & $\mathrm{CR}$ & $298-318$ & Endothermic & [83] \\
\hline PAN-EDA & Anionic & $\mathrm{CR}$ & $303-323$ & Endothermic & [67] \\
\hline \multirow{2}{*}{ EDTA-EDA-PAN } & Anionic & $\mathrm{MO}$ & \multirow{2}{*}{$298-318$} & Endothermic & \multirow{2}{*}{ [105] } \\
\hline & Anionic & $\mathrm{RR}$ & & Exothermic & \\
\hline sodium alginate & Cationic & $\mathrm{MB}$ & $288-218$ & Exothermic & {$[100]$} \\
\hline PES/PEI & Anionic & SY FCF & $278-323$ & Endothermic & [90] \\
\hline Keratin & Cationic & $\mathrm{MB}$ & $293-323$ & Exothermic & {$[102]$} \\
\hline gelatin/ $\beta-C D$ & Cationic & $\mathrm{MB}$ & $298-333$ & Exothermic & {$[103]$} \\
\hline PVA/CS/DETA/EDA & Anionic & DR-23 & $298-333$ & Endothermic & {$[106]$} \\
\hline $\mathrm{PVA} / \mathrm{CA} / \mathrm{SiO}_{2}$ & Anionic & DR-80 & 298-333 & Endothermic & {$[107]$} \\
\hline
\end{tabular}

\section{Adsorption Mechanism of Dyes onto Nanofiber Mats}

Understanding the adsorption mechanism of dyes onto adsorbent is very essential in order to optimize the adsorption process and improve the nanofiber's efficiency towards the removal of dyes. Adsorption of dyes onto the surface of nanofibrous materials depends on the conditions of the solution (e.g., $\mathrm{pH}$, temperature), the nature of the nanofibers (e.g., porosity, surface area, functional groups, morphology) and the nature of the dye (e.g., cationic form, anionic form, molecular size). Due to the multiplicity of factors affecting the adsorption process of dyes onto the surface of the nanofibers, the adsorption mechanism may not be explicit. Therefore, it is necessary to conduct isotherm, kinetic, thermodynamic and spectroscopic studies as well as studying the effect of $\mathrm{pH}$ to obtain a clear and indepth view of the adsorption mechanism. As reported from different studies [108-112], the removal of dyes from aqueous solutions using pristine, blend functionalized polymer nanofibers likely occurs via hydrogen bonding, van der Waals forces, $\pi-\pi$ stacking, hydrophobic interactions and electrostatic interactions as well as pore filling. Each interaction depends on the nature of the functional groups on the surface of nanofibers, their morphology and the nature of the additive to the nanofibers. Due to the multifunctional groups in polymer nanofibers and their nanocomposites, the adsorption mechanism of dyes can be explained by a combination of these interactions that operate simultaneously with varying degrees. For example, Qureshi et al. studied the adsorption mechanism of 
Acid Blue 117 dye onto the surface of nylon-6 nanofibers by FTIR and XPS techniques. They concluded that the adsorption of dye achieved through combination of interactions such as hydrophobic, electrostatic and hydrogen bond interactions [113]. Al-Marjeh et al. investigated the adsorption mechanism of MO onto the surface of pTSA-PANI/PLLA by $\mathrm{pH}$ and ionic strength effect [114]. They found that the adsorption process depends mainly on the electrostatic interaction between the negative charge of $\mathrm{MO}$ and the positive charge of emeraldine salt state of polyaniline on the PLLA nanofibers surface. Chaúque et al. functionalized PAN nanofibers by EDTA and EDA, and studied adsorption of anionic dyes such as MO and RR dye [105]. They found that the adsorption capacity of MO and RR dye onto the surface of EDTA-EDA-PAN nanofibers was higher than pristine PAN nanofibers and stable at various $\mathrm{pH}$ values. This result attributes that the adsorption mechanism depends on non-electrostatic interactions such as hydrogen bonding, hydrophobic interactions, and van der Waals forces, and to a lesser degree on the electrostatic interaction. Chen et al. studied the adsorption performance of gelatin/ $\beta$-cyclodextrin nanofibers towards the removal of MB dye [103]. They concluded that the adsorption mechanism in alkaline medium depends on the electrostatic interaction between carboxylic groups of gelatin and positive charge of $\mathrm{MB}$ as well as host-guest interaction between $\beta-\mathrm{CD}$ and $\mathrm{MB}$. Figure 4 summarizes adsorption mechanisms of dyes onto EPNFs and their composites.

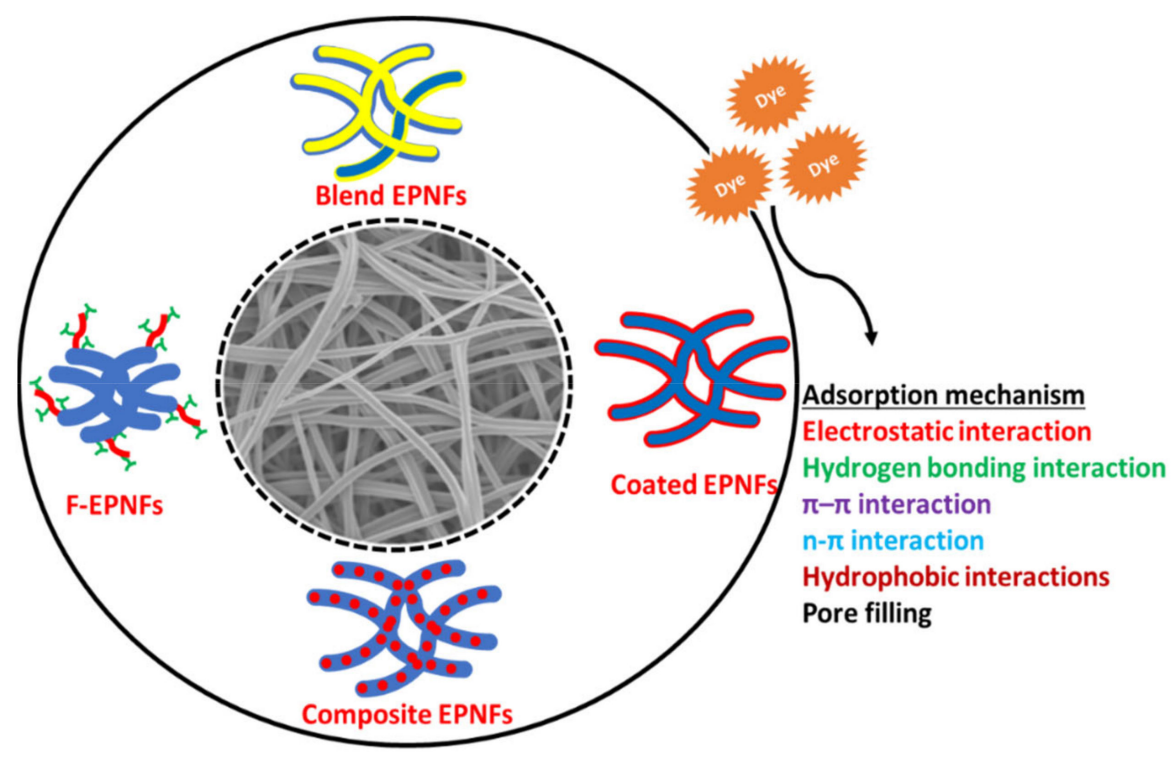

Figure 4. Adsorption mechanism of dyes onto surface EPNFs.

\section{Types of EPNFs as Adsorbent for the Removal of Dyes}

Polymers are characterized by high molecular weights and are divided according to the source into two main parts: natural and synthetic polymers. Some polymers have been used as adsorbents for many pollutants, including dyes, especially those containing effective functional groups and insoluble in water. The efficiency of polymers in dye removal depends on the effective group nature, morphology, surface area and porosity. Converting polymers into nanofibers is one of the most effective ways to improve their efficiency in removing dyes due to the unique properties of nanofibers such as high-water permeability, high surface area and porosity.

\subsection{Homopolymers-Based-EPNFs as Adsorbent for Dyes Removal}

Polyamide nanofibers are one of the common homopolymers that have been used as an effective adsorbent for the removal of dyes as it is inexpensive, insoluble in water, keeps its morphology during the adsorption process and is reusable [115]. For example, Qureshi et al. fabricated nylon-6 nanofibers by an electrospinning technique and used them as an efficient and selective adsorbent for the removal of anionic dyes [113]. The obtained 
results indicated that the removal efficiency of nylon-6 increased from approximately $20 \%$ to $90 \%$ upon converting it to nanofibers. The sulfonated polysulfone (SPES) is also considered as a synthetic polymer, is spinnable and contains the active sulfonate and sulfonic groups [116]. Yin et al. prepared ultrafine nanofibers based on SPES and applied them for the adsorption of dyes and heavy metals [117]. Recently, researchers have been focused on the use of natural and electrospinnable polymers due to their abundantly inexpensive and non-toxic properties. Li et al. have successfully fabricated chitosan nanofibers by electrospinning and used as adsorbent for the removal of acid blue-113 from an aqueous solution [87]. They found that the diameter of chitosan nanofibers has a significant effect on the removal efficiency and the adsorption capacity increased from 412 to $1377 \mathrm{mg} / \mathrm{g}$ upon converting the chitosan fibers from the micro to nanoscale. Although pure chitosan has a high ability to adsorb the dye because it contains amino and hydroxyl groups, its spinnability is weak. Therefore, in the aforementioned study, Triton-100 as surfactant was added to chitosan solution facilitate the electrospinning process. The Triton-100 is not subject to evaporation during the spinning or drying process and is soluble in water, so it can cause secondary water pollution when chitosan is used to treat water. Another example of biopolymer nanofibers that have been used as an effective bioadsorbent for dyes removal is zein but its ability to remove dyes remains low compared to chitosan nanofibers [118]. In general, the adsorption capacity of pure spinnable polymers for removal of various dyes was low compared to other materials, as Table 5 shows the adsorption capacity of PLLA [79], Keratin [102], Nylone-6 [113], polyamide 6 [115], SPES [117], Zein [118] and PMAA-co-PMMA [119].

\subsection{EPNFs Blends as Adsorbent for Dyes Removal}

Due to the low adsorption capacity, low mechanical properties and hydrophobic properties of homopolymers that are spinnable and insoluble in water, the polymer blends have been used as substituent and efficient adsorbents for the removal of dyes from an aqueous system. The blend of a polymer containing functional groups with hydrophobic polymer in different ratio plays an important role in improving its hydrophilicity and increasing the adsorption active sites as well as decreasing the cost [120]. One of the spinnable and hydrophobic polymers that have good mechanical properties is polyacrylonitrile (PAN) [121-123]. The adsorption capacity of PAN towards the adsorption of dyes is very low due to its hydrophobic character and lack of effective functional groups. Therefore, many studies have proven that blending of other polymers with PAN nanofibers has improved its ability to remove various dyes. For instance, Hou et al. fabricated a blend of PAN/polyamidoamine (PAMAM) with a certain ratio, which led to increasing its surface area and enhanced its adsorption capacity towards the removal of methyl orange dye [124]. Chitosan and its blends have also shown good adsorption efficiency due to the presence of amine groups in their backbone [125]. Recently, several studies have used blends of chitosan as effective adsorbents for dye removal. Dotto et al. fabricated a blend of chitosan/polyamide (CS/PA) nanofibers by electrospinning and used it as an effective adsorbent for the removal of Ponceau 4R (P-4R) and Reactive Black 5 (RB-5) [126]. They found that the monolayer adsorption capacity of CS/PA nanofibers was $502.4 \mathrm{~g} / \mathrm{g}$ for P4R and $456.9 \mathrm{mg} / \mathrm{g}$ at $\mathrm{pH}$ 1. Furthermore, they observed that CS/PA nanofibers can be reused four times without decline in its adsorption capacity. Lou et al. demonstrated the ability of chitosan on enhancing the adsorption capacity of PAN towards the removal of Acid Blue 113 from an aqueous solution [73]. They found that the adsorption capacity of PAN nanofibers towards the removal of $\mathrm{AB}-113$ after being coated with chitosan increased from $48.6 \mathrm{mg} / \mathrm{g}$ to $1368 \mathrm{mg} / \mathrm{g}$ and reached to equilibrium after $2 \mathrm{~h}$. This was attributed to the enhancement of the hydrophilic property of nanofibers after coating with chitosan as well as presence of amino groups. The blend of polymers in different proportions can improve its adsorption capacity and overcome non-electrospinnability of some polymers as well as enhancing their mechanical properties. For example, polyethylenimine is non-spinnable due to the ease of cross-linked and the difficulty to dissolve in a suitable solvent. Ma et al. prepared 
polyethylenimine nanofibers by electrospinning through mixing it with poly(vinylidene fluoride) [127]. They suggested a ratio of PVDF should exceed $50 \mathrm{wt} . \%$ in order to prepare fine nanofibers with less spindles. The synthesized PEI/PVDF nanofibers was used for the removal of MO dye, which exhibited good adsorption capacity $(633 \mathrm{mg} / \mathrm{g})$ and can be reused more than 10 times. $\mathrm{Xu}$ et al. fabricated PES nanofibers and enhanced its adsorption capacity by blending with amphiphilic copolymer like methyl methacrylate and sodium styrene sulfonate (P(MMA-SSNa) [128]. They found that negatively charged sulfonated groups migrated onto the surface of nanofibers and enhanced their adsorption rate and adsorption capacity towards the removal of MB as shown in Figure 5. Based on the data shown in Table 3, it was found that the adsorption capacity of polymer nanofibers increases when mixed with one or more polymers, due to the creation of new functional groups which increase the adsorption sites on the surface of the nanofibers. Moreover, the best isotherm and kinetic model to describe the adsorption process of cationic and anionic dyes on the surface of homo and blend polymer were Langmuir and PSO models. These results indicate that the surface of the EPNFs was homogeneous and that the amount of dyes adsorbed on their surface was in the form of a single layer.

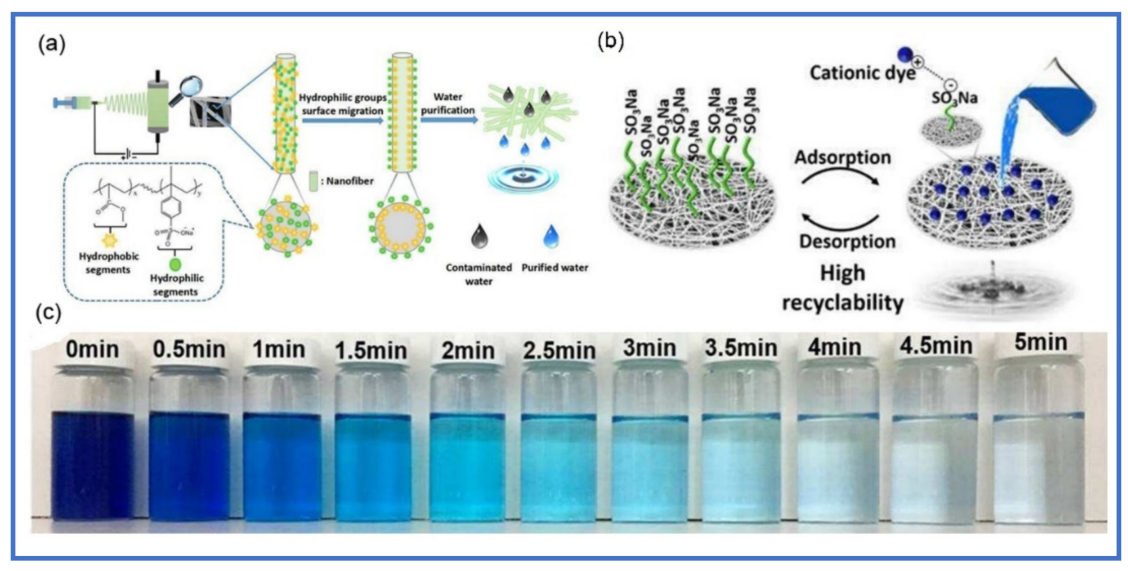

Figure 5. (a) Fabrication of blend PES/P(MMA-SSNa) nanofibers (b) migration of sulfonate groups into the surface of nanofibers and their role in interaction with MB (c) Photography of cationic dye (MB) color change with time after immersing nanofibers [128]. Copyright (C) (2020) Royal Society of Chemistry.

Table 3. Pristine and blend electrospun polymer nanofibers as adsorbent for removal of dyes.

\begin{tabular}{|c|c|c|c|c|c|c|c|c|c|}
\hline \multirow[b]{2}{*}{ Adsorbent } & \multirow[b]{2}{*}{ Dye } & \multicolumn{4}{|c|}{ Adsorption Conditions } & \multirow[b]{2}{*}{ Qmax(mg/g) } & \multirow[b]{2}{*}{$\begin{array}{l}\text { Kinetic } \\
\text { Model }\end{array}$} & \multirow[b]{2}{*}{$\begin{array}{l}\text { Isotherm } \\
\text { Model }\end{array}$} & \multirow[b]{2}{*}{ Ref } \\
\hline & & $\mathrm{pH}$ & $\mathrm{T}\left({ }^{\circ} \mathrm{C}\right)$ & Dosage (g/L) & $\begin{array}{c}\text { Range conc } \\
(\mathrm{mg} / \mathrm{L})\end{array}$ & & & & \\
\hline $\begin{array}{l}\text { PMAA-co- } \\
\text { PMMA }\end{array}$ & MV & 6 & 25 & - & $5-200$ & 135.37 & PSO & $\mathrm{L}$ & [119] \\
\hline Zein & RB5 & $2-6$ & 25 & 8 & 20-200 & 18.18 & PSO & $\mathrm{L}$ & [118] \\
\hline Chitosan & AB-113 & - & - & 0.66 & $50-250$ & 1377 & PSO & $\mathrm{L}$ & [87] \\
\hline Nylone-6 & AB-117 & 5.5 & 25 & 4 & $25-400$ & 58.8 & PSO & $\mathrm{F}$ & [113] \\
\hline polyamide 6 & AB-41 & - & 20 & 0.1 & 10 & 43.9 & - & $\mathrm{L}$ & [115] \\
\hline PLLA & MB & - & - & 3.33 & $4-200$ & 8.73 & PSO & $\mathrm{L}$ & [79] \\
\hline Keratin & MB & 6 & 20 & 1 & 50-250 & 170 & PSO & $\mathrm{L}$ & [102] \\
\hline SPES & $\mathrm{MB}$ & 6.8 & $\mathrm{RT}$ & 1 & 6 & 6.6 & PSO & $\mathrm{L}$ & [117] \\
\hline $\begin{array}{c}p \text { TSA- }^{-} \\
@ \text { PANIPLLA }\end{array}$ & $\mathrm{MO}$ & 6 & 25 & 1 & $50-600$ & 377 & PFO & $\mathrm{L}$ & [114] \\
\hline
\end{tabular}


Table 3. Cont.

\begin{tabular}{|c|c|c|c|c|c|c|c|c|c|}
\hline \multirow[b]{2}{*}{ Adsorbent } & \multirow[b]{2}{*}{ Dye } & \multicolumn{4}{|c|}{ Adsorption Conditions } & \multirow[b]{2}{*}{ Qmax(mg/g) } & \multirow[b]{2}{*}{$\begin{array}{l}\text { Kinetic } \\
\text { Model }\end{array}$} & \multirow[b]{2}{*}{$\begin{array}{l}\text { Isotherm } \\
\text { Model }\end{array}$} & \multirow[b]{2}{*}{ Ref } \\
\hline & & $\mathrm{pH}$ & $\mathrm{T}\left({ }^{\circ} \mathrm{C}\right)$ & Dosage (g/L) & $\begin{array}{l}\text { Range conc } \\
(\mathrm{mg} / \mathrm{L})\end{array}$ & & & & \\
\hline CS@PAN & AB-113 & - & 25 & - & $50-250$ & 1708 & PSO & $\mathrm{L}$ & [73] \\
\hline \multirow{2}{*}{$\mathrm{CS} / \mathrm{PA}$} & RB5 & \multirow{2}{*}{1} & \multirow{2}{*}{25} & \multirow{2}{*}{0.2} & \multirow{2}{*}{$0-150$} & 456.9 & PSO & \multirow{2}{*}{$\mathrm{L}$} & \multirow{2}{*}{ [126] } \\
\hline & P4R & & & & & 502.4 & ELV & & \\
\hline $\mathrm{P}(\beta-C D) / \mathrm{PCL}$ & MB & - & $\mathrm{RT}$ & 0.1 & - & 10.5 & $\mathrm{PSO}$ & - & {$[86]$} \\
\hline $\begin{array}{l}\text { P(MMA- } \\
\text { AA)/PES }\end{array}$ & MB & 9 & - & 0.25 & $100-3000 \mu \mathrm{mol}$ & 2257.8 & PSO & $\mathrm{L}$ & {$[62]$} \\
\hline PANI@N-6 & $\mathrm{MO}$ & 1 & $\mathrm{RT}$ & - & - & 370 & - & - & {$[74]$} \\
\hline PDA@CA & MB & 6.5 & 25 & 0.5 & $30-100$ & 88.2 & $\mathrm{PSO}$ & $\mathrm{L}$ & [89] \\
\hline HA@PAN & $\mathrm{CV}$ & 7 & 25 & 0.025 & $1-7.5 \mu \mathrm{mol}$ & 81.6 & - & $\mathrm{L}$ & [121] \\
\hline \multirow{2}{*}{$\mathrm{CS} / \mathrm{PA}$} & RB5 & \multirow{2}{*}{1} & \multirow{2}{*}{25} & \multirow{2}{*}{0.2} & \multirow{2}{*}{$0-150$} & 198.6 & \multirow[t]{2}{*}{-} & \multirow{2}{*}{$\mathrm{L}-\mathrm{F}$} & \multirow{2}{*}{ [125] } \\
\hline & P4R & & & & & 222.4 & & & \\
\hline $\begin{array}{l}\text { P(MMA-co- } \\
\text { SSNa)@PES }\end{array}$ & MB & $3-10$ & RT & 0.2 & $100-500 \mu \mathrm{mol}$ & 625 & $\mathrm{PSO}$ & $\mathrm{L}$ & [128] \\
\hline PPI-N6 & AR-252 & 4 & 25 & 0.6 & $12.5-100$ & 158.73 & $\mathrm{PSO}$ & $\mathrm{L}$ & {$[97]$} \\
\hline \multirow{2}{*}{ PPy@PVDF/PDA } & $\mathrm{MB}$ & 13 & \multirow[t]{2}{*}{-} & \multirow[t]{2}{*}{-} & \multirow{2}{*}{$30-200$} & 370.4 & \multirow[t]{2}{*}{$\mathrm{PSO}$} & \multirow{2}{*}{$\mathrm{L}$} & \multirow[t]{2}{*}{ [58] } \\
\hline & CR & 1 & & & & 384.6 & & & \\
\hline $\mathrm{m}-\mathrm{PEI} / \mathrm{PVDF}$ & $\mathrm{MO}$ & 7 & 25 & 0.5 & 200-1000 & 633.3 & $\mathrm{PSO}$ & $\mathrm{L}$ & [127] \\
\hline DETA@PAN & DR-80 & 2.1 & - & 0.044 & $20-100$ & 1250 & $\mathrm{PSO}$ & $\mathrm{L}$ & [122] \\
\hline PAN/PAMAM & $\mathrm{MO}$ & - & 30 & 3.33 & - & 120.77 & PSO & $\mathrm{L}$ & [124] \\
\hline PAN/PVDF & BB-41 & 6 & 25 & 0.66 & $10-40$ & 166.6 & PSO & $\mathrm{L}$ & [85] \\
\hline CA-PANI/ $\beta-C D$ & MB & 8 & 25 & 0.64 & $50-70$ & 49.51 & PSO & $\mathrm{L}$ & [123] \\
\hline
\end{tabular}

\subsection{Crosslinked EPNFs as Adsorbent for Dyes Removal}

Water-soluble polymers are one of the most important polymers that used in many applications and can also be converted some of them into nanofibers due to their high electrospinnability. However, the use of nanofibers derived from water-soluble polymers such as poly (vinyl alcohol) (PVA) have limitations for use in water treatments due to their instability in aqueous systems. However, this problem can be overcome by creating crosslinking points on the polymer chains to avoid their solubility in water [129]. The crosslinking between polymer chains can be achieved by creating a chemical bond or by physical interaction. Crosslinking process of electrospun nanofibers derived from water-soluble polymers is achieved after the electrospinning process. For instance, PVA nanofibers can be crosslinked by physical crosslinking (alcohol treatment or thermally) [130,131] or by chemical agents such as glutaraldehyde [132,133]. So, PVA was used to improve the spinnability of some natural polymers such as chitosan [134], starch [135,136], cellulose [137] and Polycyclodextrin $[138,139]$. Mei et al. easily fabricated PVA/CS nanofibers by electrospinning followed by crosslinked with glutaraldehyde for the adsorption of Congo red (CR) dye [140]. The maximum adsorption capacity for CR dye was $358 \mathrm{mg} / \mathrm{g}$ at $\mathrm{pH}=6$, $25^{\circ} \mathrm{C}$, dose of nanofibers $6 \mathrm{~g} / \mathrm{L}$ of $100 \mathrm{mg} / \mathrm{L} \mathrm{CR}$ solutions. In another study, Moradi et al. fabricated PVA/starch nanofibers with high surface area $(24.72 \mathrm{~m} 2 / \mathrm{g})$ by electrospinning followed by thermal crosslinking thermally crosslinked for the removal of cationic dye (MB) [141]. The adsorption capacity for MB was $400 \mathrm{mg} / \mathrm{g}$ on the crosslinked PVA/starch nanofibers and the isotherm and kinetic of the adsorption were described by Langmuir and PSO model, respectively. Wang et al. prepared sodium alginate electrospun nanofibers 
by electrospinning and the crosslinking processes were conducted by various crosslinking agents (calcium chloride $\left(\mathrm{CaCl}_{2}\right)$, glutaraldehyde (GA) and trifluoroacetic acid (TFA)) and was used as a nanoadsorbent for the removal of MB dye as shown in Figure 6 [100]. They found that the tensile strength, surface area, adsorption capacity and adsorption equilibrium time are dependent on the type of crosslinking agent. The maximum adsorption capacity of sodium alginate electrospun nanofibers that were crosslinked by $\mathrm{CaCl}_{2}$ was found to be $2230 \mathrm{mg} / \mathrm{g}$, which was higher than that crosslinked by glutaraldehyde and trifluoroacetic acid and the removal efficiency for all remained at $90 \%$ after five regeneration cycles as shown in Figure $6 \mathrm{a}, \mathrm{b}$. Song et al. successfully prepared two kinds of electrospun crosslinking PEI/PAN nanofibers; during electrospinning (in situ crosslinking) and after electrospinning (solution crosslinking) [142]. Both crosslinking processes were achieved by epichlorohydrin and the maximum adsorption capacity of PEI/PAN nanofibers (by in situ) and PEI/PAN nanofibers (by solution) for MO dye was 636.94 and $595.24 \mathrm{mg} / \mathrm{g}$, respectively. In another study, in situ crosslinking methods have been used by adding monomer of acrylic acid and sodium styrene sulfonate to the PES solution in the presence of initiator followed by electrospinning process [84]. The PSSNa/PAA@PES nanofibers were used for the adsorption and separation of $\mathrm{MB}$ from mixture of $\mathrm{MB} / \mathrm{MO}$ and $\mathrm{MB} / \mathrm{AR}$. It was found that the separation efficiency of PSSNa/PAA@PES for MB from mixture of $\mathrm{MB} / \mathrm{MO}$ and $\mathrm{MB} / \mathrm{AR}$ was $97.54 \%$ and $98.29 \%$, respectively.

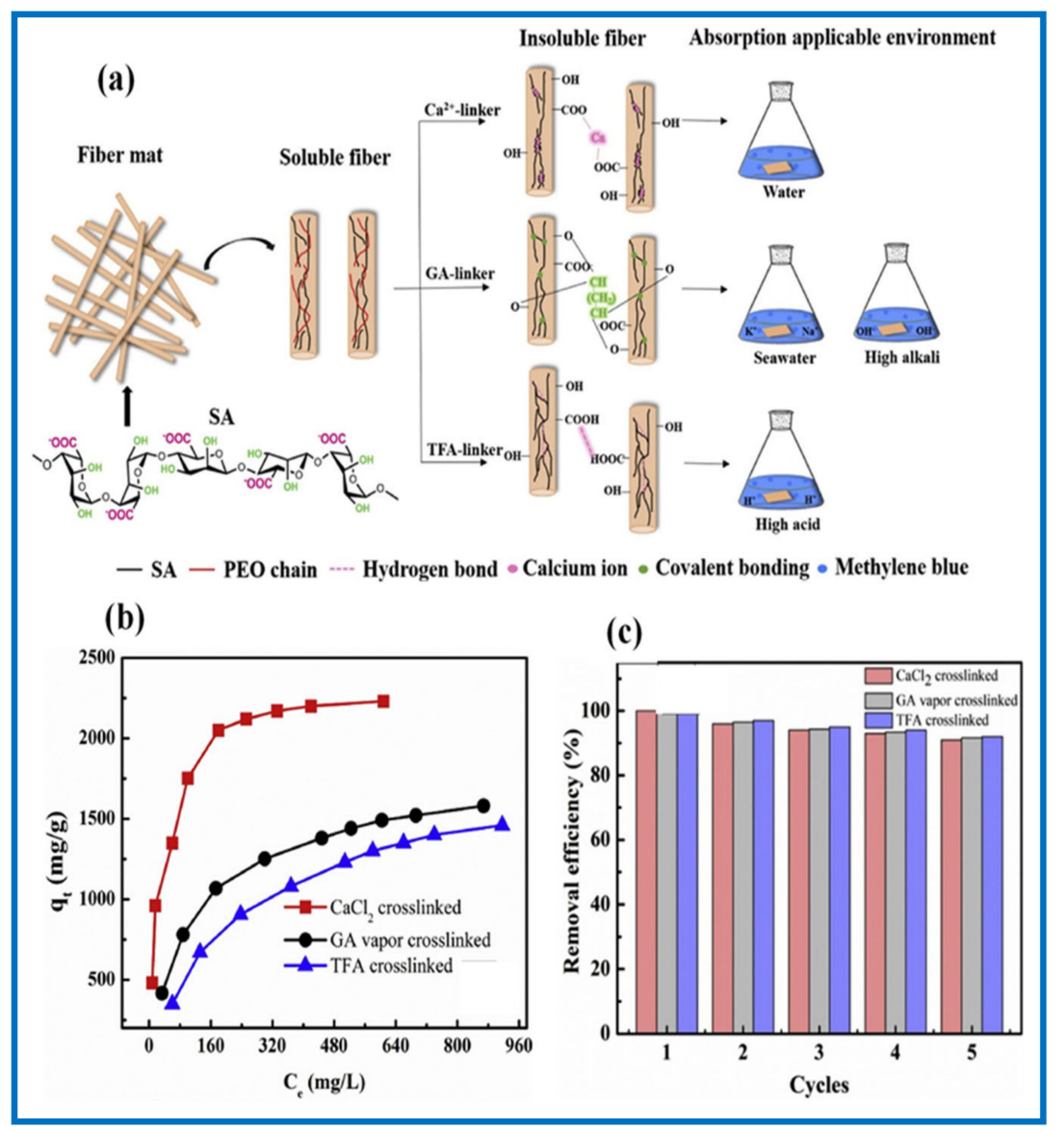

Figure 6. (a) Fabrication of sodium alginate / PEO nanofibers and crosslinking by $\mathrm{CaCl}_{2}, \mathrm{GA}$ vapor and TFA (b) Adsorption of MB by prepared crosslinked SA/PEO nanofibers (c) Reuse of crosslinked SA/PEO nanofibers for adsorption MB [100]. Copyright (C (2020) Elsevier.

The good selectivity towards the adsorption of $\mathrm{MB}$ was attributed to the electrostatic attraction between the negatively charged $\left(-\mathrm{SO}_{3}-\right)$ groups on the surface of PSSNa/PAA@PES and the positively charged MB molecules and vice versa. Dogan et al. synthesized 
crosslinked polycyclodextrin/polybenzoxazine nanofibers (PolyHP $\beta C D / P o l y B A-a)$ by electrospinning blend of hydroxypropyl- $\beta$-cyclodextrin benzoxazine and citric acid followed by thermally cured and used for the removal and separation of MB [91]. It was observed that the incorporation of $15 \%$ of citric acid into PolyHP $\beta C D /$ PolyBA-a nanofibers led to the enhancement of its stability in water and organic solvents. Despite its low adsorption capacity for MB (46 mg/g), it showed excellent selectivity to separate MB from a mixture of $\mathrm{MB} / \mathrm{MO}$. Table 4 displays the data on the adsorption of various dyes by crosslinked EPNFs. Zhu et al. fabricated crosslinked PVA/PEI nanofibers followed by a coating by dopamine through an in-situ polymerization process [143]. They noticed that the prepared crosslinked nanofibers exhibit good chemical stability in the harsh environments, good mechanical properties and excellent removal efficiency of cationic and anionic dyes. Other crosslinked EPNFs like Gel/Ca-Alg [144], PVA-TETA [145], SS/PVA [146],

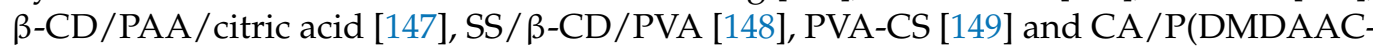
AM) [150] also showed good adsorption capacity for the removal of various cationic and anionic dyes from contaminated water. In contrast, crosslinked EPNFs such as

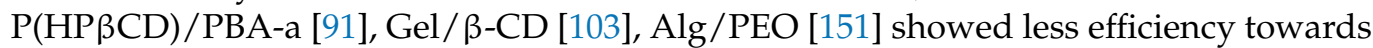
removing dyes. Based on data in Table 5 , the best isotherm and kinetic model to describe the adsorption process of cationic and anionic dyes on the surface of crosslinked EPNFs were Langmuir and PSO model, except one study that found the Freundlich model was the best for describing adsorption of MB onto the surface of PSSNa/PAA@PES [84]. These results indicate that the surface of the functionalized EPNFs was homogeneous and that the amount of dyes adsorbed on their surface was in the form of a single layer.

Table 4. Crosslinked EPNFs as adsorbent for removal of dyes.

\begin{tabular}{|c|c|c|c|c|c|c|c|c|c|c|}
\hline \multirow[b]{2}{*}{ Adsorbent } & \multirow{2}{*}{$\begin{array}{c}\text { Crosslinked } \\
\text { Type }\end{array}$} & \multirow[b]{2}{*}{ Dye } & \multicolumn{4}{|c|}{ Adsorption Conditions } & \multirow{2}{*}{$\begin{array}{l}\text { Qmax } \\
(\mathrm{mg} / \mathrm{g})\end{array}$} & \multirow{2}{*}{$\begin{array}{l}\text { Kinetic } \\
\text { Model }\end{array}$} & \multirow[b]{2}{*}{$\begin{array}{l}\text { Isotherm } \\
\text { Model }\end{array}$} & \multirow[b]{2}{*}{ Ref } \\
\hline & & & $\mathrm{pH}$ & $\mathrm{T}\left({ }^{\circ} \mathrm{C}\right)$ & $\begin{array}{l}\text { Dos. } \\
\text { (g/L) }\end{array}$ & $\begin{array}{c}\text { Range conc } \\
(\mathrm{mg} / \mathrm{L})\end{array}$ & & & & \\
\hline Na-Alg & $\mathrm{CaCl}_{2}$ & MB & 6 & 25 & 0.4 & $200-1500$ & 2230 & PSO & $\mathrm{L}$ & [100] \\
\hline $\begin{array}{c}\text { P(NIPAM-co- } \beta- \\
\text { CD)/P(NIAPM-co- } \\
\text { MAA) }\end{array}$ & thermally & MB & 9 & 55 & 0.35 & $50-1400$ & 1834.9 & PSO & $\mathrm{L}$ & [101] \\
\hline $\mathrm{P}(\mathrm{HP} \beta \mathrm{CD}) / \mathrm{PBA}-\mathrm{a}$ & thermally & MB & - & - & 1 & $10-100$ & 46.08 & PSO & $\mathrm{L}$ & [91] \\
\hline $\begin{array}{l}\text { P(NIPAM-Co- } \\
\text { MAA) } / \beta-C D\end{array}$ & thermally & $\mathrm{CV}$ & 9 & 55 & 0.35 & $50-900$ & 1253.7 & PSO & $\mathrm{L}$ & [104] \\
\hline PVA/CS/DETA/EDA & GA & DR-23 & 2.1 & 25 & 0.1 & $40-100$ & 526.31 & PSO & $\mathrm{L}$ & [106] \\
\hline $\mathrm{Pu} / \mathrm{PVA} / \mathrm{PAA}$ & thermally & MB & 11 & 25 & 1.33 & - & 383 & PSO & $\mathrm{L}$ & {$[94]$} \\
\hline$\beta-\mathrm{CD} / \mathrm{PVP}$ & GA & $\mathrm{MO}$ & 7 & 25 & 2.5 & $10-150$ & 39.82 & - & $\mathrm{L}$ & [152] \\
\hline $\mathrm{Gel} / \beta-\mathrm{CD}$ & GA & $\mathrm{MB}$ & 8 & 25 & 1.25 & $5-100$ & 47.4 & PSO & $\mathrm{L}$ & [103] \\
\hline Gel/Ca-Alg & $\mathrm{CaCl}_{2}$ & MB & 6 & 25 & 0.4 & $50-900$ & 1937 & PSO & $\mathrm{L}$ & [144] \\
\hline \multirow{3}{*}{ PES/PEI } & \multirow{3}{*}{ GA } & SY FCF & \multirow{3}{*}{1} & \multirow{3}{*}{30} & \multirow{3}{*}{0.8} & \multirow{3}{*}{$100-2000$} & 1000 & \multirow{3}{*}{ PSO } & \multirow{3}{*}{$\mathrm{L}$} & \multirow{3}{*}[90]{} \\
\hline & & FG FCF & & & & & 344.83 & & & \\
\hline & & AM & & & & & 454.55 & & & \\
\hline \multirow{3}{*}{ PVA-TETA } & \multirow{3}{*}{ GA } & DR-80 & \multirow{3}{*}{2.1} & \multirow{3}{*}{25} & \multirow{3}{*}{0.06} & \multirow{3}{*}{$20-50$} & 128.2 & \multirow{3}{*}{ PSO } & \multirow{3}{*}{$\mathrm{L}$} & \multirow{3}{*}{ [145] } \\
\hline & & DR-81 & & & & & 178.6 & & & \\
\hline & & RR-180 & & & & & 181.8 & & & \\
\hline \multirow[t]{2}{*}{$\mathrm{Alg} / \mathrm{PEO}$} & \multirow{2}{*}{$\mathrm{CaCl}_{2}$} & AR-14 & 1 & \multirow[t]{2}{*}{25} & \multirow[t]{2}{*}{4} & \multirow[t]{2}{*}{-} & 17.9 & \multirow[t]{2}{*}{-} & \multirow[t]{2}{*}{$\mathrm{L}$} & \multirow[t]{2}{*}{ [151] } \\
\hline & & BB-41 & 9 & & & & 17.3 & & & \\
\hline
\end{tabular}


Table 4. Cont.

\begin{tabular}{|c|c|c|c|c|c|c|c|c|c|c|}
\hline \multirow[b]{2}{*}{ Adsorbent } & \multirow{2}{*}{$\begin{array}{c}\text { Crosslinked } \\
\text { Type }\end{array}$} & \multirow[b]{2}{*}{ Dye } & \multicolumn{4}{|c|}{ Adsorption Conditions } & \multirow{2}{*}{$\underset{(\mathrm{mg} / \mathrm{g})}{\operatorname{Qmax}}$} & \multirow[b]{2}{*}{$\begin{array}{l}\text { Kinetic } \\
\text { Model }\end{array}$} & \multirow[b]{2}{*}{$\begin{array}{l}\text { Isotherm } \\
\text { Model }\end{array}$} & \multirow[b]{2}{*}{ Ref } \\
\hline & & & $\mathrm{pH}$ & $\mathrm{T}\left({ }^{\circ} \mathrm{C}\right)$ & $\begin{array}{l}\text { Dos. } \\
(\mathrm{g} / \mathrm{L})\end{array}$ & $\begin{array}{l}\text { Range conc } \\
(\mathrm{mg} / \mathrm{L})\end{array}$ & & & & \\
\hline PSSNa/PAA@PES & MBA & $\mathrm{MB}$ & 11 & & - & $50-250 \mu \mathrm{mol}$ & 119.65 & PSO & $\mathrm{F}$ & [84] \\
\hline PMETAC@PES & MBA & CR & 3 & 25 & - & $50-800 \mu \mathrm{mol}$ & 208 & - & $\mathrm{L}$ & [83] \\
\hline SS/PVA & GA & MB & 7 & - & - & $40-450$ & 223.21 & PSO & $\mathrm{L}$ & [146] \\
\hline PEI/EPI/PAN & thermally & $\mathrm{MO}$ & - & 30 & - & - & 636.94 & - & $\mathrm{L}$ & [142] \\
\hline \multirow{3}{*}{ PVA-CS } & \multirow{3}{*}{ GA } & DR-80 & \multirow{3}{*}{2.1} & \multirow{3}{*}{25} & \multirow{3}{*}{0.06} & \multirow{3}{*}{$20-80$} & 151 & \multirow{3}{*}{ PSO } & \multirow{3}{*}{$\mathrm{L}$} & \multirow{3}{*}{ [153] } \\
\hline & & DR-81 & & & & & 95 & & & \\
\hline & & RR-180 & & & & & 114 & & & \\
\hline PVA-CS & GA & CR & 6 & 25 & 6 & - & 358 & PSO & $\mathrm{L}$ & [140] \\
\hline $\begin{array}{l}\beta-\mathrm{CD} / \mathrm{PAA} / \text { citric } \\
\text { acid }\end{array}$ & thermally & MB & 9 & 20 & 0.175 & $80-800$ & 826.45 & PSO & $\mathrm{L}$ & [147] \\
\hline PVA-ST & thermally & $\mathrm{MB}$ & 8.5 & 25 & 0.083 & $25-400$ & 400 & PSO & $\mathrm{L}$ & [141] \\
\hline $\mathrm{SS} / \beta-\mathrm{CD} / \mathrm{PVA}$ & thermally & MB & 8 & 20 & 0.175 & $20-200$ & 187.97 & PSO & $\mathrm{L}$ & [148] \\
\hline PVA-CS & GA & $\mathrm{MO}$ & - & - & 5 & 200-1000 & 183 & - & $\mathrm{L}$ & [149] \\
\hline $\begin{array}{c}\text { CA/P(DMDAAC- } \\
\text { AM) }\end{array}$ & MBA & AB-172 & & 25 & 0.1 & $20-120$ & 192 & PSO & $\mathrm{L}$ & [150] \\
\hline \multirow{2}{*}{ PDA/PEI@PVA/PEI } & \multirow[t]{2}{*}{ GA } & P-s & \multirow[t]{2}{*}{7} & \multirow[t]{2}{*}{25} & \multirow[t]{2}{*}{0.5} & \multirow[t]{2}{*}{$50-1200$} & 1180 & \multirow[t]{2}{*}{ PSO } & \multirow[t]{2}{*}{$\mathrm{L}$} & \multirow[t]{2}{*}{ [143] } \\
\hline & & MB & & & & & 1290 & & & \\
\hline
\end{tabular}

\subsection{Functionalized EPNFs as Adsorbent for Dyes Removal}

The surface functionalization of EPNFs plays an important role in enhancing the adsorption capacity for the removal of dyes and other pollutants. Introducing active and hydrophilic functional groups is an effective method to increase the active sites of adsorption onto the surface of nanofibers. The surface functionalization can be carried out by alkaline hydrolysis, chemical grafting method, plasma-induced grafting. PAN is one of the most synthetic polymers that can be easily electrospun into nanofibers and have unique properties such as good stability in aqueous solutions due to its hydrophobic nature as well as its mechanical properties. However, the adsorption ability of PAN nanofibers for dyes removal from aqueous solutions still week due to its hydrophobic nature. Therefore, the surface modification of PAN nanofibers is an effective way to increase its hydrophilicity properties as well as the adsorption sites on the surface with keeping its morphology [154-156]. For example, Patel and Hota prepared PAN nanofibers and carboxylate-functionalized by alkaline hydrolysis using sodium hydroxide and sodium bicarbonate [157]. They found that the removal of MG from aqueous solutions increase significantly after functionalization. The adsorption capacity of PAN-COOH was found to be $1038 \mathrm{mg} / \mathrm{g}$ at $\mathrm{pH} 5$ and $35^{\circ} \mathrm{C}$. In another study, Haider et al. fabricated and functionalized PAN nanofibers with hydroxylamine hydrochloride to produce oxime grafted PAN and applied as a good adsorbent for the removal of $\mathrm{MB}, \mathrm{RhB}$ and ST dyes [82]. After oxime grafting, PAN nanofibers keep its morphology and the adsorption capacity for removal of $\mathrm{MB}, \mathrm{RB}$ and ST increases from 42.66, 72.46 and $99.3 \mathrm{mg} / \mathrm{g}$ to $102.1,118.3$ and $221.2 \mathrm{mg} / \mathrm{g}$, respectively. Amine amino-functionalized PAN nanofibers is another route to improve its surface properties such as hydrophilicity and improve its ability to adsorb different dyes. A total of three amino-functionalized PAN nanofibers prepared by Patel and Hota were used as effective adsorbents for the removal of Congo red dye as shown in Figure 7a [67]. It was found that the adsorption capacity depends on the density of amino groups and the number of active sites on the surface of nanofibers. The maximum adsorption capacity of 
PAN-EDA was $130 \mathrm{mg} / \mathrm{g}$ and the adsorption process followed Langmuir and PSO model for describing isotherm and kinetic, respectively. In another study, Chauque et al. functionalized surface of poly (acrylonitrile-methyl acrylate-itaconic acid) with ethylenediamine followed by ethylenediaminetetraacetic acid (EDTA) and was used as adsorbent for the removal of ionic dyes as shown in Figure $7 \mathrm{~b}$ [105]. They found that the modified nanofibers have good adsorption capacity towards the removal of $\mathrm{MO}$ and RR dye and can be used five times without significant decline in their efficiency. Mahmoodi et al. developed novel porous amino-functionalized PAN nanofibers fabricated through incorporation of $\mathrm{Na}_{2} \mathrm{CO}_{3}$ salt into PAN nanofibers by electrospinning followed by leaching and functionalization processes [158]. Amine-functionalization was carried out by triethylenetetriamine and was used for the removal of Direct Blue 78 dye. The porous aminated-PAN nanofibers exhibited superior adsorption capacity $(2500 \mathrm{mg} / \mathrm{g})$ towards the removal of Direct Blue 78 dye. Recently, a similar study by Shourijeh et al. prepared porous aminated PAN/PVDF nanofibers by incorporation of $\mathrm{NaHCO}_{3}$ salt using electrospinning, followed by leaching and functionalization by diethylenetriamine agent [159]. It was found that the adsorption capacity of the prepared nanofibers was $685.63 \mathrm{mg} / \mathrm{g}$ for the removal of DR-23 dye. In another work, Almasian et al. functionalized poly(acrylonitrile-co-vinyl acetate) with polyamidoamine then turned to nanofibers using electrospinning and used as an effective adsorbent for the removal of DR-80 and DR-23 dye [160]. They found that the increase in the ratio of polyamidoamine in the nanofiber mats is accompanied with an increase in fiber diameters and decrease in the surface area. The maximum adsorption capacity increased from 1666.66 to $2000 \mathrm{mg} / \mathrm{g}$ with increasing the amount of polyamidoamine from 10 to $20 w / w \%$. Chen et al. prepared PVA/CS nanofibers that were functionalized by polyhexamethylene guanidine and used as adsorbent membrane for the removal of Congo red dye [161]. They found that the functionalization results in a slight change in the surface area of the nanofibers with adsorption capacity of $289 \mathrm{mg} / \mathrm{g}$ for the removal of CR dye but the reusability was sharply declined after the first cycle. Wang et al. used polydopamine for the functionalization of polycaprolactone/polyethylene oxide nanofibers via in-situ oxidation self-polymerization and was applied for the removal of both cationic and anionic dyes [75]. The synthesized nanofibers exhibited adsorption capacity towards the removal of anionic dye (MO) higher than cationic dye (MB). It is noteworthy that the nanofibers can also be reused more than eight times without a significant change in the adsorption capacity of the MO dye. Another polymer that could be converted into EPNFs and modified its surface by different methods and used as an effective and selective adsorbent for removal of cationic dyes is cyclodextrin [162]. Additionally, in-situ polymerization was used for functionalization surface of EPNFs. For example, poly(butylene succinate-co-terephthalate) functionalized by $\beta$-cyclodextrin through the in-situ polymerization and was used for the removal of MB dye as displayed in Figure 7c [163]. It was found that the adsorption capacity of functionalized nanofibers was higher than unmodified nanofibers. Recently, Liu et al. preparation biodegradable aminated copolyesters nanofibers by multi-steps and applied as effective adsorbent for removal of cationic MB dye [88]. They showed that the removal efficiency of $\mathrm{MB}$ was $98 \%$ after five-time reuse and maximum adsorption capacity was $543 \mathrm{mg} / \mathrm{g}$. According to Table 5, the functionalized EPNFs can be used as effective nanoadsorbents for the removal of various dyes due to their structure containing more than one polymer and different polar functional groups. The best isotherm model to describe the adsorption process of cationic and anionic dyes on the surface of functionalized EPNFs were Langmuir model, except two studies that found the Freundlich model was the best for describing adsorption of MO, RB onto the surface of EDTA-PAN nanofibers [105] and CR dye onto the surface PHMG-OCS-PVA nanofibers [161]. 


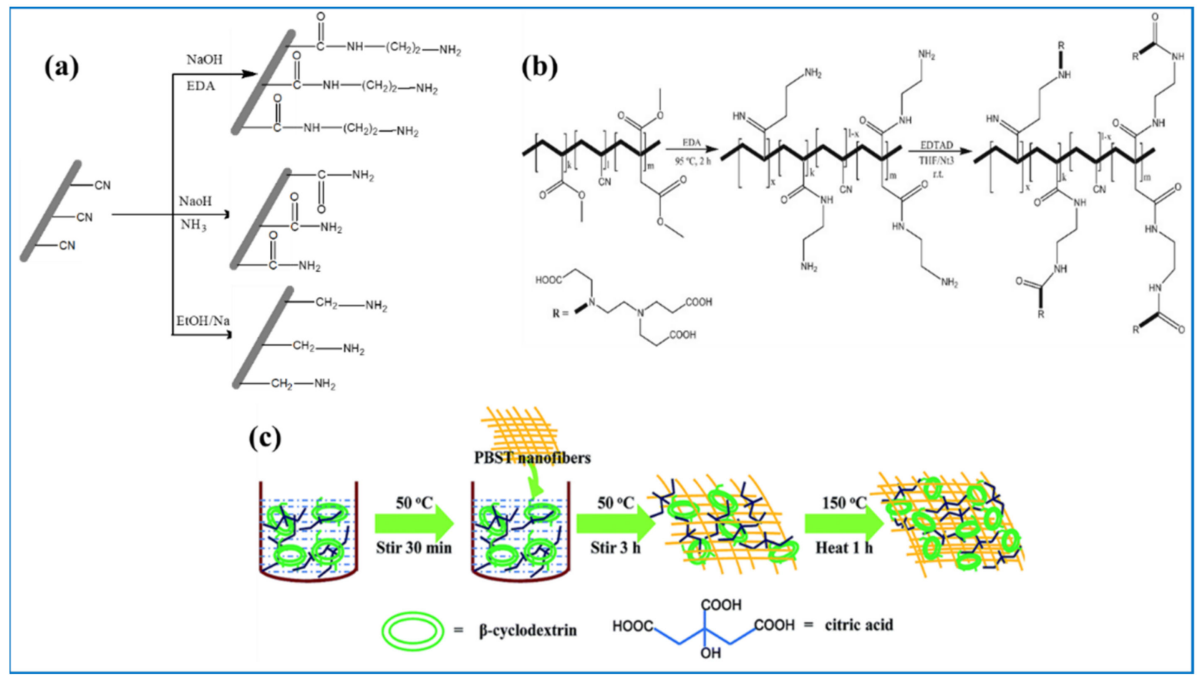

Figure 7. (a) surface functionalization of $\mathrm{PAN}$ by EDA, $\mathrm{NH}_{3}$ and $\mathrm{EtOH} / \mathrm{Na}$ [67], Copyright (C) (2020) Elsevier (b) surface functionalization of poly(acrylonitrile-methyl acrylate-itaconic acid) nanofibers by EDTA [105], a Copyright ( $(2020)$ Elsevier and (c) surface functionalization of poly(butylene succinateco-terephthalate) by cyclodextrin [163], Copyright (c) (2020) Royal Society of Chemistry.

Table 5. Functionalized electrospun polymer nanofibers as adsorbent for removal of dyes.

\begin{tabular}{|c|c|c|c|c|c|c|c|c|c|}
\hline \multirow[b]{2}{*}{ Adsorbent } & \multirow[b]{2}{*}{ Dye } & \multicolumn{4}{|c|}{ Adsorption Conditions } & \multirow[b]{2}{*}{$\underset{(\mathrm{mg} / \mathrm{g})}{\mathrm{Q}_{\max }}$} & \multirow[b]{2}{*}{$\begin{array}{l}\text { Kinetic } \\
\text { Model }\end{array}$} & \multirow[b]{2}{*}{$\begin{array}{l}\text { Isotherm } \\
\text { Model }\end{array}$} & \multirow[b]{2}{*}{ Ref } \\
\hline & & $\mathrm{pH}$ & $\begin{array}{c}\mathrm{T} \\
\left({ }^{\circ} \mathrm{C}\right)\end{array}$ & Dosage (g/L) & $\begin{array}{l}\text { Range Conc } \\
(\mathrm{mg} / \mathrm{L})\end{array}$ & & & & \\
\hline \multirow{3}{*}{ EDA-g-PAN } & MB & \multirow{3}{*}{-} & \multirow{3}{*}{25} & \multirow{3}{*}{-} & \multirow{3}{*}{-} & 94.07 & \multirow{3}{*}{ PSO } & \multirow{3}{*}{$\mathrm{L}$} & \multirow{3}{*}{ [81] } \\
\hline & ST & & & & & 110.62 & & & \\
\hline & $\mathrm{RB}$ & & & & & 138.69 & & & \\
\hline \multirow{3}{*}{ OX-g-PAN } & MB & \multirow{3}{*}{-} & \multirow{3}{*}{25} & \multirow{3}{*}{-} & \multirow{3}{*}{-} & 102.15 & \multirow{3}{*}{ PSO } & \multirow{3}{*}{$\mathrm{L}$} & \multirow{3}{*}{ [82] } \\
\hline & ST & & & & & 118.34 & & & \\
\hline & $\mathrm{RB}$ & & & & & 221.24 & & & \\
\hline \multirow{2}{*}{ PAN-g-HPEI } & $\mathrm{MB}$ & 10 & \multirow{2}{*}{25} & \multirow{2}{*}{1.66} & \multirow{2}{*}{-} & 161 & \multirow{2}{*}{ PSO } & \multirow{2}{*}{$\mathrm{L}$} & \multirow{2}{*}{ [93] } \\
\hline & $\mathrm{MO}$ & 5 & & & & 194 & & & \\
\hline $\begin{array}{c}\text { Carboxylated } \\
\text { poly(AN-co-St) }\end{array}$ & BV-14 & 6.2 & 25 & 2 & $0-100$ & 67.11 & PSO & $\mathrm{L}$ & [154] \\
\hline PAN-COOH & MG & 5 & 35 & 0.5 & $100-500$ & 1038 & PSO & $\mathrm{L}$ & [157] \\
\hline PCD-f-PBST & MB & - & 30 & 1.25 & $5-100$ & 90.9 & PSO & $\mathrm{L}$ & [163] \\
\hline \multirow{3}{*}{ EDTA-PAN } & & \multirow{3}{*}{7} & \multirow{3}{*}{25} & & & 90.15 & & & \\
\hline & $\mathrm{MO}$ & & & 2 & $10-300$ & 110 & PSO & $\mathrm{F}$ & [105] \\
\hline & $\mathrm{RB}$ & & & & & & & & \\
\hline $\begin{array}{c}\text { CM- } \beta-C D-g- \\
\text { PBSST }\end{array}$ & MB & 9 & RT & - & 5-200 & 543.48 & PSO & $\mathrm{L}$ & [88] \\
\hline PAMAM-g-PAN- & DR-80 & & & ح00 & 100 & 3333 & & 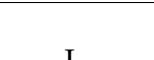 & [72] \\
\hline DETA & DR-23 & 3.5 & RI & 0.02 & $40-100$ & 2500 & PSO & L & [/2] \\
\hline PHMG-OCS-PVA & $\mathrm{CR}$ & - & 30 & 1 & - & 289 & PSO & $\mathrm{F}$ & [161] \\
\hline AOPAN & $\mathrm{MO}$ & 3 & 30 & - & $10-100$ & 68.07 & $\mathrm{PFO}$ & $\mathrm{L}$ & [155] \\
\hline TETA-PPAN & DB-78 & 2.1 & 25 & 0.06 & $80-140$ & 2500 & PSO & $\mathrm{L}$ & [158] \\
\hline
\end{tabular}


Table 5. Cont.

\begin{tabular}{|c|c|c|c|c|c|c|c|c|c|}
\hline \multirow[b]{2}{*}{ Adsorbent } & \multirow[b]{2}{*}{ Dye } & \multicolumn{4}{|c|}{ Adsorption Conditions } & \multirow[b]{2}{*}{$\underset{(\mathrm{mg} / \mathrm{g})}{Q_{\max }}$} & \multirow[b]{2}{*}{$\begin{array}{l}\text { Kinetic } \\
\text { Model }\end{array}$} & \multirow[b]{2}{*}{$\begin{array}{l}\text { Isotherm } \\
\text { Model }\end{array}$} & \multirow[b]{2}{*}{ Ref } \\
\hline & & $\mathrm{pH}$ & $\begin{array}{c}\mathrm{T} \\
\left({ }^{\circ} \mathrm{C}\right)\end{array}$ & Dosage (g/L) & $\begin{array}{l}\text { Range Conc } \\
(\mathrm{mg} / \mathrm{L})\end{array}$ & & & & \\
\hline \multirow{3}{*}{ TETA-PAN } & & \multirow{3}{*}{2.1} & \multirow{3}{*}{ RT } & \multirow{3}{*}{0.012} & \multirow{3}{*}{$40-100$} & 5000 & \multirow{3}{*}{ PSO } & \multirow{3}{*}{$\mathrm{L}$} & \multirow{3}{*}{ [156] } \\
\hline & DR-80 & & & & & 5000 & & & \\
\hline & DR-23 & & & & & & & & \\
\hline EDA-PAN & $\mathrm{CR}$ & 3 & 30 & 0.5 & $10-70$ & 130 & PSO & $\mathrm{L}$ & {$[67]$} \\
\hline DETA-PAN/PVDF & DR-23 & 2 & - & 0.044 & $20-50$ & 685.63 & IPD & $\mathrm{L}$ & [159] \\
\hline PIM-1 & $\mathrm{MB}$ & - & - & 0.25 & $50-500$ & 157 & - & $\mathrm{L}$ & [164] \\
\hline \multirow{2}{*}{ TM-PAN } & DR-80 & \multirow{2}{*}{3.5} & \multirow{2}{*}{ RT } & \multirow{2}{*}{0.033} & \multirow{2}{*}{$40-100$} & 1250 & \multirow{2}{*}{ PSO } & \multirow{2}{*}{$\mathrm{L}$} & \multirow{2}{*}{ [96] } \\
\hline & DR23 & & & & & 1111 & & & \\
\hline \multirow{2}{*}{ PDA@PCL/PEO } & $\mathrm{MB}$ & \multirow{2}{*}{-} & \multirow{2}{*}{25} & \multirow{2}{*}{0.3} & \multirow{2}{*}{-} & 14.8 & \multirow{2}{*}{ PSO } & \multirow{2}{*}{-} & \multirow{2}{*}[75]{} \\
\hline & $\mathrm{MO}$ & & & & & 60.2 & & & \\
\hline \multirow{2}{*}{ PAN/PAMAM } & DR80 & \multirow{2}{*}{2.1} & \multirow{2}{*}{25} & \multirow{2}{*}{0.033} & \multirow{2}{*}{$40-100$} & 1666.6 & \multirow{2}{*}{ PSO } & & 1601 \\
\hline & DR23 & & & & & 2000 & & L & {$[100]$} \\
\hline
\end{tabular}

\subsection{EPNFs Based on Composites Polymers as an Adsorbent for Dye Removal 6.5.1. EPNFs/Clay Nanocomposites}

Mineral clays are natural materials, constructed from hydrous aluminum, magnesium and iron silicates and used as low-cost adsorbents for the removal of various pollutants [165]. Clay has been used as a filler to improve the properties of some materials such as polymers and to prepare nanocomposite membranes. Hosseini et al. fabricated novel PVA/CS/montmorillonite nanofiber composites by using electrospinning and utilized as adsorbent for the removal of Basic Blue 41 [166]. They concluded that the incorporation of montmorillonite into PVA/CS led to enhancing their mechanical properties permeability and adsorption capacity. The zeolite was also used as a filler to improve the mechanical properties of some of polymeric nanofibers as well as the adsorption property. Lee et al. fabricated PMMA/zeolite nanofibers as adsorbent for the removal of MO [167]. They found that the maximum adsorption capacity was $95.33 \mathrm{mg} / \mathrm{g}$. Habiba et al. prepared PVA/CS/zeolite using electrospinning for the removal of MO from aqueous solutions [168]. The maximum MO adsorption capacity on PVA/CS/Zeo nanofibers was $153 \mathrm{mg} / \mathrm{g}$ at $\mathrm{pH}$ 4.0. They also reported that the addition of zeolite to PVA/CS nanofibers led to increase the Young's Modulus by more than $100 \%$.

\subsubsection{EPNFs/Carbon Nanomaterials Nanocomposites}

Despite the high efficiency of polymeric nanofibers towards removing dyes and other contaminants, some of these nanofibers have some limitation, such as low mechanical properties, especially when used in harsh environments. Therefore, the incorporation of nanofillers into polymeric nanofibers is an appropriate way to improve their mechanical properties and hydrophilicity. Carbon nanomaterials such as carbon nanotubes, carbon nanofibers and graphene oxide are the most common nanofillers that were used to improve the mechanical properties as well as the adsorption capacity. Sundaran et al. fabricated PU/GO nanofibers using electrospinning and used them for the adsorption of $\mathrm{MB}$ and RB dye [169]. It was found the Young's modulus and tensile strength values of PU/GO nanofibers increased from 0.02 to $0.109 \mathrm{~N} / \mathrm{mm}^{2}$ and from 2.74 to $11.94 \mathrm{~N} / \mathrm{mm}^{2}$ with incorporation of $10.0 \%$ of GO, respectively. This was attributed to strong interaction between GO sheets and PU chains. Additionally, hydrophilicity was enhanced with increasing GO ratio and became PU nanofibers with a super-hydrophilic nature 
with $10 \mathrm{wt} \%$ of GO. The maximum adsorption capacity of PU/GO was 109.8 and 77.15 for removal of MB and RB, respectively. Guo et al. incorporated oxidized MWCNTs into electrospun polyhydroxybutyrate-calcium alginate using electrospinning followed by ionic cross-linking process using $\mathrm{CaCl}_{2}$ and was used for the adsorption of Brilliant blue dye [170]. They found that the mechanical and hydrophilic properties were enhanced after incorporation of oxidized MWCNTs and the maximum adsorption capacity also increased from 10.89 to $24.09 \mathrm{mg} / \mathrm{g}$. Ma et al. prepared electrospun PVDF nanofibers and deposited GO onto its surface by ultrasonication and investigated the adsorption of MB [171]. The result showed that the maximum adsorption capacity of PVDF/GO nanofibers was $621.1 \mathrm{mg} / \mathrm{g}$ for MB removal with exhibition of good regeneration ability and adsorption stability. Mercante et al. fabricated PMMA-rGO nanofibers by solution blow spinning followed by plasma treatment; and studied its ability towards removal of MB [172]. After plasma treatment, the surface of PMMA nanofibers changed from hydrophobic nature $\left(114^{\circ}\right)$ to hydrophilic nature $\left(41^{\circ}\right)$. The showing maximum adsorption capacity of was $698.51 \mathrm{mg} / \mathrm{g}$ for MB. Zhana et al. fabricated PEN/PDA nanofibers and coated GO and used as effective membrane for filtration and separation anionic dye (Direct Blue 14 dye) as shown in Figure 8c [173]. They found that the prepared membrane exhibited good permeate flux, high rejection, antifouling properties and reusability. Despite the contribution of carbon nanomaterials and clays to improving the mechanical and stability properties of EPNFs, their effect is insignificant towards improving their efficiency compared to crosslinked and functionalized EPNFs. However, only graphene oxide was found to play an influential role in improving the adsorption capacity of EPNFs towards removing dyes such as incorporating GO and r-GO into PVDF [171] and PMMA [172], respectively. Table 6 summarize the adsorption data of dyes by EPNFs/carbon nanomaterials and EPNFs/clay nanocomposites.

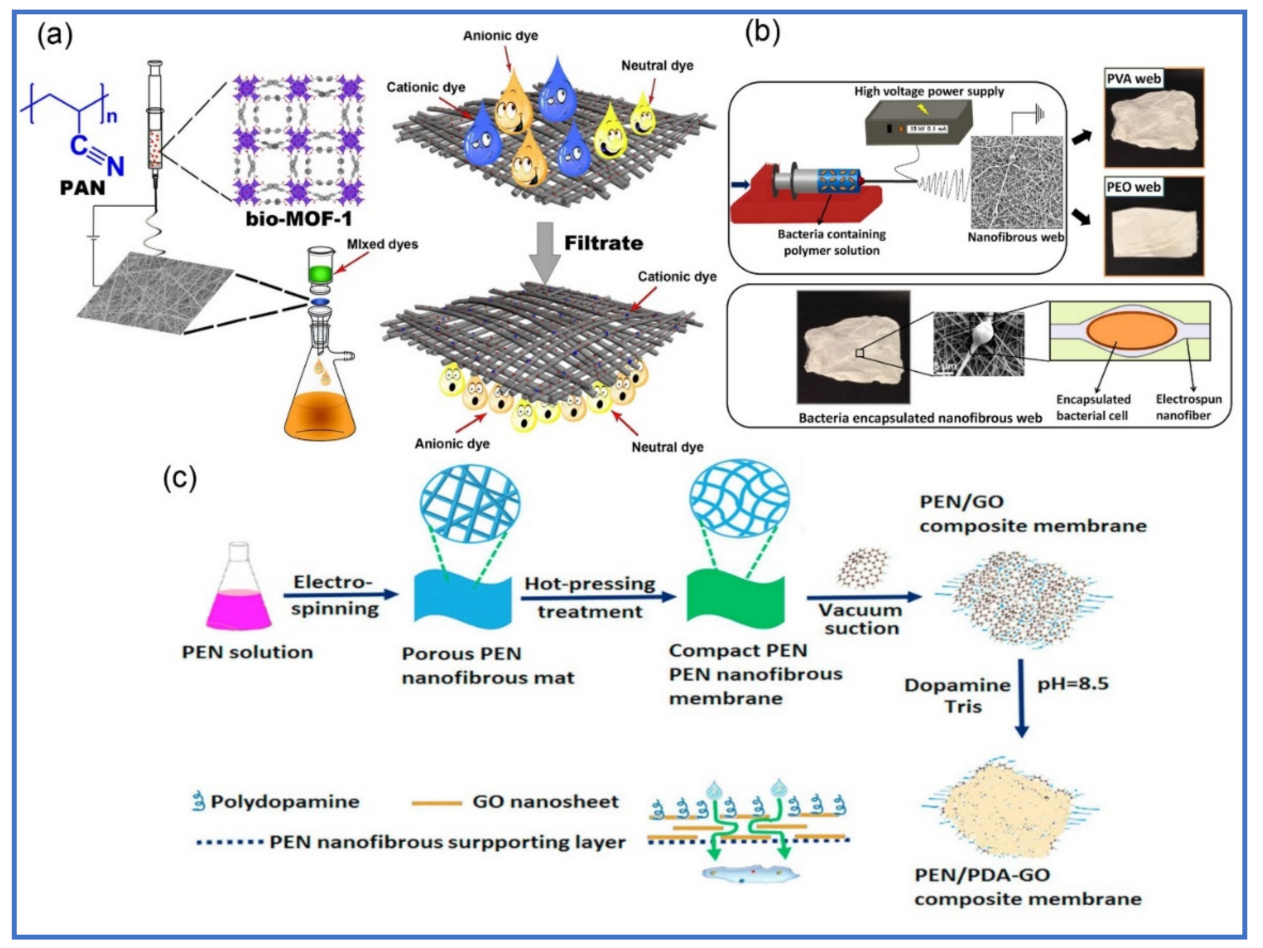

Figure 8. (a) Fabrication of bio-MOF/PAN nanofiber composite for removal MB dye [174], Copyright (c) (2020) Elsevier (b) Incorporation bacteria into PVA/PEO nanofibers for removal MB dye [175], Copyright ( $(2020)$ Elsevier and (c) Fabrication of PAEN/GO-PDA nanofiber composite for removal DB-14 dye [173], Copyright ( $(2020)$ Elsevier. 
Table 6. EPNFs/clay nanocomposites and EPNFs/carbon nanomaterials as adsorbents for removal of dyes.

\begin{tabular}{|c|c|c|c|c|c|c|c|c|c|}
\hline \multirow[b]{2}{*}{ Adsorbent } & \multirow[b]{2}{*}{ Dye } & \multicolumn{4}{|c|}{ Adsorption Conditions } & \multirow{2}{*}{$\underset{(\mathrm{mg} / \mathrm{g})}{\mathrm{Q}_{\max }}$} & \multirow[b]{2}{*}{$\begin{array}{l}\text { Kinetic } \\
\text { Model }\end{array}$} & \multirow[b]{2}{*}{$\begin{array}{l}\text { Isotherm } \\
\text { Model }\end{array}$} & \multirow[b]{2}{*}{ Ref } \\
\hline & & ph & $\begin{array}{c}\mathrm{T} \\
\left({ }^{\circ} \mathrm{C}\right)\end{array}$ & $\begin{array}{c}\text { Dosage } \\
(\mathrm{g} / \mathrm{L})\end{array}$ & $\begin{array}{l}\text { Range Conc } \\
(\mathrm{mg} / \mathrm{L})\end{array}$ & & & & \\
\hline PMMA/zeo & $\mathrm{MO}$ & - & - & 10 & $30-100$ & 95.33 & PSO & $\mathrm{L}$ & [167] \\
\hline CS/PVA/Zeo & $\mathrm{MO}$ & 4 & - & - & $100-500$ & 153 & PSO & $\mathrm{F}$ & [168] \\
\hline \multirow{2}{*}{ PU/GO } & $\mathrm{MB}$ & 12 & \multirow{2}{*}{30} & \multirow{2}{*}{-} & \multirow{2}{*}{-} & 109.88 & \multirow{2}{*}{ PSO } & \multirow{2}{*}{$\mathrm{L}$} & \multirow{2}{*}[169]{} \\
\hline & $\mathrm{RB}$ & 10 & & & & 77.15 & & & \\
\hline $\begin{array}{c}\text { PHB } \\
\mathrm{CaAlg} / \mathrm{CMWCNT}\end{array}$ & $\mathrm{Bb}$ & - & 25 & 1 & $5-50$ & 24.09 & PSO & $\mathrm{F}$ & [170] \\
\hline PVDF/GO & MB & - & 30 & 0.1 & $30-200$ & 621.1 & PSO & $\mathrm{F}$ & [171] \\
\hline PMMA-rGO & $\mathrm{MB}$ & - & RT25 & 0.3 & - & 698.51 & PSO & $\mathrm{L}$ & {$[172]$} \\
\hline $\begin{array}{c}\text { PVA/PAA/GO- } \\
\text { COOH@PDA }\end{array}$ & $\mathrm{MB}$ & - & 25 & 0.3 & 10 & 34.05 & PSO & - & [176] \\
\hline PVA/Gr & $\mathrm{CV}$ & - & 25 & - & $1-10$ & 10.96 & $\mathrm{PSO}$ & $\mathrm{L}$ & [177] \\
\hline PAN/MWCNT-OH & $\mathrm{MB}$ & 10 & & 1 & $10-30$ & 8 & $\mathrm{PSO}$ & $\mathrm{F}$ & [178] \\
\hline $\mathrm{P}(\mathrm{St}-\mathrm{co}-\mathrm{AN}) / \mathrm{CNTs}$ & $\mathrm{MB}$ & 8 & - & - & $5-60$ & 23.55 & PSO & $\mathrm{L}$ & [179] \\
\hline
\end{tabular}

\subsubsection{EPNFs/Silica Nanocomposites}

Silica is characterized by large surface area and surface functionalized hydroxyl groups that and is a good nanofillers that was used for enhancing the properties of nanofibers such as surface area, mechanical properties and adsorption property. Li et al. prepared PVA$\mathrm{SH} / \mathrm{SiO}_{2}$ nanofiber composites as adsorbents for the removal of indigo carmine and acid red [180]. They found that the adsorption capacity was 246.88 and $81.72 \mathrm{mg} / \mathrm{g}$ for indigo carmine and acid red, respectively. Teng et al. fabricated mesoporous PVA/SiO2/CD with surface area of $497 \mathrm{~m} 2 / \mathrm{g}$ using electrospinning as an adsorbent for the removal of indigo carmine dye [181]. They found that the maximum adsorption capacity was $495 \mathrm{mg} / \mathrm{g}$ and the equilibrium contact time was less than $40 \mathrm{~min}$.

\subsubsection{EPNFs/Metal Oxides Nanocomposites}

Metal oxides are one of the materials that have been used as an adsorbent for removing various pollutants. However, the application of metal oxide NPs for the adsorption of dyes especially in acidic media is still limited due to the dissolution and chemical corrosion at low $\mathrm{pH}$. The incorporation of metal oxides into polymeric nanofibers can solve the corrosion problem of metals oxides as well as the low mechanical properties of polymer nanofibers. Fard et al. incorporated $\alpha-\mathrm{Fe}_{2} \mathrm{O}_{3}$ nanoparticles into poly(vinyl acetate) (PVAc) nanofibers with surface area of $124.5 \mathrm{~m}^{2} / \mathrm{g}$ using electrospinning and in-situ polymerization process as effective adsorbent for the removal of basic red dyes [182]. They presented that the adsorption capacity was $940.57,946.28$ and $912.53 \mathrm{mg} / \mathrm{g}$ for the removal of BB41, BB46 and BB18, respectively. Phan et al. fabricated PAN/hinokitiol/ZnO nanofibers using electrospinning and investigated its antibacterial activity and their ability to remove dyes [183]. The maximum adsorption capacity of PAN/hinokitiol/ZnO was $245.76 \mathrm{mg} / \mathrm{g}$ and $267.37 \mathrm{mg} / \mathrm{g}$ for RR 195 and RB 19, respectively. Xu et al. fabricated $\mathrm{PAN} / \mathrm{Ag}_{3} \mathrm{VO}_{4} / \mathrm{TiO}_{2}$ nanofiber composites as an adsorbent for MB removal. The optimum conditions of $\mathrm{MB}$ adsorption onto the surface prepared nanofiber composites were dose of 1 $\mathrm{g} / \mathrm{L}, \mathrm{pH} 8$, contact time of $20 \mathrm{~min}$ and temperature of $25^{\circ} \mathrm{C}$ [184]. Additionally, they found that adsorption capacity of $\mathrm{PAN} / \mathrm{Ag}_{3} \mathrm{VO}_{4} / \mathrm{TiO}_{2}$ nanofiber composite was $155.4 \mathrm{mg} / \mathrm{g}$ for the removal of $\mathrm{MB}$ from an aqueous system. 


\subsubsection{EPNFs/MOFs Nanocomposites}

Metal organic frameworks (MOFs) are a promising class of hybrid material that is constructed from organic linkers and metal-oxide units. MOFs were characterized by high porosity, high surface area, thermal stability, chemical stability and good mechanical properties $[185,186]$. MOFs are used in many applications such as hydrogen storage [187], catalysis [188-190] and water treatment [191,192]. Recently, there is an attention towards the incorporation of MOFs into polymeric materials for the application in water treatment [193-196]. Li et al. successfully fabricated bio-MOF-1/PAN nanofibers for selective adsorption of methylene blue as cationic dye model as display in Figure 8a [174]. They found that the incorporation of bio-MOF-1 into PAN nanofibers led to enhancement of its mechanical and hydrophilicity properties. The bio-MOF-1/PAN nanofibers exhibited better selectivity for the adsorption and separation towards of $\mathrm{MB}$ from mixed dyes aqueous solutions. The significant selectivity in the adsorption and separation was attributed to synergistic effect between nucleophilicity of $-\mathrm{C} \equiv \mathrm{N}$ in PAN and anionic charge of bio-MOF-1. Mahmoodi et al. developed novel ZIF-8@PVA/CS nanofibers prepared by electrospinning for the removal of MG dye from aqueous solutions [95]. The maximum adsorption capacity of ZIF-8@PVA/CS nanofibers was $1000 \mathrm{mg} / \mathrm{g}$ for MG removal. Zhan et al. fabricated ZIF-8/PAN nanofibers as an effective adsorbent to remove MB and MG dyes from aqueous solutions [92]. They found that the adsorption capacity of ZIF-8/PAN nanofibers towards the removal of MG was $\backsim 14$ times higher than that of $\mathrm{MB}$ removal. This was attributed to the p-p stacking interaction between aromatic ring of MG and two double bonds and a pair of electrons of imidazole moieties in ZIF-8. Jin et al. fabricated ZIF-67/PAN nanofibers with $54 \%$ of ZIF- 67 by electrospinning and investigated its ability towards the removal of MG, $\mathrm{CR}$ and BF dye [197]. They found that the maximum adsorption capacity of ZIF-67/PAN nanofibers was 1305, 849 and $730 \mathrm{mg} / \mathrm{g}$ for MG, CR and BF, respectively. Additionally, the results confirmed that the ZIF-67/PAN nanofibers can be used more than four times for the removal of MG. Table 7 displays the adsorption data of dyes by EPNFs/silica [198], EPNFs/metal oxides [199-204] and EPNFs/MOFs nanocomposites [92,95,197]. Despite the role of MOFs in improving the ability of some EPNFs to remove some dyes from aqueous solutions, there are some challenges facing the incorporation of MOFs into EPNFs matrix. One of these challenges is low interface bonding between polymers and MOFs due to complex composition of MOFs, low dispersion in solvents of polymers and their different chemical properties with polymers, which makes it difficult to electrospun some polymers directly.

Table 7. EPNFs/silica, EPNFs/metal oxides and EPNFs/metal organic frameworks (MOFs) nanocomposites as adsorbent for the removal of dyes.

\begin{tabular}{|c|c|c|c|c|c|c|c|c|c|}
\hline \multirow[b]{2}{*}{ Adsorbent } & \multirow[b]{2}{*}{ Dye } & \multicolumn{4}{|c|}{$\begin{array}{l}\text { Adsorption } \\
\text { Conditions }\end{array}$} & \multirow[b]{2}{*}{$\begin{array}{l}\text { Qmax } \\
(\mathrm{mg} / \mathrm{g})\end{array}$} & \multirow[b]{2}{*}{$\begin{array}{l}\text { Kinetic } \\
\text { Model }\end{array}$} & \multirow[b]{2}{*}{$\begin{array}{l}\text { Isotherm } \\
\text { Model }\end{array}$} & \multirow[b]{2}{*}{ Ref } \\
\hline & & $\mathrm{pH}$ & $\begin{array}{c}\mathrm{T} \\
\left({ }^{\circ} \mathrm{C}\right)\end{array}$ & $\begin{array}{l}\text { Dosage } \\
\text { (g/L) }\end{array}$ & $\begin{array}{c}\text { Range } \\
\text { Conc } \\
(\mathrm{mg} / \mathrm{L})\end{array}$ & & & & \\
\hline \multirow{2}{*}{ PVA-SH/SiO 2} & IC & \multirow{2}{*}{2} & \multirow{2}{*}{25} & \multirow{2}{*}{1} & \multirow{2}{*}{$10-500$} & 246.88 & $\mathrm{PSO}$ & \multirow{2}{*}{ R-P } & \multirow{2}{*}{ [180] } \\
\hline & AR-1 & & & & & 81.72 & $\mathrm{PFO}$ & & \\
\hline PAN-Ti/Ag & MB & 8 & 25 & 1 & $5-210$ & 155.4 & PSO & $\mathrm{L}$ & [184] \\
\hline APAN/Fe ${ }_{3} \mathrm{O}_{4} @ 3-\mathrm{MPA}$ & IC & 5 & 23 & 1 & $5-100$ & 154.5 & $\mathrm{PFO}$ & $\mathrm{L}$ & [199] \\
\hline $\mathrm{PVA} / \mathrm{CS} / \mathrm{SiO}_{2}$ & DR-80 & 2 & RT & 0.06 & $15-30$ & 322 & $\mathrm{PSO}$ & $\mathrm{L}$ & [107] \\
\hline ZIF-67/PAN & MG & - & RT & 0.5 & $100-600$ & 1305 & PSO & F & [197] \\
\hline $\mathrm{SiO}_{2} @ P V A-C D$ & IC & 5.2 & RT & 1 & $90-720$ & 495 & $\mathrm{PSO}$ & $\mathrm{L}$ & [181] \\
\hline PAN/PEI-Fe & $\mathrm{CR}$ & - & $\mathrm{RT}$ & 1 & $20-60$ & 77.51 & $\mathrm{PSO}$ & $\mathrm{L}$ & [200] \\
\hline \multirow{2}{*}{ ZIF-8/PAN } & $\mathrm{MB}$ & 11 & \multirow{2}{*}{30} & \multirow{2}{*}{0.25} & 15-100 & 120.48 & \multirow{2}{*}{ PSO } & \multirow{2}{*}{$\mathrm{L}$} & \multirow{2}{*}{ [92] } \\
\hline & MG & 5 & & & $15-700$ & 1666.6 & & & \\
\hline
\end{tabular}


Table 7. Cont.

\begin{tabular}{|c|c|c|c|c|c|c|c|c|c|}
\hline \multirow[b]{2}{*}{ Adsorbent } & \multirow[b]{2}{*}{ Dye } & \multicolumn{4}{|c|}{$\begin{array}{l}\text { Adsorption } \\
\text { Conditions }\end{array}$} & \multirow[b]{2}{*}{$\begin{array}{l}\text { Qmax } \\
(\mathrm{mg} / \mathrm{g})\end{array}$} & \multirow[b]{2}{*}{$\begin{array}{l}\text { Kinetic } \\
\text { Model }\end{array}$} & \multirow[b]{2}{*}{$\begin{array}{l}\text { Isotherm } \\
\text { Model }\end{array}$} & \multirow[b]{2}{*}{ Ref } \\
\hline & & $\mathrm{pH}$ & $\begin{array}{c}\mathrm{T} \\
\left({ }^{\circ} \mathrm{C}\right)\end{array}$ & $\begin{array}{l}\text { Dosage } \\
(\mathrm{g} / \mathrm{L})\end{array}$ & $\begin{array}{l}\text { Range } \\
\text { Conc } \\
(\mathrm{mg} / \mathrm{L})\end{array}$ & & & & \\
\hline PVAc-TEOS@ $\alpha-\mathrm{Fe}_{2} \mathrm{O}_{3}$ & BR-46 & 8.5 & - & 0.035 & $20-60$ & 946.28 & $\mathrm{PSO}$ & $\mathrm{L}$ & [182] \\
\hline PVDF@CoAl-LDH & MO & 7 & 30 & 0.4 & $20-500$ & 621.17 & PSO & $\mathrm{L}$ & [201] \\
\hline \multirow{2}{*}{$\mathrm{PAMAM} / \alpha-\mathrm{Fe}_{2} \mathrm{O}_{3}$} & DR-80 & \multirow{2}{*}{3} & \multirow{2}{*}{-} & \multirow{2}{*}{0.032} & \multirow{2}{*}{$40-70$} & 1428.5 & \multirow{2}{*}{ PSO } & \multirow{2}{*}{$\mathrm{L}$} & \multirow{2}{*}{ [202] } \\
\hline & AR-18 & & & & & 1250 & & & \\
\hline${\mathrm{PAN}-\mathrm{MoS}_{2}}_{2}$ & RhB & - & - & 3 & $20-1000$ & 75.41 & PSO & $\mathrm{L}$ & [98] \\
\hline $\mathrm{PAA} / \mathrm{SiO}_{2}$ & MG & - & 30 & 1 & $5-300$ & 220.49 & PSO & $\mathrm{R}-\mathrm{P}$ & [198] \\
\hline PLA@TiO2@MTS & MB & - & RT & - & $10-40$ & 236.25 & - & - & [203] \\
\hline \multirow{2}{*}{$\mathrm{CA} / \mathrm{CS} / \mathrm{SWCNT} / \mathrm{Fe}_{3} \mathrm{O}_{4} / \mathrm{TiO}_{2}$} & MB & \multirow{2}{*}{3} & \multirow{2}{*}{-} & \multirow{2}{*}{0.5} & \multirow[t]{2}{*}{-} & 97.6 & \multirow{2}{*}{ PSO } & \multirow[t]{2}{*}{$\mathrm{L}$} & \multirow[t]{2}{*}{ [204] } \\
\hline & $\mathrm{CR}$ & & & & & 74.2 & & & \\
\hline ZIF-8@CS/PVA & MG & 7 & 25 & 0.03 & $10-40$ & 1000 & PSO & $\mathrm{L}$ & [95] \\
\hline \multirow{2}{*}{ ZnO-HT-PAN } & RB-19 & \multirow[t]{2}{*}{-} & \multirow[t]{2}{*}{25} & \multirow[t]{2}{*}{0.66} & \multirow[t]{2}{*}{$10-400$} & 267.37 & \multirow[t]{2}{*}{$\mathrm{PFO}$} & \multirow[t]{2}{*}{$\mathrm{L}$} & \multirow[t]{2}{*}{ [183] } \\
\hline & RR-195 & & & & & 245.76 & & & \\
\hline
\end{tabular}

\subsubsection{EPNFs/Microorganisms Composite for Dyes Removal}

Recently, many studies have been focused on incorporating microorganisms (e.g., bacteria, fungi, algae) into polymeric nanofibers as adsorbents for various pollutants [205-208]. Despite the ability of free some microorganisms to remove various pollutants, incorporating them into electrospun nanofibers increases their surface area and provides them the possibility of reusing as well as easier handling with nanofibers. However, the number of studies that focused on using of EPNFs/microorganisms nanocomposites to remove dyes from aqueous solutions is still limited. San et al. incorporated three types of bacteria (e.g., Pseudomonas aeruginosa, Aeromonas eucrenophila and Clavibacter michiganensis) into cellulose acetate nanofibers by electrospinning for the removal of MB from wastewater [99]. They found that the efficiency of dye decolorization was $95 \%$ after $24 \mathrm{~h}$ and was declined to $45 \%$ after recycling for four times. In similar study, Keskin et al. developed novel microalgae/polysulfone nanofibers fabricated through electrospinning for the removal of Remazol Black 5 dye [209]. The removal efficiency of microalgae/polysulfone nanofibers was $72.97 \%$ and was higher than pristine polysulfone nanofibers (12.36\%). Sarioglu et al. encapsulated bacteria (Pseudomonas aeruginosa) into PVA and PEO nanofibers as adsorbents for the remediation of MB dye as displayed in Figure 8b [175]. They found that removal efficiency of bacteria/PEO nanofibers was higher than of bacteria/PVA. Zamel et al. incorporated bacteria (Bacillus paramycoides) into CA/PEO nanofibers by electrospinning technique and used for the decolorization of MB dye [210]. The removal efficiency of bacteria/CA/PEO nanofibers was $93 \%$ at first cycle and was decreased to $44 \%$ after the 4 th cycle. Keskin et al. fabricated and encapsulated living bacteria into cyclodextrin nanofibers for remediation of nickel, chromium and RB-5 dye [211]. They found that the viability of bacteria inside cyclodextrin nanofibers was seven days at $4{ }^{\circ} \mathrm{C}$ and the removal efficiency was $82 \%$ for decolorization of RB5 dye. Table 8 display removal of efficiency of EPNFs/bacteria nanocomposites for removal organic dyes. Incorporation of bacteria into EPNFs is an early field and needs further study in order to enhance efficiency and reduce the required time to breakdown organic dyes and others pollutants. As we can see in Table 8 , more than 24 hours are required for the adsorption and breakdown of dyes by various bacteria/EPNFs. 
Table 8. Removal of dyes by EPNFs/bacteria nanocomposites.

\begin{tabular}{|c|c|c|c|c|c|c|}
\hline $\begin{array}{l}\text { Polymer } \\
\text { Nanofibers }\end{array}$ & Microorganisms & Dye & $\begin{array}{c}\text { Dye } \\
\begin{array}{c}\text { Concentration } \\
\text { (ppm) }\end{array}\end{array}$ & $\begin{array}{c}\text { Removal } \\
\text { Efficiency } \\
(\%)\end{array}$ & Time & Ref \\
\hline Polysulfone & Lysinibacillus sp. & RB-5 & 30 & 99.7 & $24 \mathrm{~h}$ & [208] \\
\hline CA & $\begin{array}{l}\text { Aeromonas } \\
\text { eucrenophila, }\end{array}$ & MB & 20 & 95 & $24 \mathrm{~h}$ & [99] \\
\hline \multirow{2}{*}{ polysulfone } & \multirow{2}{*}{ microalgae } & RB-5 & 10 & 72.97 & \multirow{2}{*}{14 day } & \multirow{2}{*}{ [209] } \\
\hline & & RB-221 & 10 & 30.2 & & \\
\hline PVA & \multirow{2}{*}{$\begin{array}{c}\text { Pseudomonas } \\
\text { aeruginosa }\end{array}$} & \multirow{2}{*}{ MB } & 25 & 68 & \multirow{2}{*}{$48 \mathrm{~h}$} & \multirow{2}{*}{ [175] } \\
\hline $\mathrm{PEO}$ & & & 25 & 69 & & \\
\hline $\mathrm{CA} / \mathrm{PEO}$ & Bacillus paramycoides & $\mathrm{MB}$ & 20 & 87.39 & $48 \mathrm{~h}$ & [210] \\
\hline $\mathrm{CD}$ & $\begin{array}{l}\text { Lysinibacillus sp. } \\
\text { NOSK }\end{array}$ & RB-5 & 30 & 82 & $24 \mathrm{~h}$ & [211] \\
\hline PCL & \multirow{2}{*}{$\begin{array}{l}\text { Clavibacter } \\
\text { michiganensis }\end{array}$} & \multirow{2}{*}{ STB G } & 200 & 93.18 & \multirow{2}{*}{$48 \mathrm{~h}$} & \multirow{2}{*}{ [212] } \\
\hline PLA & & & 200 & 93.6 & & \\
\hline
\end{tabular}

\section{EPNFs-Based Carbon Nanofibers as Adsorbents for Dyes Removal}

Carbon nanofibers (CNFs) have been prepared in the form of mats (webs) from EPNFs by carbonization process and can be used in water treatment. However, the efficiency of pristine CNFs towards removal of ionic pollutants from aqueous solutions is low due to their hydrophobic nature and low dispersion in some solvents as well as their relatively low surface area. Therefore, surface modification is an important approach for enhancing some properties of pristine $\mathrm{CNFs}$ and making them more effective towards removal various pollutants. The surface modification of CNMs can be done by different methods, including activation (e.g., physical or chemical) and functionalization processes by various agents. Recently, Thamer et al. reported the fabrication and functionalization of electrospun carbon nanofibers (ECNFs) as novel nanomaterials for the applications in in water treatment including heavy metal removal [213] and dyes removal [214-216]. They found that the adsorption capacity of all modified ECNFs for the removal of lead ions, MB, CR and CBB dye was higher than pristine ECNFs. For example, Figure 9 shows the fabrication and functionalization of ECNFs by ethylene diamine (EDA), phenylene diamine (PDA), diamino pyridine (DAPy) and melamine (Melam) and used as adsorbent for removal of MB dye from contaminated water. It was found that the adsorption capacity of DAPy-ECNFs was higher than pristine and others functionalized ECNFs [217]. Recently, oxidized ECNFs has been incorporated into the hydrogel to improve some of its properties such as reducing swelling capacity, improving its mechanical properties, and increasing its efficiency in removing dyes from polluted water [218]. Therefore, ECNFs are promising nanomaterials in the field of water treatment which can be modified their surface properties according to need. 


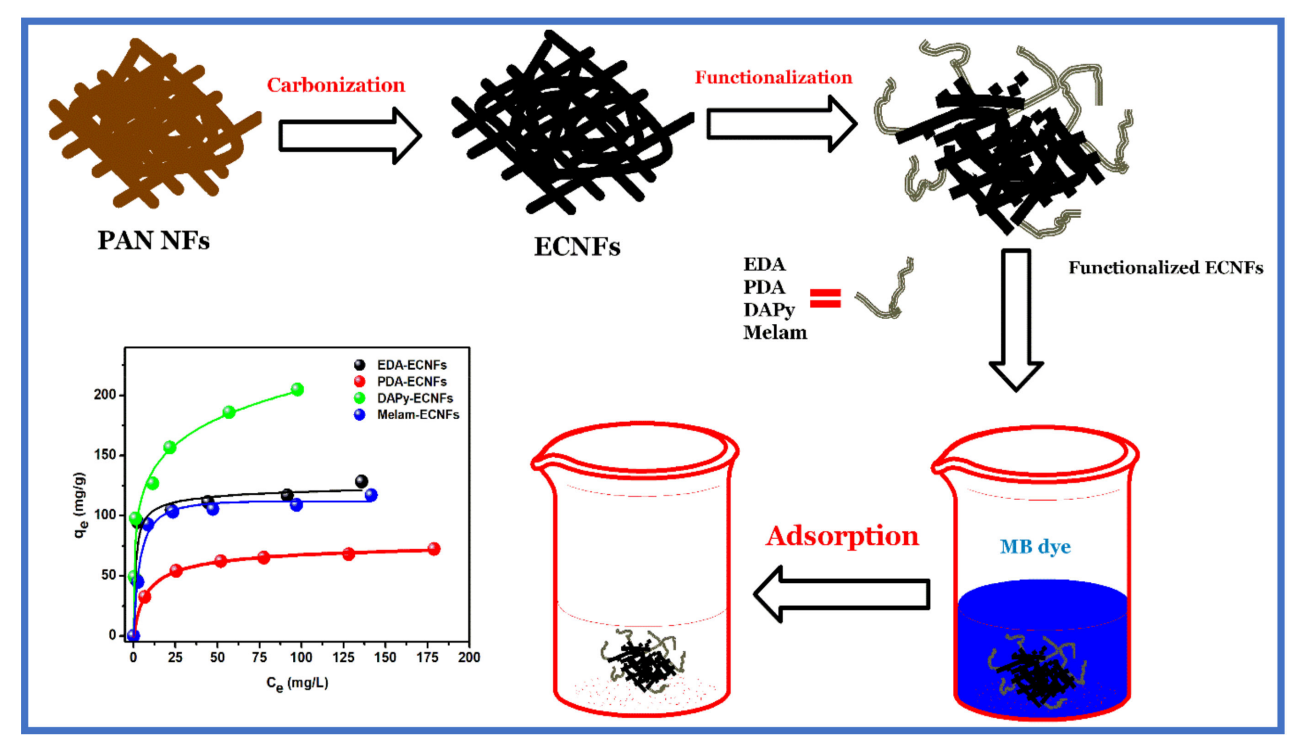

Figure 9. Fabrication and functionalization of ECNFs as a nanoadsorbent for removal of MB dye [217], Copyright (C) (2020) Elsevier.

\section{Conclusions and Future Perspectives}

The unique properties of EPNFs such as their high surface area-to-volume ratio, and high porosity nominate them for various applications such as environmental applications as water treatment. Moreover, the introduction of functional groups on its surface can enhance their efficiency towards the removal of pollutants from water especially for the removal of cationic and anionic dyes. In this review, we introduced the applications of electrospun polymers nanofibers and their modified ones as nanoadsorbents for the removal of dyes from aqueous solution. The modified EPNFs by blending, crosslinking, functionalization and incorporation processes showed higher efficiency towards the removal of various dyes and stability in aqueous media than the unmodified one due to the increase in the adsorption sites and enhancing mechanical properties. The review is limited for the in vitro reported studies during the last two decades for using EPNFs as new adsorbents for the removal of dyes for aqueous systems. Moreover, the review discussed the most important factors affecting the adsorption capacity of EPNFs in removing dyes, the adsorption mechanism and different modifying methods for enhancing their stability in aqueous media and the mechanical properties as well as their efficiency. On the other hand, the main challenge for the applications of these materials is their use in filed application via treatment of real wastewater, which contains different types of pollutants. So, the future perspective for using these types of materials can be developed in different ways. The first is the in vitro study for their selectivity in removing dyes. The second is the field applications via their use in treatment of real industrial wastewater. The third is to overcome the low production of electrospun polymers nanofibers in the lab scale, especially with adding inorganic materials as nano-fillers. The fourth, application of nonlinear three-parameters isotherm models to describe the adsorption process as well as conducting column study and not being limited to batch adsorption study. Additionally, another consideration that should be taken for future research is the development of modification methods with the aim of enhancing the surface properties of EPNFs (e.g., surface area, porosity, active functional groups), mechanical properties and their stability in aqueous solutions.

Supplementary Materials: The following are available online at https:/ / www.mdpi.com/2073-436 0/13/1/20/s1, Table S1: Chemical structure of dyes included in this review.

Author Contributions: Conceptualization, B.M.T.; investigation, B.M.T., A.A., M.M.A., M.R. and M.H.E.-N.; data curation, B.M.T., A.A.; writing—original draft preparation, B.M.T.; writing-review and editing, B.M.T., A.A.; M.M.A. and M.H.E.-N.; visualization, B.M.T. and M.E.; supervision, A.A. 
and M.H.E.-N.; project administration, A.A. All authors have read and agreed to the published version of the manuscript.

Funding: Ministry of Education, Saudi Arabia, project number IFKSURP-139.

Institutional Review Board Statement: Not applicable.

Informed Consent Statement: Not applicable.

Data Availability Statement: Not applicable.

Acknowledgments: The authors extend their appreciation to the Deputyship for Research and Innovation, "Ministry of Education "in Saudi Arabia for funding this research work through the project number IFKSURP-139.

Conflicts of Interest: The authors declare no conflict of interest.

\begin{tabular}{|c|c|}
\hline Nomenclature & Abbreviation \\
\hline Acetic acid & $\mathrm{AcOH}$ \\
\hline Acid blue 113 & AB-113 \\
\hline Acid blue 117 & AB-117 \\
\hline Acid blue 41 & AB-41 \\
\hline Acid red 252 & AR-252 \\
\hline Alternating current & $\mathrm{AC}$ \\
\hline Amaranth & $\mathrm{AM}$ \\
\hline Amidoximated polyacrilonitrile & APAN \\
\hline Amidoxime-modified polyacrylonitrile & AOPAN \\
\hline Azobisisobutyronitrile & AIBN \\
\hline Basic blue 41 & BB-41 \\
\hline Basic fuschin & $\mathrm{BF}$ \\
\hline Basic violet 14 & BV-14 \\
\hline Benzoxazine & $\mathrm{P}(\mathrm{BA}-\mathrm{a})$ \\
\hline Beta-cyclodextrin & $\beta-C D$ \\
\hline Brilliant blue & $\mathrm{Bb}$ \\
\hline Calcium alginate & Ca-Alg \\
\hline Carboxymethyl-b-cyclodextrin & $C M-\beta-C D$ \\
\hline Chitosan & CA \\
\hline Chitosan & CS \\
\hline Chitosan/Poly (vinyl alcohol) & $\mathrm{CA} / \mathrm{PVA}$ \\
\hline Congo red & $\mathrm{CR}$ \\
\hline Crystal violet & $\mathrm{CV}$ \\
\hline Deacetylated cellulose acetate & DCA \\
\hline Dichloromethane & DCM \\
\hline Diethylenetriamine & DETA \\
\hline Diethylenetriamine & DETA \\
\hline Dimethyl formamide & DMF \\
\hline Direct current & $\mathrm{DC}$ \\
\hline Direct red 23 & DR-23 \\
\hline Direct red 80 & DR-80 \\
\hline Electrospun polymer nanofibers & EPNFs \\
\hline Epichlorohydrin & EPI \\
\hline Ethanol & $\mathrm{EtOH}$ \\
\hline Ethylene diamine & EDA \\
\hline Ethylenediaminetetraacetic & EDTA \\
\hline Fast green $\mathrm{fcf}$ & FG FCF \\
\hline Flow rate & F. R \\
\hline Fourier-transform infrared spectroscopy & FTIR \\
\hline Freundlich model & $\mathrm{F}$ \\
\hline
\end{tabular}


Gelatin

Glutaraldehyde

GA

Graphene

Graphene oxide

Gr

Hinokitiol

GO

Humic acid

HT

Hyperbranched polyethylenimine

HA

Indigo carmine

HPEI

Intraparticle diffusion

IC

Langmuir model

IPD

Layered double hydroxide

$\mathrm{L}$

Malachite green

$\mathrm{LDH}$

Maximum adsorption capacity

MG

Mercaptopropionic acid

Qmax

Metal-organic-frameworks

MPA

Methyl orange

MOFs

Methylene blue

$\mathrm{MO}$

Methyltrichlorosilane

$\mathrm{MB}$

Molybdenum disulfide

MTS

Nanoparticles

MoS2

Nylone 6

NPs

Oxidized chitosan

Oxidized multiwall carbon nanotubes

N-6

OCS

Oxime

MWCNTs-COOH

OX

Poly ((butylene succinate-co-terephthalate)-co-serinolTerephthalate)

PBSST

Poly ([2- (methacryloyloxy)-ethyl] trimethyl ammonium chloride)

PMETAC

Poly (lactic-co-glycolic acid)

PLGA

Poly (l-lactic acid)

Poly (N-Isopropyl acrylamide-co-Methacrylic acid)

PLLA

Poly (N-Isopropyl acrylamide-co- $\beta$-cyclodextrin)

P(NIAPM-co-MAA)

Poly (styrene-co-acrylonitrile)

Poly (vinyl alcohol)

Poly(2-(dimethylamino)ethyl methacrylate)

P(NIPAM-Co- $\beta C D)$

Poly(amidoamine)

Poly(arylene ether nitrile)(PEN)

Poly(butylene succinate-co-terephthalate)

Poly(hexamethylene guanidine)

Poly(St-co-AN)

PVA

PDMAEMA

PAMAM

PAEN

PBST

PHMG

Poly(hydroxypropyl- $\beta$-cyclodextrin)

Poly(methacrylic acid)

Poly(methyl methacrylate-co-acrylic acid)

$\mathrm{P}(\mathrm{HP} \beta \mathrm{CD})$

PMAA

P(MMA-co-AA)

Poly(propylene imine)

PPI

Poly $(\gamma$-benzyl-L-glutamate $)$

PBGL

Polyacrylamide

PAM

Polyacrylonitrile

PAN

Polyamide

PA

Polyamide 6

PA6

Polyaniline

PANI

Polycaprolactone

PCL

Polydopamine

PDA

Polyether sulfone

PES

Polyethylene oxide

PEO

Polyethylene terephthalate

PET

Polyethyleneimine

PEI

Polymer of intrinsic microporosity

PIM-1

Polymethyl methacrylate

PMMA 


\begin{tabular}{|c|c|}
\hline Polypyrrole & PPy \\
\hline Polystyrene & PS \\
\hline Polyurethane & PU \\
\hline Polyvinyl acetate & PVAc \\
\hline Polyvinyl chloride & PVC \\
\hline Polyvinyl pyrrolidone & PVP \\
\hline Polyvinylidene fluoride & PVDF \\
\hline Ponceau 4R & P4R \\
\hline Ponceau s & P-s \\
\hline Pseudo first order model & PFO \\
\hline Pseudo second order model & PSO \\
\hline P-toluenesulfonic acid & pTSA \\
\hline Pullulan & $\mathrm{Pu}$ \\
\hline Reactive black 5 & RB-5 \\
\hline Reactive blue 180 & RR-180 \\
\hline Reactive red & $\mathrm{RR}$ \\
\hline Redlich-Peterson model & R-P \\
\hline Reduced graphene oxide & rGO \\
\hline Rhodamine B & $\mathrm{RhB}$ \\
\hline Safranin $\mathrm{T}$ & ST \\
\hline Sericin & SS \\
\hline Sodium alginate & $\mathrm{Na}-\mathrm{Alg}$ \\
\hline Sodium styrene sulfonate & SSNa \\
\hline Sulfonated polysulfone & SPES \\
\hline Sunset yellow fcf & SY FCF \\
\hline Tectomer & $\mathrm{TM}$ \\
\hline Tetraethyl orthosilicate & TEOS \\
\hline Thiol-functionalized polyvinyl alcohol & PVA-SH \\
\hline Tip-collector-distance & TCD \\
\hline Titanium dioxide & $\mathrm{TiO} 2$ \\
\hline Triethylenetetramine & TETA \\
\hline Volatage & $\mathrm{V}$ \\
\hline X-ray photoelectron spectroscopy & XPS \\
\hline Zeolite & Zeo \\
\hline Zeolitic imidazolate frameworks & ZIF \\
\hline
\end{tabular}

\section{References}

1. Wang, Y.; Zhu, J.; Dong, G.; Zhang, Y.; Guo, N.; Liu, J. Sulfonated halloysite nanotubes/polyethersulfone nanocomposite membrane for efficient dye purification. Sep. Purif. Technol. 2015, 150, 243-251. [CrossRef]

2. Tkaczyk, A.; Mitrowska, K.; Posyniak, A. Synthetic organic dyes as contaminants of the aquatic environment and their implications for ecosystems: A review. Sci. Total Environ. 2020, 717, 137222. [CrossRef] [PubMed]

3. Harrelkas, F.; Azizi, A.; Yaacoubi, A.; Benhammou, A.; Pons, M.N. Treatment of textile dye effluents using coagulation-flocculation coupled with membrane processes or adsorption on powdered activated carbon. Desalination 2009, 235, 330-339. [CrossRef]

4. Lin, S.H.; Chen, M.L. Treatment of textile wastewater by-chemical methods for reuse. Water Res. 1997, 31, 868-876. [CrossRef]

5. Varjani, S.; Rakholiya, P.; Ng, H.Y.; You, S.; Teixeira, J.A. Microbial degradation of dyes: An overview. Bioresour. Technol. 2020, 314, 123728. [CrossRef] [PubMed]

6. Rehorek, A.; Tauber, M.; Gübitz, G. Application of power ultrasound for azo dye degradation. Ultrason. Sonochem. 2004, 11, 177-182. [CrossRef] [PubMed]

7. Ayodhya, D.; Veerabhadram, G. A review on recent advances in photodegradation of dyes using doped and heterojunction based semiconductor metal sulfide nanostructures for environmental protection. Mater. Today Energy. 2018, 9, 83-113. [CrossRef]

8. Mo, J.H.; Lee, Y.H.; Kim, J.; Jeong, J.Y.; Jegal, J. Treatment of dye aqueous solutions using nanofiltration polyamide composite membranes for the dye wastewater reuse. Dye. Pigment. 2008, 76, 429-434. [CrossRef]

9. Kausar, A.; Iqbal, M.; Javed, A.; Aftab, K.; Nazli, Z. i. H.; Bhatti, H.N.; Nouren, S. Dyes adsorption using clay and modified clay: A review. J. Mol. Liq. 2018, 256, 395-407. [CrossRef]

10. Salleh, M.A.M.; Mahmoud, D.K.; Karim, W.A.W.A.; Idris, A. Cationic and anionic dye adsorption by agricultural solid wastes: A comprehensive review. Desalination 2011, 280, 1-13. [CrossRef]

11. Yagub, M.T.; Sen, T.K.; Afroze, S.; Ang, H.M. Dye and its removal from aqueous solution by adsorption: A review. Adv. Colloid Interface Sci. 2014, 209, 172-184. [CrossRef] [PubMed] 
12. Ray, S.S.; Chen, S.S.; Li, C.W.; Nguyen, N.C.; Nguyen, H.T. A comprehensive review: Electrospinning technique for fabrication and surface modification of membranes for water treatment application. RSC Adv. 2016, 6, 85495-85514. [CrossRef]

13. Xue, J.; Wu, T.; Dai, Y.; Xia, Y. Electrospinning and electrospun nanofibers: Methods, materials, and applications. Chem. Rev. 2019, 119, 5298-5415. [CrossRef] [PubMed]

14. Ahmed, F.E.; Lalia, B.S.; Hashaikeh, R. A review on electrospinning for membrane fabrication: Challenges and applications. Desalination 2015, 356, 15-30. [CrossRef]

15. Wang, S.X.; Yap, C.C.; He, J.; Chen, C.; Wong, S.Y.; Li, X. Electrospinning: A facile technique for fabricating functional nanofibers for environmental applications. Nanotechnol. Rev. 2016, 5, 51-73. [CrossRef]

16. Islam, M.S.; Ang, B.C.; Andriyana, A.; Afifi, A.M. A review on fabrication of nanofibers via electrospinning and their applications. SN Appl. Sci. 2019, 1,1-16. [CrossRef]

17. Homaeigohar, S.; Elbahri, M. Nanocomposite Electrospun Nanofiber Membranes for Environmental Remediation. Materials 2014, 7, 1017-1045. [CrossRef]

18. Zhang, W.; He, Z.; Han, Y.; Jiang, Q.; Zhan, C.; Zhang, K.; Li, Z.; Zhang, R. Structural design and environmental applications of electrospun nanofibers. Compos. Part A Appl. Sci. Manuf. 2020, 137, 106009. [CrossRef]

19. Najafi, M.; Frey, M.W. Electrospun Nanofibers for Chemical Separation. Nanomaterials 2020, 10, 982. [CrossRef]

20. Pereao, O.K.; Bode-Aluko, C.; Ndayambaje, G.; Fatoba, O.; Petrik, L.F. Electrospinning: Polymer Nanofibre Adsorbent Applications for Metal Ion Removal. J. Polym. Environ. 2017, 25, 1175-1189. [CrossRef]

21. Pham, Q.P.; Sharma, U.; Mikos, A.G. Electrospinning of polymeric nanofibers for tissue engineering applications: A review. Tissue Eng. 2006, 12, 1197-1211. [CrossRef] [PubMed]

22. Jian, S.; Zhu, J.; Jiang, S.; Chen, S.; Fang, H.; Song, Y.; Duan, G.; Zhang, Y.; Hou, H. Nanofibers with diameter below one nanometer from electrospinning. RSC Adv. 2018, 8, 4794-4802. [CrossRef]

23. Agarwal, S.; Greiner, A.; Wendorff, J.H. Functional materials by electrospinning of polymers. Prog. Polym. Sci. 2013, 38, 963991. [CrossRef]

24. Zeleny, J. The role of surface instability in electrical discharges from drops of alcohol and water in air at atmospheric pressure. J. Franklin Inst. 1935, 219, 659-675. [CrossRef]

25. Zargham, S.; Bazgir, S.; Tavakoli, A.; Rashidi, A.S.; Damerchely, R. The Effect of Flow Rate on Morphology and Deposition Area of Electrospun Nylon 6 Nanofiber. J. Eng. Fiber. Fabr. 2012, 7, 155892501200700. [CrossRef]

26. Theron, S.A.; Zussman, E.; Yarin, A.L. Experimental investigation of the governing parameters in the electrospinning of polymer solutions. Polymer 2004, 45, 2017-2030. [CrossRef]

27. Sun, B.; Long, Y.Z.; Zhang, H.D.; Li, M.M.; Duvail, J.L.; Jiang, X.Y.; Yin, H.L. Advances in three-dimensional nanofibrous macrostructures via electrospinning. Prog. Polym. Sci. 2014, 39, 862-890. [CrossRef]

28. Haider, S.; Al-Zeghayer, Y.; Ahmed Ali, F.A.; Haider, A.; Mahmood, A.; Al-Masry, W.A.; Imran, M.; Aijaz, M.O. Highly aligned narrow diameter chitosan electrospun nanofibers. J. Polym. Res. 2013, 20, 1-11. [CrossRef]

29. SalehHudin, H.S.; Mohamad, E.N.; Mahadi, W.N.L.; Muhammad Afifi, A. Multiple-jet electrospinning methods for nanofiber processing: A review. Mater. Manuf. Process. 2018, 33, 479-498. [CrossRef]

30. Hardick, O.; Stevens, B.; Bracewell, D.G. Nanofibre fabrication in a temperature and humidity controlled environment for improved fibre consistency. J. Mater. Sci. 2011, 46, 3890-3898. [CrossRef]

31. Greiner, A.; Wendorff, J.H. Electrospinning: A fascinating method for the preparation of ultrathin fibers. Angew. Chem. Int. Ed. 2007, 46, 5670-5703. [CrossRef] [PubMed]

32. Doshi, J.; Reneker, D.H. Electrospinning process and applications of electrospun fibers. J. Electrostat. 1995, 35, 151-160. [CrossRef]

33. Huang, Z.M.; Zhang, Y.Z.; Kotaki, M.; Ramakrishna, S. A review on polymer nanofibers by electrospinning and their applications in nanocomposites. Compos. Sci. Technol. 2003, 63, 2223-2253. [CrossRef]

34. Wang, X.; Niu, H.; Lin, T.; Wang, X. Needleless electrospinning of nanofibers with a conical wire coil. Polym. Eng. Sci. 2009, 49, 1582-1586. [CrossRef]

35. Varesano, A.; Rombaldoni, F.; Mazzuchetti, G.; Tonin, C.; Comotto, R. Multi-jet nozzle electrospinning on textile substrates: Observations on process and nanofibre mat deposition. Polym. Int. 2010, 59, 1606-1615. [CrossRef]

36. Yang, R.; He, J.; Xu, L.; Yu, J. Bubble-electrospinning for fabricating nanofibers. Polymer 2009, 50, 5846-5850. [CrossRef]

37. Um, I.C.; Fang, D.; Hsiao, B.S.; Okamoto, A.; Chu, B. Electro-spinning and electro-blowing of hyaluronic acid. Biomacromolecules 2004, 5, 1428-1436. [CrossRef]

38. Moghe, A.K.; Gupta, B.S. Co-axial electrospinning for nanofiber structures: Preparation and applications. Polym. Rev. 2008, 48, 353-377. [CrossRef]

39. Xu, X.; Zhuang, X.; Chen, X.; Wang, X.; Yang, L.; Jing, X. Preparation of core-sheath composite nanofibers by emulsion electrospinning. Macromol. Rapid Commun. 2006, 27, 1637-1642. [CrossRef]

40. Yarin, A.L. Coaxial electrospinning and emulsion electrospinning of core-shell fibers. Polym. Adv. Technol. 2011, 22, 310-317. [CrossRef]

41. Li, M.; Zheng, Y.; Xin, B.; Xu, Y. Roles of Coaxial Spinneret in Taylor Cone and Morphology of Core-Shell Fibers. Ind. Eng. Chem. Res. 2018, 57, 17310-17317. [CrossRef]

42. Liu, W.; Ni, C.; Chase, D.B.; Rabolt, J.F. Preparation of multilayer biodegradable nanofibers by triaxial electrospinning. ACS Macro Lett. 2013, 2, 466-468. [CrossRef] 
43. Han, D.; Steckl, A.J. Triaxial electrospun nanofiber membranes for controlled dual release of functional molecules. ACS Appl. Mater. Interfaces 2013, 5, 8241-8245. [CrossRef] [PubMed]

44. Elkasaby, M.; Hegab, H.A.; Mohany, A.; Rizvi, G.M. Modeling and optimization of electrospinning of polyvinyl alcohol (PVA). Adv. Polym. Technol. 2018, 37, 2114-2122. [CrossRef]

45. Shahabadi, S.M.S.; Kheradmand, A.; Montazeri, V.; Ziaee, H. Effects of process and ambient parameters on diameter and morphology of electrospun polyacrylonitrile nanofibers. Polym. Sci. Ser. A 2015, 57, 155-167. [CrossRef]

46. Park, J.Y.; Lee, I.H.; Bea, G.N. Optimization of the electrospinning conditions for preparation of nanofibers from polyvinylacetate (PVAc) in ethanol solvent. J. Ind. Eng. Chem. 2008, 14, 707-713. [CrossRef]

47. Nasouri, K.; Shoushtari, A.M.; Mojtahedi, M.R.M. Evaluation of effective electrospinning parameters controlling polyvinylpyrrolidone nanofibers surface morphology via response surface methodology. Fibers Polym. 2015, 16, 1941-1954. [CrossRef]

48. Rajput, M. Optimization of Electrospinning Parameters to Fabricate Aligned Nanofibers for Neural Tissue Engineering-CORE Reader. Master's Thesis, National Institute of Technology Rourkela, Rourkela, India, 2012.

49. Homayoni, H.; Ravandi, S.A.H.; Valizadeh, M. Electrospinning of chitosan nanofibers: Processing optimization. Carbohydr. Polym. 2009, 77, 656-661. [CrossRef]

50. Bazbouz, M.B.; Stylios, G.K. Alignment and optimization of nylon 6 nanofibers by electrospinning. J. Appl. Polym. Sci. 2008, 107, 3023-3032. [CrossRef]

51. Senthil, T.; Anandhan, S. Electrospinning of non-woven poly(styrene-co-acrylonitrile) nanofibrous webs for corrosive chemical filtration: Process evaluation and optimization by Taguchi and multiple regression analyses. J. Electrostat. 2015, 73, 43-55. [CrossRef]

52. Khanlou, H.M.; Sadollah, A.; Ang, B.C.; Kim, J.H.; Talebian, S.; Ghadimi, A. Prediction and optimization of electrospinning parameters for polymethyl methacrylate nanofiber fabrication using response surface methodology and artificial neural networks. Neural Comput. Appl. 2014, 25, 767-777. [CrossRef]

53. Yousefi Abdolmaleki, A.; Zilouei, H.; Nouri Khorasani, S.; Abdolmaleki, A. Optimization and characterization of electrospun chitosan/poly(vinyl alcohol) nanofibers as a phenol adsorbent via response surface methodology. Polym. Adv. Technol. 2017, 28, 1872-1878. [CrossRef]

54. Naderi, N.; Agend, F.; Faridi-Majidi, R.; Sharifi-Sanjani, N.; Madani, M. Prediction of nanofiber diameter and optimization of electrospinning process via response surface methodology. J. Nanosci. Nanotechnol. 2008, 8, 2509-2515.

55. Nagarajan, S.; Balme, S.; Narayana Kalkura, S.; Miele, P.; Bohatier, C.P.; Bechelany, M. Various Techniques to Functionalize Nanofibers. In Handbook of Nanofibers; Springer International Publishing: Cham, Switzerland, 2019; pp. $347-372$.

56. Kurusu, R.S.; Demarquette, N.R. Surface modification to control the water wettability of electrospun mats. Int. Mater. Rev. 2019, 64, 249-287. [CrossRef]

57. Rezaei Kolahchi, A.; Ajji, A.; Carreau, P.J. Enhancing hydrophilicity of polyethylene terephthalate surface through melt blending. Polym. Eng. Sci. 2015, 55, 349-358. [CrossRef]

58. Ma, F. fang; Zhang, D.; Zhang, N.; Huang, T.; Wang, Y. Polydopamine-assisted deposition of polypyrrole on electrospun poly(vinylidene fluoride) nanofibers for bidirectional removal of cation and anion dyes. Chem. Eng. J. 2018, 354, 432-444. [CrossRef]

59. Valiquette, D.; Pellerin, C. Miscible and core-sheath PS/PVME fibers by electrospinning. Macromolecules 2011, 44, 28382843. [CrossRef]

60. Li, G.; Zhao, Y.; Lv, M.; Shi, Y.; Cao, D. Super hydrophilic poly(ethylene terephthalate) (PET)/poly(vinyl alcohol) (PVA) composite fibrous mats with improved mechanical properties prepared via electrospinning process. Colloids Surfaces A Physicochem. Eng. Asp. 2013, 436, 417-424. [CrossRef]

61. Jia, Y.T.; Zhu, X.Y.; Liu, Q.Q. In Vitro Degradation of Electrospun Fiber Membranes of PCL/PVP Blends. Adv. Mater. Res. 2011, 332, 1330-1334. [CrossRef]

62. Xu, Y.; Bao, J.; Zhang, X.; Li, W.; Xie, Y.; Sun, S.; Zhao, W.; Zhao, C. Functionalized polyethersulfone nanofibrous membranes with ultra-high adsorption capacity for organic dyes by one-step electrospinning. J. Colloid Interface Sci. 2019, 533, 526-538. [CrossRef]

63. Ghani, M.; Gharehaghaji, A.A.; Arami, M.; Takhtkuse, N.; Rezaei, B. Fabrication of electrospun polyamide-6/chitosan nanofibrous membrane toward anionic dyes removal. Beilstein J. Nanotechnol. 2014, 2014, 13. [CrossRef]

64. Nie, H.; He, A.; Jia, B.; Wang, F.; Jiang, Q.; Han, C.C. A novel carrier of radionuclide based on surface modified poly(lactide-coglycolide) nanofibrous membrane. Polymer 2010, 51, 3344-3348. [CrossRef]

65. Zhou, Z.; Zhou, Y.; Chen, Y.; Nie, H.; Wang, Y.; Li, F.; Zheng, Y. Bilayer porous scaffold based on poly-( $\varepsilon$-caprolactone) nanofibrous membrane and gelatin sponge for favoring cell proliferation. Appl. Surf. Sci. 2011, 258, 1670-1676. [CrossRef]

66. Hakamada, Y.; Ohgushi, N.; Fujimura-Kondo, N.; Matsuda, T. Electrospun poly( $\gamma$-benzyl-L-glutamate) and its alkali-treated meshes: Their water wettability and cell-adhesion potential. J. Biomater. Sci. Polym. Ed. 2012, 23, 1055-1067. [CrossRef] [PubMed]

67. Patel, S.; Hota, G. Synthesis of novel surface functionalized electrospun PAN nanofibers matrix for efficient adsorption of anionic CR dye from water. J. Environ. Chem. Eng. 2018, 6, 5301-5310. [CrossRef]

68. Horzum, N.; Shahwan, T.; Parlak, O.; Demir, M.M. Synthesis of amidoximated polyacrylonitrile fibers and its application for sorption of aqueous uranyl ions under continuous flow. Chem. Eng. J. 2012, 213, 41-49. [CrossRef]

69. Nasreen, S.A.A.N.; Sundarrajan, S.; Nizar, S.A.S.; Balamurugan, R.; Ramakrishna, S. Advancement in electrospun nanofibrous membranes modification and their application in water treatment. Membranes 2013, 3, 266-284. [CrossRef]

70. Kaur, S.; Ma, Z.; Gopal, R.; Singh, G.; Ramakrishna, S.; Matsuura, T. Plasma-induced graft copolymerization of poly(methacrylic acid) on electrospun poly(vinylidene fluoride) nanofiber membrane. Langmuir 2007, 23, 13085-13092. [CrossRef] 
71. Li, C.; Wang, H.; Wu, C.; Wei, Z.; Liu, Q.; Fan, T. Hydrophilic surface modification of DPVC nanofibrous membrane by free-radical graft polymerization. Fibers Polym. 2016, 17, 663-670. [CrossRef]

72. Almasian, A.; Olya, M.E.; Mahmoodi, N.M.; Zarinabadi, E. Grafting of polyamidoamine dendrimer on polyacrylonitrile nanofiber surface: Synthesis and optimization of anionic dye removal process by response surface methodology method. Desalin. Water Treat. 2019, 147, 343-361. [CrossRef]

73. Lou, T.; Yan, X.; Wang, X. Chitosan coated polyacrylonitrile nanofibrous mat for dye adsorption. Int. J. Biol. Macromol. 2019, 135, 919-925. [CrossRef]

74. Zarrini, K.; Rahimi, A.A.; Alihosseini, F.; Fashandi, H. Highly efficient dye adsorbent based on polyaniline-coated nylon-6 nanofibers. J. Clean. Prod. 2017, 142, 3645-3654. [CrossRef]

75. Wang, C.; Yin, J.; Wang, R.; Jiao, T.; Huang, H.; Zhou, J.; Zhang, L.; Peng, Q. Facile preparation of self-assembled polydopaminemodified electrospun fibers for highly effective removal of organic dyes. Nanomaterials 2019, 9, 116. [CrossRef]

76. Wang, Y.; Zhang, X.; He, X.; Zhang, W.; Zhang, X.; Lu, C. In situ synthesis of MnO2 coated cellulose nanofibers hybrid for effective removal of methylene blue. Carbohydr. Polym. 2014, 110, 302-308. [CrossRef] [PubMed]

77. Yoo, H.S.; Kim, T.G.; Park, T.G. Surface-functionalized electrospun nanofibers for tissue engineering and drug delivery. Adv. Drug Deliv. Rev. 2009, 61, 1033-1042. [CrossRef] [PubMed]

78. Martins, A.; Pinho, E.D.; Faria, S.; Pashkuleva, I.; Marques, A.P.; Reis, R.L.; Neves, N.M. Surface modification of electrospun polycaprolactone nanofiber meshes by plasma treatment to enhance biological performance. Small 2009, 5, 1195-1206. [CrossRef] [PubMed]

79. Bai, L.; Jia, L.; Yan, Z.; Liu, Z.; Liu, Y. Plasma-etched electrospun nanofiber membrane as adsorbent for dye removal. Chem. Eng. Res. Des. 2018, 132, 445-451. [CrossRef]

80. Correia, D.M.; Ribeiro, C.; Sencadas, V.; Botelho, G.; Carabineiro, S.A.C.; Ribelles, J.L.G.; Lanceros-Méndez, S. Influence of oxygen plasma treatment parameters on poly(vinylidene fluoride) electrospun fiber mats wettability. Prog. Org. Coatings 2015, 85, 151-158. [CrossRef]

81. Haider, S.; Binagag, F.F.; Haider, A.; Mahmood, A.; Shah, N.; Al-Masry, W.A.; Khan, S.U.D.; Ramay, S.M. Adsorption kinetic and isotherm of methylene blue, safranin $\mathrm{T}$ and rhodamine $\mathrm{B}$ onto electrospun ethylenediamine-grafted-polyacrylonitrile nanofibers membrane. Desalin. Water Treat. 2015, 55, 1609-1619. [CrossRef]

82. Haider, S.; Binagag, F.F.; Haider, A.; Al-Masry, W.A. Electrospun oxime-grafted-polyacrylonitrile nanofiber membrane and its application to the adsorption of dyes. J. Polym. Res. 2014, 21, 1-13. [CrossRef]

83. Lv, C.; Chen, S.; Xie, Y.; Wei, Z.; Chen, L.; Bao, J.; He, C.; Zhao, W.; Sun, S.; Zhao, C. Positively-charged polyethersulfone nanofibrous membranes for bacteria and anionic dyes removal. J. Colloid Interface Sci. 2019, 556, 492-502. [CrossRef]

84. Chen, S.; Du, Y.; Zhang, X.; Xie, Y.; Shi, Z.; Ji, H.; Zhao, W.; Zhao, C. One-step electrospinning of negatively-charged polyethersulfone nanofibrous membranes for selective removal of cationic dyes. J. Taiwan Inst. Chem. Eng. 2018, 82, 179-188. [CrossRef]

85. Mokhtari-Shourijeh, Z.; Montazerghaem, L.; Olya, M.E. Preparation of Porous Nanofibers from Electrospun Polyacrylonitrile/Polyvinylidene Fluoride Composite Nanofibers by Inexpensive Salt Using for Dye Adsorption. J. Polym. Environ. 2018, 26, 3550-3563. [CrossRef]

86. Guo, R.; Wang, R.; Yin, J.; Jiao, T.; Huang, H.; Zhao, X.; Zhang, L.; Li, Q.; Zhou, J.; Peng, Q. Fabrication and highly efficient dye removal characterization of beta-cyclodextrin-based composite polymer fibers by electrospinning. Nanomaterials $2019,9,127$. [CrossRef] [PubMed]

87. Li, C.; Lou, T.; Yan, X.; Long, Y. ze; Cui, G.; Wang, X. Fabrication of pure chitosan nanofibrous membranes as effective absorbent for dye removal. Int. J. Biol. Macromol. 2018, 106, 768-774. [CrossRef] [PubMed]

88. Liu, Y.; Wu, D.; Wang, X.; Yu, J.; Li, F. Fabrication of eco-friendly nanofibrous membranes functionalized with carboxymethyl- $\beta$ cyclodextrin for efficient removal of methylene blue with good recyclability. RSC Adv. 2018, 8, 37715-37723. [CrossRef]

89. Cheng, J.; Zhan, C.; Wu, J.; Cui, Z.; Si, J.; Wang, Q.; Peng, X.; Turng, L.S. Highly Efficient Removal of Methylene Blue Dye from an Aqueous Solution Using Cellulose Acetate Nanofibrous Membranes Modified by Polydopamine. ACS Omega 2020, 5, 5389-5400. [CrossRef] [PubMed]

90. Min, M.; Shen, L.; Hong, G.; Zhu, M.; Zhang, Y.; Wang, X.; Chen, Y.; Hsiao, B.S. Micro-nano structure poly(ether sulfones) / poly(ethyleneimine) nanofibrous affinity membranes for adsorption of anionic dyes and heavy metal ions in aqueous solution. Chem. Eng. J. 2012, 197, 88-100. [CrossRef]

91. Dogan, Y.E.; Satilmis, B.; Uyar, T. Crosslinked PolyCyclodextrin/PolyBenzoxazine electrospun microfibers for selective removal of methylene blue from an aqueous system. Eur. Polym. J. 2019, 119, 311-321. [CrossRef]

92. Zhan, Y.; Guan, X.; Ren, E.; Lin, S.; Lan, J. Fabrication of zeolitic imidazolate framework-8 functional polyacrylonitrile nanofibrous mats for dye removal. J. Polym. Res. 2019, 26, 1-11. [CrossRef]

93. Fan, Y.; Liu, H.J.; Zhang, Y.; Chen, Y. Adsorption of anionic MO or cationic MB from MO/MB mixture using polyacrylonitrile fiber hydrothermally treated with hyperbranched polyethylenimine. J. Hazard. Mater. 2015, 283, 321-328. [CrossRef]

94. Mousavi, S.; Deuber, F.; Petrozzi, S.; Federer, L.; Aliabadi, M.; Shahraki, F.; Adlhart, C. Efficient dye adsorption by highly porous nanofiber aerogels. Colloids Surfaces A Physicochem. Eng. Asp. 2018, 547, 117-125. [CrossRef]

95. Mahmoodi, N.M.; Oveisi, M.; Taghizadeh, A.; Taghizadeh, M. Synthesis of pearl necklace-like ZIF-8@chitosan/PVA nanofiber with synergistic effect for recycling aqueous dye removal. Carbohydr. Polym. 2020, 227, 115364. [CrossRef] [PubMed] 
96. Almasian, A.; Mahmoodi, N.M.; Olya, M.E. Tectomer grafted nanofiber: Synthesis, characterization and dye removal ability from multicomponent system. J. Ind. Eng. Chem. 2015, 32, 85-98. [CrossRef]

97. Khosravi Mohammad Soltan, F.; Hajiani, M.; Haji, A. Nylon-6/poly(propylene imine) dendrimer hybrid nanofibers: An effective adsorbent for the removal of anionic dyes. J. Text. Inst. 2020, 7, 1-11. [CrossRef]

98. Lu, Y.; Fang, Y.; Xiao, X.; Qi, S.; Huan, C.; Zhan, Y.; Cheng, H.; Xu, G. Petal-like molybdenum disulfide loaded nanofibers membrane with superhydrophilic property for dye adsorption. Colloids Surfaces A Physicochem. Eng. Asp. 2018, 553, 210217. [CrossRef]

99. San, N.O.; Celebioglu, A.; Tümtaş, Y.; Uyar, T.; Tekinay, T. Reusable bacteria immobilized electrospun nanofibrous webs for decolorization of methylene blue dye in wastewater treatment. RSC Adv. 2014, 4, 32249-32255. [CrossRef]

100. Wang, Q.; Ju, J.; Tan, Y.; Hao, L.; Ma, Y.; Wu, Y.; Zhang, H.; Xia, Y.; Sui, K. Controlled synthesis of sodium alginate electrospun nanofiber membranes for multi-occasion adsorption and separation of methylene blue. Carbohydr. Polym. 2019, 205, 125134. [CrossRef]

101. Shuyue, J.; Dongyan, T.; Jing, P.; Xu, Y.; Zhaojie, S. Crosslinked electrospinning fibers with tunable swelling behaviors: A novel and effective adsorbent for Methylene Blue. Chem. Eng. J. 2020, 390, 124472. [CrossRef]

102. Aluigi, A.; Rombaldoni, F.; Tonetti, C.; Jannoke, L. Study of Methylene Blue adsorption on keratin nanofibrous membranes. J. Hazard. Mater. 2014, 268, 156-165. [CrossRef]

103. Chen, Y.; Ma, Y.; Lu, W.; Guo, Y.; Zhu, Y.; Lu, H.; Song, Y. Environmentally friendly gelatin/ $\beta$-cyclodextrin composite fiber adsorbents for the efficient removal of dyes from wastewater. Molecules 2018, 23, 473. [CrossRef]

104. Jia, S.; Tang, D.; Peng, J.; Sun, Z.; Yang, X. $\beta$-Cyclodextrin modified electrospinning fibers with good regeneration for efficient temperature-enhanced adsorption of crystal violet. Carbohydr. Polym. 2019, 208, 486-494. [CrossRef] [PubMed]

105. Chaúque, E.F.C.; Dlamini, L.N.; Adelodun, A.A.; Greyling, C.J.; Ngila, J.C. Electrospun polyacrylonitrile nanofibers functionalized with EDTA for adsorption of ionic dyes. Phys. Chem. Earth 2017, 100, 201-211. [CrossRef]

106. Mahmoodi, N.M.; Mokhtari-Shourijeh, Z.; Ghane-Karade, A. Dye removal from wastewater by the cross-linked blend nanofiber and homogenous surface diffusion modeling. Environ. Prog. Sustain. Energy 2017, 36, 1634-1642. [CrossRef]

107. Mahmoodi, N.M.; Mokhtari-Shourijeh, Z.; Abdi, J. Preparation of mesoporous polyvinyl alcohol/chitosan/silica composite nanofiber and dye removal from wastewater. Environ. Prog. Sustain. Energy 2019, 38, S100-S109. [CrossRef]

108. Mohammad, N.; Atassi, Y. Adsorption of methylene blue onto electrospun nanofibrous membranes of polylactic acid and polyacrylonitrile coated with chloride doped polyaniline. Sci. Rep. 2020, 10, 13412. [CrossRef] [PubMed]

109. Bahalkeh, F.; Habibi juybari, M.; Zafar Mehrabian, R.; Ebadi, M. Removal of Brilliant Red dye (Brilliant Red E-4BA) from wastewater using novel Chitosan/SBA-15 nanofiber. Int. J. Biol. Macromol. 2020, 164, 818-825. [CrossRef]

110. Huong, D.T.M.; Chai, W.S.; Show, P.L.; Lin, Y.L.; Chiu, C.Y.; Tsai, S.L.; Chang, Y.K. Removal of cationic dye waste by nanofiber membrane immobilized with waste proteins. Int. J. Biol. Macromol. 2020, 164, 3873-3884. [CrossRef]

111. Domingues, J.T.; Orlando, R.M.; Sinisterra, R.D.; Pinzón-García, A.D.; Rodrigues, G.D. Polymer-bixin nanofibers: A promising environmentally friendly material for the removal of dyes from water. Sep. Purif. Technol. 2020, 248, 117118. [CrossRef]

112. Qi, F.F.; Ma, T.Y.; Liu, Y.; Fan, Y.M.; Li, J.Q.; Yu, Y.; Chu, L. ling 3D superhydrophilic polypyrrole nanofiber mat for highly efficient adsorption of anionic azo dyes. Microchem. J. 2020, 159, 105389. [CrossRef]

113. Qureshi, U.A.; Khatri, Z.; Ahmed, F.; Ibupoto, A.S.; Khatri, M.; Mahar, F.K.; Brohi, R.Z.; Kim, I.S. Highly efficient and robust electrospun nanofibers for selective removal of acid dye. J. Mol. Liq. 2017, 244, 478-488. [CrossRef]

114. Al-Qassar Bani Al-Marjeh, R.; Atassi, Y.; Mohammad, N.; Badour, Y. Adsorption of methyl orange onto electrospun nanofiber membranes of PLLA coated with pTSA-PANI. Environ. Sci. Pollut. Res. 2019, 26, 37282-37295. [CrossRef] [PubMed]

115. Wang, Y.; Wiener, J.; Zhu, G. Langmuir isotherm models applied to the sorption of acid dyes from effluent onto polyamide nanofibers. Autex Res. J. 2013, 13, 95-98. [CrossRef]

116. Liu, J.; Liu, S.; Yang, J. Preparation and Properties of Electrospun Polyethersulfone Membranes with its Sulfonated Derivative. J. Macromol. Sci. Part B 2013, 52, 373-382. [CrossRef]

117. Yin, X.; Zhang, Z.; Ma, H.; Venkateswaran, S.; Hsiao, B.S. Ultra-fine electrospun nanofibrous membranes for multicomponent wastewater treatment: Filtration and adsorption. Sep. Purif. Technol. 2020, 242, 116794. [CrossRef]

118. Qureshi, U.A.; Khatri, Z.; Ahmed, F.; Khatri, M.; Kim, I.S. Electrospun Zein Nanofiber as a Green and Recyclable Adsorbent for the Removal of Reactive Black 5 from the Aqueous Phase. ACS Sustain. Chem. Eng. 2017, 5, 4340-4351. [CrossRef]

119. De A., B.; Barbosa, J.; dos Santos, M.R.; de Oliveira, H.P. Electrospun Fibers of Copolymers for the Removal of Ionic Dyes: The Influence of Processing Variables. Fibers Polym. 2018, 19, 94-104. [CrossRef]

120. Liao, Y.; Loh, C.H.; Tian, M.; Wang, R.; Fane, A.G. Progress in electrospun polymeric nanofibrous membranes for water treatment: Fabrication, modification and applications. Prog. Polym. Sci. 2018, 77, 69-94. [CrossRef]

121. Gezici, O.; Guven, I.; Özcan, F.; Ertul, S.; Bayrakci, M. Humic-makeup approach for simultaneous functionalization of polyacrylonitrile nanofibers during electrospinning process, and dye adsorption study. Soft Mater. 2016, 14, 278-287. [CrossRef]

122. Almasian, A.; Olya, M.E.; Mahmoodi, N.M. Preparation and adsorption behavior of diethylenetriamine/polyacrylonitrile composite nanofibers for a direct dye removal. Fibers Polym. 2015, 16, 1925-1934. [CrossRef]

123. Ali, A.S.M.; El-Aassar, M.R.; Hashem, F.S.; Moussa, N.A. Surface Modified of Cellulose Acetate Electrospun Nanofibers by Polyaniline/ $\beta$-cyclodextrin Composite for Removal of Cationic Dye from Aqueous Medium. Fibers Polym. 2019, 20, 2057-2069. [CrossRef] 
124. Hou, C.; Yang, H.; Xu, Z.L.; Wei, Y.M. Preparation of PAN/PAMAM blend nanofiber mats as efficient adsorbent for dye removal. Fibers Polym. 2015, 16, 1917-1924. [CrossRef]

125. Li, Z.; Sellaoui, L.; Dotto, G.L.; Lamine, A. Ben; Bonilla-Petriciolet, A.; Hanafy, H.; Belmabrouk, H.; Netto, M.S.; Erto, A. Interpretation of the adsorption mechanism of Reactive Black 5 and Ponceau $4 \mathrm{R}$ dyes on chitosan/polyamide nanofibers via advanced statistical physics model. J. Mol. Liq. 2019, 285, 165-170. [CrossRef]

126. Dotto, G.L.; Santos, J.M.N.; Tanabe, E.H.; Bertuol, D.A.; Foletto, E.L.; Lima, E.C.; Pavan, F.A. Chitosan/polyamide nanofibers prepared by Forcespinning ${ }^{\circledR}$ technology: A new adsorbent to remove anionic dyes from aqueous solutions. J. Clean. Prod. 2017, 144, 120-129. [CrossRef]

127. Ma, Y.; Zhang, B.; Ma, H.; Yu, M.; Li, L.; Li, J. Polyethylenimine nanofibrous adsorbent for highly effective removal of anionic dyes from aqueous solution. Sci. China Mater. 2016, 59, 38-50. [CrossRef]

128. Xu, Y.; Yuan, D.; Bao, J.; Xie, Y.; He, M.; Shi, Z.; Chen, S.; He, C.; Zhao, W.; Zhao, C. Nanofibrous membranes with surface migration of functional groups for ultrafast wastewater remediation. J. Mater. Chem. A 2018, 6, 13359-13372. [CrossRef]

129. Rivas, B.L.; Urbano, B.F.; Sánchez, J. Water-soluble and insoluble polymers, nanoparticles, nanocomposites and hybrids with ability to remove Hazardous inorganic pollutants in water. Front. Chem. 2018, 6, 320. [CrossRef]

130. Miraftab, M.; Saifullah, A.N.; Çay, A. Physical stabilisation of electrospun poly(vinyl alcohol) nanofibres: Comparative study on methanol and heat-based crosslinking. J. Mater. Sci. 2015, 50, 1943-1957. [CrossRef]

131. Esparza, Y.; Ullah, A.; Boluk, Y.; Wu, J. Preparation and characterization of thermally crosslinked poly(vinyl alcohol)/feather keratin nanofiber scaffolds. Mater. Des. 2017, 133, 1-9. [CrossRef]

132. Figueiredo, K.C.S.; Alves, T.L.M.; Borges, C.P. Poly(vinyl alcohol) films crosslinked by glutaraldehyde under mild conditions. J. Appl. Polym. Sci. 2009, 111, 3074-3080. [CrossRef]

133. Destaye, A.G.; Lin, C.K.; Lee, C.K. Glutaraldehyde vapor cross-linked nanofibrous PVA mat with in situ formed silver nanoparticles. ACS Appl. Mater. Interfaces 2013, 5, 4745-4752. [CrossRef]

134. Paipitak, K.; Pornpra, T.; Mongkontalang, P.; Techitdheer, W.; Pecharapa, W. Characterization of PVA-chitosan nanofibers prepared by electrospinning. Eng. Proc. 2011, 8, 101-105. [CrossRef]

135. Liu, G.; Gu, Z.; Hong, Y.; Cheng, L.; Li, C. Electrospun starch nanofibers: Recent advances, challenges, and strategies for potential pharmaceutical applications. J. Control. Release 2017, 252, 95-107. [CrossRef] [PubMed]

136. Jaiturong, P.; Sirithunyalug, B.; Eitsayeam, S.; Asawahame, C.; Tipduangta, P.; Sirithunyalug, J. Preparation of glutinous rice starch/polyvinyl alcohol copolymer electrospun fibers for using as a drug delivery carrier. Asian J. Pharm. Sci. 2018, 13, 239-247. [CrossRef]

137. Enayati, M.S.; Behzad, T.; Sajkiewicz, P.; Bagheri, R.; Ghasemi-Mobarakeh, L.; Pierini, F. Theoretical and experimental study of the stiffness of electrospun composites of poly(vinyl alcohol), cellulose nanofibers, and nanohydroxy apatite. Cellulose 2018, 25, 65-75. [CrossRef]

138. Celebioglu, A.; Aytac, Z.; Umu, O.C.O.; Dana, A.; Tekinay, T.; Uyar, T. One-step synthesis of size-tunable Ag nanoparticles incorporated in electrospun PVA/cyclodextrin nanofibers. Carbohydr. Polym. 2014, 99, 808-816. [CrossRef] [PubMed]

139. Costoya, A.; Concheiro, A.; Alvarez-Lorenzo, C. Electrospun fibers of cyclodextrins and poly(cyclodextrins). Molecules 2017, 22, 230. [CrossRef] [PubMed]

140. Mei, Y.; Runjun, S.; Yan, F.; Honghong, W.; Hao, D.; Chengkun, L. Preparation, characterization and kinetics study of chitosan/PVA electrospun nanofiber membranes for the adsorption of dye from water. J. Polym. Eng. 2019, 39, 459-471. [CrossRef]

141. Moradi, E.; Ebrahimzadeh, H.; Mehrani, Z.; Asgharinezhad, A.A. The efficient removal of methylene blue from water samples using three-dimensional poly (vinyl alcohol)/starch nanofiber membrane as a green nanosorbent. Environ. Sci. Pollut. Res. 2019, 26, 35071-35081. [CrossRef]

142. Song, Y.; Wang, F.; Lu, G.; Zhou, L.; Yang, Q. Preparation of PEI nanofiber membrane based on in situ and solution crosslinking technology and their adsorption properties. J. Appl. Polym. Sci. 2020, 137, 48279. [CrossRef]

143. Zhu, Z.; Wu, P.; Liu, G.; He, X.; Qi, B.; Zeng, G.; Wang, W.; Sun, Y.; Cui, F. Ultrahigh adsorption capacity of anionic dyes with sharp selectivity through the cationic charged hybrid nanofibrous membranes. Chem. Eng. J. 2017, 313, 957-966. [CrossRef]

144. Ma, Y.; Qi, P.; Ju, J.; Wang, Q.; Hao, L.; Wang, R.; Sui, K.; Tan, Y. Gelatin/alginate composite nanofiber membranes for effective and even adsorption of cationic dyes. Compos. Part B Eng. 2019, 162, 671-677. [CrossRef]

145. Mahmoodi, N.M.; Mokhtari-Shourijeh, Z. Modified poly(vinyl alcohol)-triethylenetetramine nanofiber by glutaraldehyde: Preparation and dye removal ability from wastewater. Desalin. Water Treat. 2016, 57, 20076-20083. [CrossRef]

146. Zhao, R.; Li, X.; Sun, B.; Li, Y.; Li, Y.; Wang, C. Preparation of molecularly imprinted sericin/poly(vinyl alcohol) electrospun fibers for selective removal of methylene blue. Chem. Res. Chinese Univ. 2017, 33, 986-994. [CrossRef]

147. Zhao, R.; Wang, Y.; Li, X.; Sun, B.; Wang, C. Synthesis of $\beta$-cyclodextrin-based electrospun nanofiber membranes for highly efficient adsorption and separation of methylene blue. ACS Appl. Mater. Interfaces 2015, 7, 26649-26657. [CrossRef] [PubMed]

148. Zhao, R.; Wang, Y.; Li, X.; Sun, B.; Jiang, Z.; Wang, C. Water-insoluble sericin/ $\beta$-cyclodextrin/PVA composite electrospun nanofibers as effective adsorbents towards methylene blue. Colloids Surfaces B Biointerfaces 2015, 136, 375-382. [CrossRef]

149. Habiba, U.; Siddique, T.A.; Talebian, S.; Lee, J.J.L.; Salleh, A.; Ang, B.C.; Afifi, A.M. Effect of deacetylation on property of electrospun chitosan/PVA nanofibrous membrane and removal of methyl orange, Fe(III) and Cr(VI) ions. Carbohydr. Polym. 2017, 177, 32-39. [CrossRef] 
150. Xu, Q.; Peng, J.; Zhang, W.; Wang, X.; Lou, T. Electrospun cellulose acetate/P(DMDAAC-AM) nanofibrous membranes for dye adsorption. J. Appl. Polym. Sci. 2020, 137, 48565. [CrossRef]

151. GHANI, M.; REZAEI, B.; GHARE AGHAJI, A.; ARAMI, M. Novel Cross-linked Superfine Alginate-Based Nanofibers: Fabrication, Characterization, and Their Use in the Adsorption of Cationic and Anionic Dyes. Adv. Polym. Technol. 2016, 35, 428-438. [CrossRef]

152. Xiao, N.; Wen, Q.; Liu, Q.; Yang, Q.; Li, Y. Electrospinning preparation of $\beta$-cyclodextrin/glutaraldehyde crosslinked PVP nanofibrous membranes to adsorb dye in aqueous solution. Chem. Res. Chinese Univ. 2014, 30, 1057-1062. [CrossRef]

153. Mahmoodi, N.M.; Mokhtari-Shourijeh, Z. Preparation of PVA-chitosan blend nanofiber and its dye removal ability from colored wastewater. Fibers Polym. 2015, 16, 1861-1869. [CrossRef]

154. Elkady, M.; El-Aassar, M.; Hassan, H. Adsorption Profile of Basic Dye onto Novel Fabricated Carboxylated Functionalized Co-Polymer Nanofibers. Polymers 2016, 8, 177. [CrossRef] [PubMed]

155. Ren, J.; Yan, C.; Liu, Q.; Yang, Q.; Lu, G.; Song, Y.; Li, Y. Preparation of amidoxime-modified polyacrylonitrile nanofibrous adsorbents for the extraction of copper(II) and lead(II) ions and dye from aqueous media. J. Appl. Polym. Sci. 2018, 135, 45697. [CrossRef]

156. Almasian, A.; Chizari Fard, G.; Parvinzadeh Gashti, M.; Mirjalili, M.; Mokhtari Shourijeh, Z. Surface modification of electrospun PAN nanofibers by amine compounds for adsorption of anionic dyes. Desalin. Water Treat. 2016, 57, 10333-10348. [CrossRef]

157. Patel, S.; Hota, G. Adsorptive removal of malachite green dye by functionalized electrospun PAN nanofibers membrane. Fibers Polym. 2014, 15, 2272-2282. [CrossRef]

158. Mahmoodi, N.M.; Mokhtari-Shourijeh, Z. Preparation of aminated nanoporous nanofiber by solvent casting/porogen leaching technique and dye adsorption modeling. J. Taiwan Inst. Chem. Eng. 2016, 65, 378-389. [CrossRef]

159. Mokhtari-Shourijeh, Z.; Langari, S.; Montazerghaem, L.; Mahmoodi, N.M. Synthesis of porous aminated PAN/PVDF composite nanofibers by electrospinning: Characterization and Direct Red 23 removal. J. Environ. Chem. Eng. 2020, 8, 103876. [CrossRef]

160. Almasian, A.; Olya, M.E.; Mahmoodi, N.M. Synthesis of polyacrylonitrile/polyamidoamine composite nanofibers using electrospinning technique and their dye removal capacity. J. Taiwan Inst. Chem. Eng. 2015, 49, 119-128. [CrossRef]

161. Chen, S.; Li, C.; Hou, T.; Cai, Y.; Liang, L.; Chen, L.; Li, M. Polyhexamethylene guanidine functionalized chitosan nanofiber membrane with superior adsorption and antibacterial performances. React. Funct. Polym. 2019, 145, 104379. [CrossRef]

162. Liu, Y.; Jia, J.; Gao, T.; Wang, X.; Yu, J.; Wu, D.; Li, F. Rapid, Selective Adsorption of Methylene Blue from Aqueous Solution by Durable Nanofibrous Membranes. J. Chem. Eng. Data 2020, 65, 3998-4008. [CrossRef]

163. Wei, Z.; Liu, Y.; Hu, H.; Yu, J.; Li, F. Biodegradable poly(butylene succinate-co-terephthalate) nanofibrous membranes functionalized with cyclodextrin polymer for effective methylene blue adsorption. RSC Adv. 2016, 6, 108240-108246. [CrossRef]

164. Satilmis, B.; Budd, P.M.; Uyar, T. Systematic hydrolysis of PIM-1 and electrospinning of hydrolyzed PIM-1 ultrafine fibers for an efficient removal of dye from water. React. Funct. Polym. 2017, 121, 67-75. [CrossRef]

165. Novikova, L.; Belchinskaya, L. Adsorption of Industrial Pollutants by Natural and Modified Aluminosilicates. In Clays, Clay Minerals and Ceramic Materials Based on Clay Minerals; IntechOpen: London, UK, 2016.

166. Hosseini, S.A.; Vossoughi, M.; Mahmoodi, N.M.; Sadrzadeh, M. Clay-based electrospun nanofibrous membranes for colored wastewater treatment. Appl. Clay Sci. 2019, 168,77-86. [CrossRef]

167. Lee, J.J.L.; Ang, B.C.; Andriyana, A.; Shariful, M.I.; Amalina, M.A. Fabrication of PMMA/zeolite nanofibrous membrane through electrospinning and its adsorption behavior. J. Appl. Polym. Sci. 2017, 134. [CrossRef]

168. Habiba, U.; Siddique, T.A.; Li Lee, J.J.; Joo, T.C.; Ang, B.C.; Afifi, A.M. Adsorption study of methyl orange by chitosan/polyvinyl alcohol/zeolite electrospun composite nanofibrous membrane. Carbohydr. Polym. 2018, 191, 79-85. [CrossRef] [PubMed]

169. Sundaran, S.P.; Reshmi, C.R.; Sagitha, P.; Manaf, O.; Sujith, A. Multifunctional graphene oxide loaded nanofibrous membrane for removal of dyes and coliform from water. J. Environ. Manag. 2019, 240, 494-503. [CrossRef]

170. Guo, J.; Zhang, Q.; Cai, Z.; Zhao, K. Preparation and dye filtration property of electrospun polyhydroxybutyrate-calcium alginate/carbon nanotubes composite nanofibrous filtration membrane. Sep. Purif. Technol. 2016, 161, 69-79. [CrossRef]

171. Ma, F. fang; Zhang, D.; Huang, T.; Zhang, N.; Wang, Y. Ultrasonication-assisted deposition of graphene oxide on electrospun poly(vinylidene fluoride) membrane and the adsorption behavior. Chem. Eng. J. 2019, 358, 1065-1073. [CrossRef]

172. Mercante, L.A.; Facure, M.H.M.; Locilento, D.A.; Sanfelice, R.C.; Migliorini, F.L.; Mattoso, L.H.C.; Correa, D.S. Solution blow spun PMMA nanofibers wrapped with reduced graphene oxide as an efficient dye adsorbent. New J. Chem. 2017, 41, 9087-9094. [CrossRef]

173. Zhan, Y.; Wan, X.; He, S.; Yang, Q.; He, Y. Design of durable and efficient poly(arylene ether nitrile)/bioinspired polydopamine coated graphene oxide nanofibrous composite membrane for anionic dyes separation. Chem. Eng. J. 2018, 333, 132-145. [CrossRef]

174. Li, T.; Liu, L.; Zhang, Z.; Han, Z. Preparation of nanofibrous metal-organic framework filter for rapid adsorption and selective separation of cationic dye from aqueous solution. Sep. Purif. Technol. 2020, 237, 116360. [CrossRef]

175. Sarioglu, O.F.; Keskin, N.O.S.; Celebioglu, A.; Tekinay, T.; Uyar, T. Bacteria encapsulated electrospun nanofibrous webs for remediation of methylene blue dye in water. Colloids Surfaces B Biointerfaces 2017, 152, 245-251. [CrossRef] [PubMed]

176. Xing, R.; Wang, W.; Jiao, T.; Ma, K.; Zhang, Q.; Hong, W.; Qiu, H.; Zhou, J.; Zhang, L.; Peng, Q. Bioinspired Polydopamine Sheathed Nanofibers Containing Carboxylate Graphene Oxide Nanosheet for High-Efficient Dyes Scavenger. ACS Sustain. Chem. Eng. 2017, 5, 4948-4956. [CrossRef]

177. Chailek, N.; Daranarong, D.; Punyodom, W.; Molloy, R.; Worajittiphon, P. Crosslinking assisted fabrication of ultrafine poly(vinyl alcohol)/functionalized graphene electrospun nanofibers for crystal violet adsorption. J. Appl. Polym. Sci. 2018, 135, 46318. [CrossRef] 
178. Swaminathan, S.; Imayathamizhan, N.; Muthumanickkam, A. Kinetic and isotherm studies on adsorption of methylene blue using polyacrylonitrile/hydroxyl group functionalized multiwall carbon nanotube multilayered nanofibrous composite. J. Elastomers Plast. 2020, 009524431989728. [CrossRef]

179. Elzain, A.A.; El-Aassar, M.R.; Hashem, F.S.; Mohamed, F.M.; Ali, A.S.M. Removal of methylene dye using composites of poly (styrene-co-acrylonitrile) nanofibers impregnated with adsorbent materials. J. Mol. Liq. 2019, 291, 111335. [CrossRef]

180. Li, M.; Wang, H.; Wu, S.; Li, F.; Zhi, P. Adsorption of hazardous dyes indigo carmine and acid red on nanofiber membranes. RSC Adv. 2012, 2, 900-907. [CrossRef]

181. Teng, M.; Li, F.; Zhang, B.; Taha, A.A. Electrospun cyclodextrin-functionalized mesoporous polyvinyl alcohol/SiO2 nanofiber membranes as a highly efficient adsorbent for indigo carmine dye. Colloids Surfaces A Physicochem. Eng. Asp. 2011, 385, 229234. [CrossRef]

182. Chizari Fard, G.; Mirjalili, M.; Najafi, F. Hydroxylated $\alpha$-Fe2O3 nanofiber: Optimization of synthesis conditions, anionic dyes adsorption kinetic, isotherm and error analysis. J. Taiwan Inst. Chem. Eng. 2017, 70, 188-199. [CrossRef]

183. Phan, D.N.; Rebia, R.A.; Saito, Y.; Kharaghani, D.; Khatri, M.; Tanaka, T.; Lee, H.; Kim, I.S. Zinc oxide nanoparticles attached to polyacrylonitrile nanofibers with hinokitiol as gluing agent for synergistic antibacterial activities and effective dye removal. J. Ind. Eng. Chem. 2020, 85, 258-268. [CrossRef]

184. Xu, Z.; Wei, C.; Jin, J.; Xu, W.; Wu, Q.; Gu, J.; Ou, M.; Xu, X. Development of a novel mixed titanium, silver oxide polyacrylonitrile nanofiber as a superior adsorbent and its application for MB removal in wastewater treatment. J. Braz. Chem. Soc. 2018, 29, 560-570. [CrossRef]

185. Long, J.R.; Yaghi, O.M. The pervasive chemistry of metal-organic frameworks. Chem. Soc. Rev. 2009, 38, 1213-1214. [CrossRef] [PubMed]

186. Chen, Y.Z.; Zhang, R.; Jiao, L.; Jiang, H.L. Metal-organic framework-derived porous materials for catalysis. Coord. Chem. Rev. 2018, 362, 1-23. [CrossRef]

187. Langmi, H.W.; Ren, J.; North, B.; Mathe, M.; Bessarabov, D. Hydrogen storage in metal-organic frameworks: A review. Electrochim. Acta 2014, 128, 368-392. [CrossRef]

188. Ma, L.; Abney, C.; Lin, W. Enantioselective catalysis with homochiral metal-organic frameworks. Chem. Soc. Rev. 2009, 38, 1248-1256. [CrossRef]

189. Zhu, L.; Liu, X.Q.; Jiang, H.L.; Sun, L.B. Metal-Organic Frameworks for Heterogeneous Basic Catalysis. Chem. Rev. 2017, 117, 8129-8176. [CrossRef]

190. Chughtai, A.H.; Ahmad, N.; Younus, H.A.; Laypkov, A.; Verpoort, F. Metal-organic frameworks: Versatile heterogeneous catalysts for efficient catalytic organic transformations. Chem. Soc. Rev. 2015, 44, 6804-6849. [CrossRef]

191. Khan, N.A.; Hasan, Z.; Jhung, S.H. Adsorptive removal of hazardous materials using metal-organic frameworks (MOFs): A review. J. Hazard. Mater. 2013, 244-245, 444-456. [CrossRef]

192. Hasan, Z.; Jhung, S.H. Removal of hazardous organics from water using metal-organic frameworks (MOFs): Plausible mechanisms for selective adsorptions. J. Hazard. Mater. 2015, 283, 329-339. [CrossRef]

193. Elrasheedy, A.; Nady, N.; Bassyouni, M.; El-Shazly, A. Metal Organic Framework Based Polymer Mixed Matrix Membranes: Review on Applications in Water Purification. Membranes 2019, 9, 88. [CrossRef]

194. Tan, Y.; Sun, Z.; Meng, H.; Han, Y.; Wu, J.; Xu, J.; Xu, Y.; Zhang, X. A new MOFs/polymer hybrid membrane: MIL68(Al)/PVDF, fabrication and application in high-efficient removal of p-nitrophenol and methylene blue. Sep. Purif. Technol. 2019, 215, 217-226. [CrossRef]

195. Zhuang, Y.; Kong, Y.; Wang, X.; Shi, B. Novel one step preparation of a 3D alginate based MOF hydrogel for water treatment. New J. Chem. 2019, 43, 7202-7208. [CrossRef]

196. Sun, D.T.; Peng, L.; Reeder, W.S.; Moosavi, S.M.; Tiana, D.; Britt, D.K.; Oveisi, E.; Queen, W.L. Rapid, Selective Heavy Metal Removal from Water by a Metal-Organic Framework/Polydopamine Composite. ACS Cent. Sci. 2018, 4, 349-356. [CrossRef] [PubMed]

197. Jin, L.; Ye, J.; Wang, Y.; Qian, X.; Dong, M. Electrospinning Synthesis of ZIF-67/PAN Fibrous Membrane with High-capacity Adsorption for Malachite Green. Fibers Polym. 2019, 20, 2070-2077. [CrossRef]

198. Xu, R.; Jia, M.; Zhang, Y.; Li, F. Sorption of malachite green on vinyl-modified mesoporous poly(acrylic acid)/SiO2 composite nanofiber membranes. Microporous Mesoporous Mater. 2012, 149, 111-118. [CrossRef]

199. Yazdi, M.G.; Ivanic, M.; Mohamed, A.; Uheida, A. Surface modified composite nanofibers for the removal of indigo carmine dye from polluted water. RSC Adv. 2018, 8, 24588-24598. [CrossRef]

200. Sadasivam, R.K.; Mohiyuddin, S.; Packirisamy, G. Electrospun polyacrylonitrile (PAN) Templated 2D Nanofibrous Mats: A platform toward practical applications for dye removal and bacterial disinfection. ACS Omega 2017, 2, 6556-6569. [CrossRef]

201. Mei, Q.; Lv, W.; Du, M.; Zheng, Q. Morphological control of poly(vinylidene fluoride)@layered double hydroxide composite fibers using metal salt anions and their enhanced performance for dye removal. RSC Adv. 2017, 7, 46576-46588. [CrossRef]

202. Chizari Fard, G.; Mirjalili, M.; Almasian, A.; Najafi, F. PAMAM grafted $\alpha$-Fe2O3 nanofiber: Preparation and dye removal ability from binary system. J. Taiwan Inst. Chem. Eng. 2017, 80, 156-167. [CrossRef]

203. Zhou, Z.; Liu, L.; Yuan, W. A superhydrophobic poly(lactic acid) electrospun nanofibrous membrane surface-functionalized with $\mathrm{TiO} 2$ nanoparticles and methyltrichlorosilane for oil/water separation and dye adsorption. New J. Chem. 2019, 43, 15823-15831. [CrossRef] 
204. ZabihiSahebi, A.; Koushkbaghi, S.; Pishnamazi, M.; Askari, A.; Khosravi, R.; Irani, M. Synthesis of cellulose acetate/chitosan/ SWCNT/Fe3O4/TiO2 composite nanofibers for the removal of $\mathrm{Cr}(\mathrm{VI})$, As(V), Methylene blue and Congo red from aqueous solutions. Int. J. Biol. Macromol. 2019, 140, 1296-1304. [CrossRef]

205. Eroglu, E.; Agarwal, V.; Bradshaw, M.; Chen, X.; Smith, S.M.; Raston, C.L.; Swaminathan Iyer, K. Nitrate removal from liquid effluents using microalgae immobilized on chitosan nanofiber mats. Green Chem. 2012, 14, 2682-2685. [CrossRef]

206. Klein, S.; Kuhn, J.; Avrahami, R.; Tarre, S.; Beliavski, M.; Green, M.; Zussman, E. Encapsulation of bacterial cells in electrospun microtubes. Biomacromolecules 2009, 10, 1751-1756. [CrossRef] [PubMed]

207. Bouabidi, Z.B.; El-Naas, M.H.; Zhang, Z. Immobilization of microbial cells for the biotreatment of wastewater: A review. Environ. Chem. Lett. 2019, 17, 241-257. [CrossRef]

208. Sarioglu, O.F.; Celebioglu, A.; Tekinay, T.; Uyar, T. Bacteria-immobilized electrospun fibrous polymeric webs for hexavalent chromium remediation in water. Int. J. Environ. Sci. Technol. 2016, 13, 2057-2066. [CrossRef]

209. San Keskin, N.O.; Celebioglu, A.; Uyar, T.; Tekinay, T. Microalgae immobilized by nanofibrous web for removal of reactive dyes from wastewater. Ind. Eng. Chem. Res. 2015, 54, 5802-5809. [CrossRef]

210. Zamel, D.; Hassanin, A.H.; Ellethy, R.; Singer, G.; Abdelmoneim, A. Novel Bacteria-Immobilized Cellulose Acetate/Poly(ethylene oxide) Nanofibrous Membrane for Wastewater Treatment. Sci. Rep. 2019, 9, 1-11. [CrossRef]

211. San Keskin, N.O.; Celebioglu, A.; Sarioglu, O.F.; Uyar, T.; Tekinay, T. Encapsulation of living bacteria in electrospun cyclodextrin ultrathin fibers for bioremediation of heavy metals and reactive dye from wastewater. Colloids Surfaces B Biointerfaces 2018, 161, 169-176. [CrossRef]

212. Sarioglu, O.F.; San Keskin, N.O.; Celebioglu, A.; Tekinay, T.; Uyar, T. Bacteria immobilized electrospun polycaprolactone and polylactic acid fibrous webs for remediation of textile dyes in water. Chemosphere 2017, 184, 393-399. [CrossRef]

213. Thamer, B.M.; Aldalbahi, A.; Moydeen A, M.; Al-Enizi, A.M.; El-Hamshary, H.; El-Newehy, M.H. Fabrication of functionalized electrospun carbon nanofibers for enhancing lead-ion adsorption from aqueous solutions. Sci. Rep. 2019, 9, 1-15. [CrossRef]

214. Thamer, B.M.; El-Hamshary, H.; Al-Deyab, S.S.; El-Newehy, M.H. Functionalized electrospun carbon nanofibers for removal of cationic dye. Arab. J. Chem. 2019, 12, 747-759. [CrossRef]

215. Thamer, B.M.; Aldalbahi, A.; Moydeen A, M.; El-Hamshary, H.; Al-Enizi, A.M.; El-Newehy, M.H. Effective adsorption of Coomassie brilliant blue dye using poly(phenylene diamine)grafted electrospun carbon nanofibers as a novel adsorbent. Mater. Chem. Phys. 2019, 234, 133-145. [CrossRef]

216. Thamer, B.M.; Aldalbahi, A.; Moydeen A, M.; Al-Enizi, A.M.; El-Hamshary, H.; Singh, M.; Bansal, V.; El-Newehy, M.H. Alkaliactivated electrospun carbon nanofibers as an efficient bifunctional adsorbent for cationic and anionic dyes. Colloids Surfaces $A$ Physicochem. Eng. Asp. 2019, 582, 123835. [CrossRef]

217. Thamer, B.M.; Aldalbahi, A.; Moydeen A, M.; Al-Enizi, A.M.; El-Hamshary, H.; El-Newehy, M.H. Synthesis of aminated electrospun carbon nanofibers and their application in removal of cationic dye. Mater. Res. Bull. 2020, 132, 111003. [CrossRef]

218. Thamer, B.M.; Aldalbahi, A.; Moydeen A., M.; El-Newehy, M.H. In Situ Preparation of Novel Porous Nanocomposite Hydrogel as Effective Adsorbent for the Removal of Cationic Dyes from Polluted Water. Polymers 2020, 12, 3002. [CrossRef] 